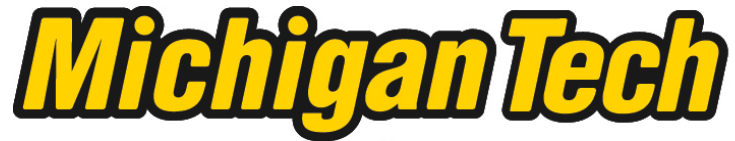 \\ Michigan Technological University Create the Future Digital Commons @ Michigan Tech
}

Dissertations, Master's Theses and Master's Reports - Open

Dissertations, Master's Theses and Master's

Reports

2011

Sonic log prediction in carbonates

Nayyer Islam

Michigan Technological University

Follow this and additional works at: https://digitalcommons.mtu.edu/etds

Part of the Geology Commons

Copyright 2011 Nayyer Islam

\section{Recommended Citation}

Islam, Nayyer, "Sonic log prediction in carbonates ", Master's Thesis, Michigan Technological University, 2011.

https://doi.org/10.37099/mtu.dc.etds/326

Follow this and additional works at: https://digitalcommons.mtu.edu/etds

Part of the Geology Commons 


\title{
SONIC LOG PREDICTION IN CARBONATES
}

\section{By}

Nayyer Islam

\begin{abstract}
A THESIS
Submitted in partial fulfillment of the requirements for the degree of MASTER OF SCIENCE

(Geological Engineering)
\end{abstract}

MICHIGAN TECHNOLOGICAL UNIVERSITY

2011

(C) 2011 Nayyer Islam 
This thesis, "Sonic Log Prediction in Carbonates," is hereby approved in partial fulfillment of the requirements for the degree of MASTER OF SCIENCE IN GEOLOGICAL ENGINEERING

Department of Geological and Mining Engineering and Sciences

Signatures:

Thesis Adviser

Dr. Wayne D. Pennington

Department Chair

Dr. Wayne D. Pennington

Date 


\section{Table of Contents}

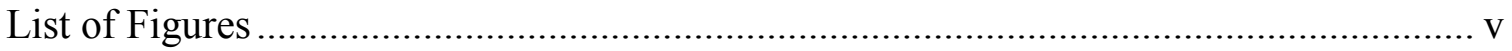

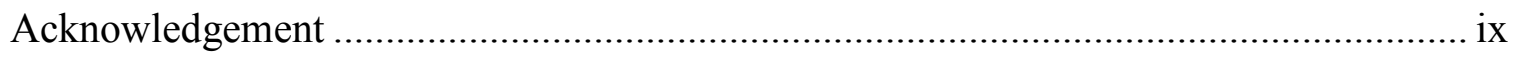

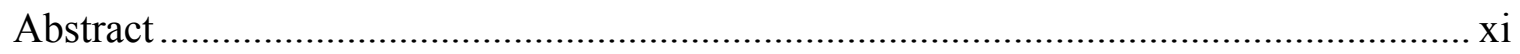

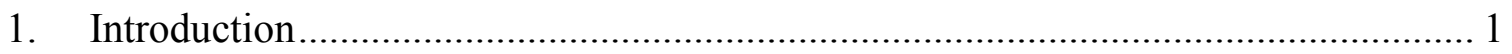

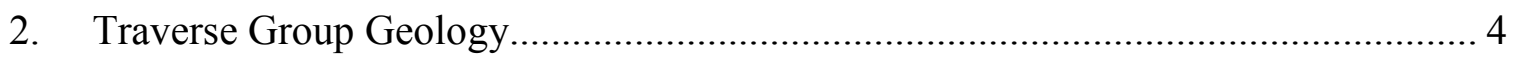

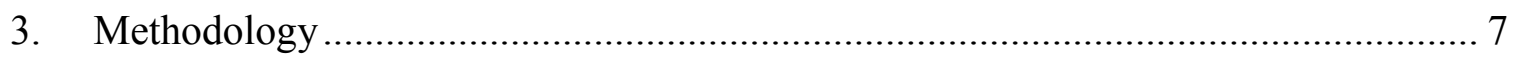

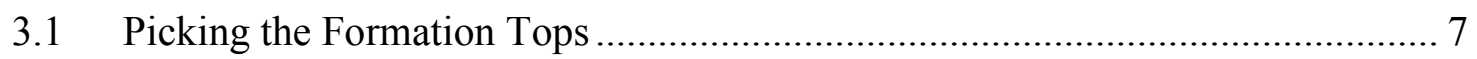

3.2 Petrophysical Analysis ............................................................................ 13

3.2.1 Crossplot between Neutron Porosity and Bulk Density .............................. 14

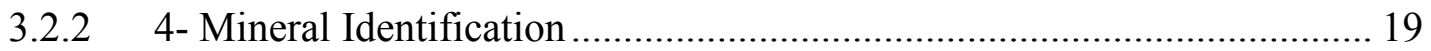

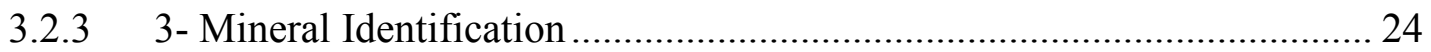

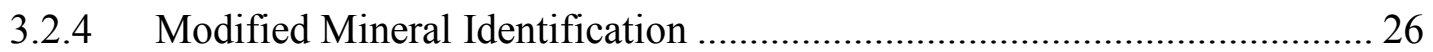

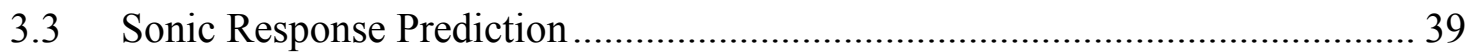

3.3.1 From Density Porosity ………………………………........................... 39

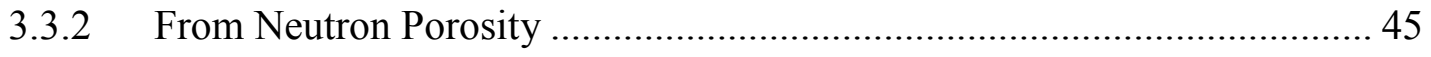

3.3.3 Sonic response from average porosity ................................................... 49

3.3.4 From Mineral Identification results ......................................................... 55

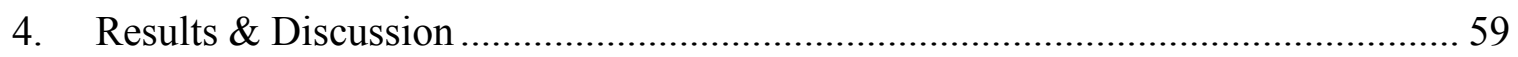

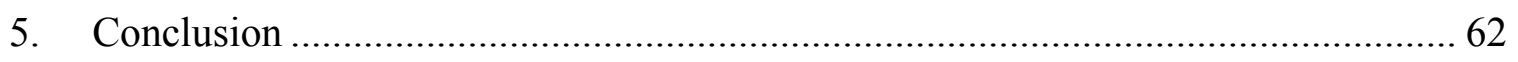

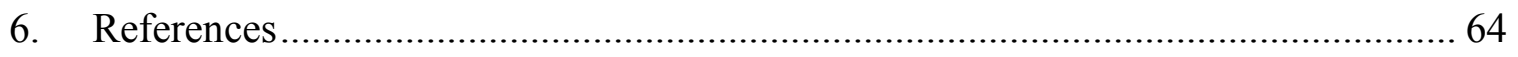




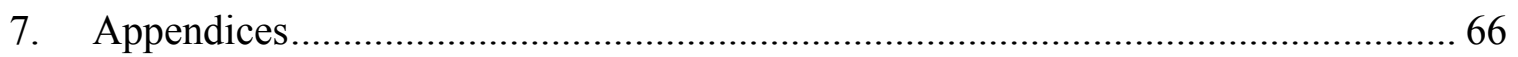

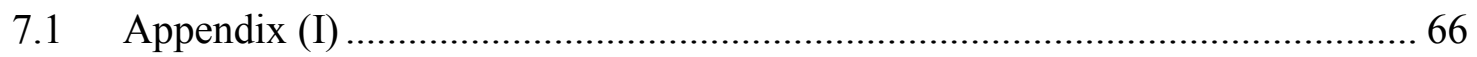

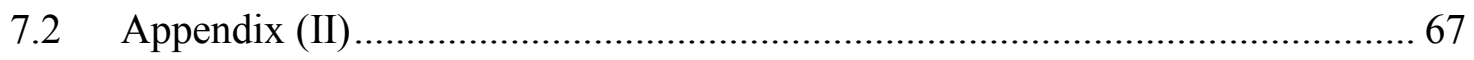

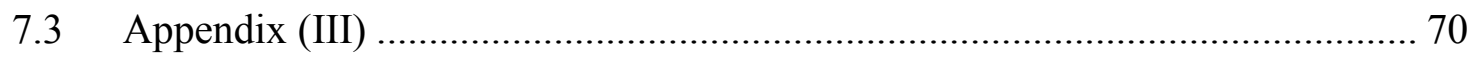

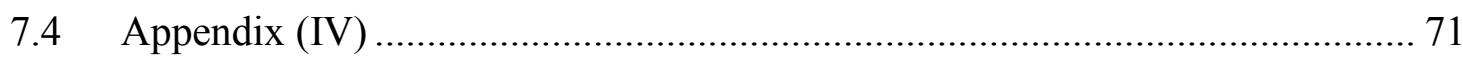

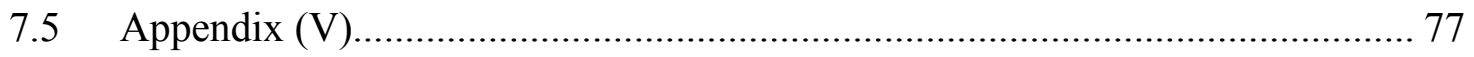

7.5.1 Sonic Prediction from density porosity....................................................... 77

7.5.2 From Neutron Porosity ………………………………............................... 77

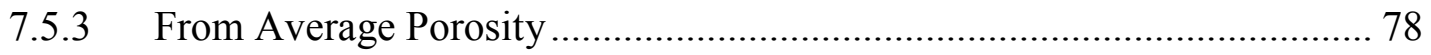

7.5.4 From Mineral Identification.................................................................. 78

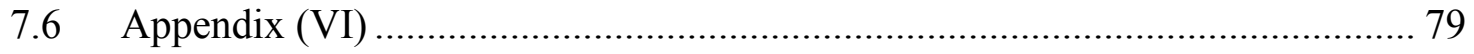

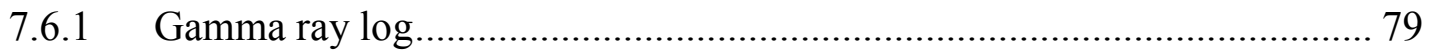

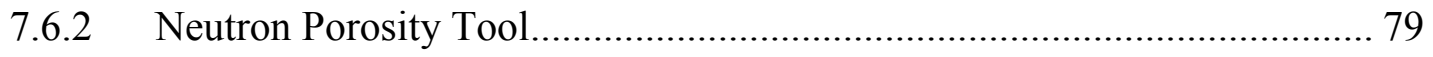

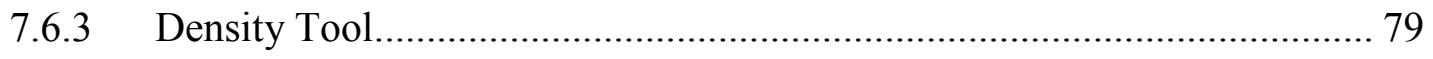

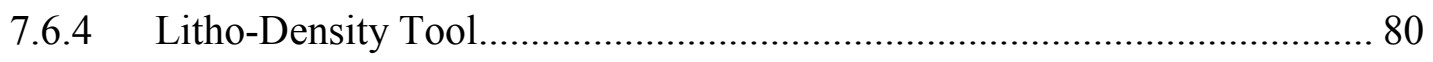

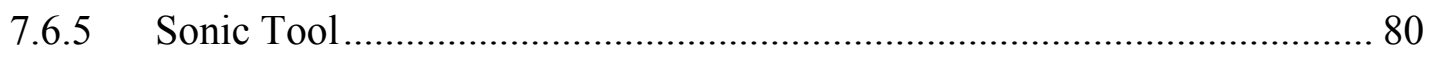




\section{List of Figures}

Figure 3.1. Well logs presenting the tops of Traverse Limestone, Bell Shale and Dundee Limeston. (a) From Eaton (b) From Clare.................................................... 9

Figure 3.2. Isopach map of Traverse Group (Traverse Limestone plus Bell Shale). Black contour lines in the figure present the thickness in $\mathrm{ft}$ plotted with a contour interval of $10 \mathrm{ft}$ while the back ground color displays the depth of the Traverse Limestone in feet.

Figure 3.3. Isopach map of the Bell Shale. Color-bar indicates the thickness of the Bell Shale in $\mathrm{ft}$. 12

Figure 3.4. Map of Michigan's Lower Peninsula showing the locations of wells used in this work. 13

Figure 3.5. Neutron-Density Crossplot of Well A indicating pure limestone. 14

Figure 3.6. Neutron-Density crossplot of Well B indicating the presence of dolomite and limestone.

Figure 3.7. (a) Neutron Density cross plot of Well C displaying complex response before shale correction. (b) Neutron-Density crossplot colored according to gamma ray response before shale correction

Figure 3.8. (a) Neutron-density crossplot of Well $\mathrm{C}$ after applying shale correction. (b) Colored with respect to the gamma ray log to make it compareable with Figure 3.7 (b)

Figure 3.9. (a)- Cross-plot between DGA and UMA presenting the data from Traverse Limestone of Well A. (b)- A part of respective lithology log. Red Line in first track show the gamma ray response, blue line is the clean line and green line is the shale line. 20

Figure 3.10. (a) Cross-plot between DGA and UMA presenting the data from Traverse Limestone of Well B. (b) Respective Litholog prepared by 4-mineral identification. Red Line in first track show the gamma ray response, blue line is the clean line and green line is the shale line. 21

Figure 3.11. (a) UMA-DGA Plot of Well $\mathrm{C}$ for Traverse limestone before shale correction (b) Respective Litholog describing the lithology. Red Line in first 
track show the gamma ray response, blue line is the clean line and green line is the shale line. 23

Figure 3.12. Lithologs prepared from 3-mineral clay inclusive identification. (a) Well A (b) Well B (c) Well C. Note the circled areas displaying disagreement with the gamma ray log (Red line in the first track). Red Line in first track show

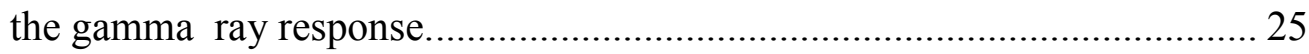

Figure 3.13. UMA-DGA crossplot after removing the shale fractions with characteristic ternary diagram of Well C. 27

Figure 3.14. Lithologs from Modified 3- Mineral Identification clay exclusive performed on the data after correcting for the shale effects. (a) Well A (b) Well B (c) Well C. Red Line in first track show the gamma ray response, blue line is the clean line and green line is the shale line. 28

Figure 3.15. Basin wide distribution of Shale fraction in Trvaerse Limestone. (a) Calculated by 4-mineral identification. (b) Calculated by Modified 3-mineral clay exclusive approach 32

Figure 3.16. Basin wide distribution of limestone fraction in Traverse Limestone (a) Calculated by 4-mineral identification. (b) Calculated by Modified 3-mineral clay exclusive approach 34

Figure 3.17. Basin wide distribution of chert fraction in Traverse Limestone (a) Calculated by 4-mineral identification (b) Calculated by Modified 3-Mineral clay Exclusive approach 36

Figure 3.18. Basin wide distribution of dolomite fraction in Traverse Limestone (a) Calculated by 4-mineral identification (b) Calculated by Modified 3-Mineral clay Exclusive Approach. 38

Figure 3.19. Plot of average error (between predicted and actual sonic logs) versus respective assumed DTshl (Shale Transit Time) to determine the value of DTshl for minimum error. Zero line is marked with the black line. 40

Figure 3.20. Logs displaying sonic prediction from density log. Green (DT): Measured Log; Red (PHIDa): Predicted by using Wylie's Time Average Equation; and Blue (PHIDb): Predicted by using Modified Time Average Equation including the effect of shale. Note the very nice fit in clean formations of 
Well A. Also see the error in prediction in Well B because of dolomite fraction. Well $\mathrm{C}$ presents the huge error in red caused by shale while modified equation in blue gave reasonable results. (a) Well A, (b) Well B (c) Well C 41

Figure 3.21. Crossplots describing error in sonic prediction with the increase in clay volume and dolomite fraction. Shale volume is shown along the $\mathrm{x}$-axis, and error is shown in the y-axis ( 0.0 is in the center and is marked with black line). Color of dots indicates dolomite content. (a) and (b) present the data from Well B. (c) and (d) present the data from Well C

Figure 3.22. Frequency of RMS error observed in sonic prediction (in 46 wells) from density porosity using (a) Wylie's Time Average Equation (Without Shale correction), (b) Modified Time Average Equation (Dealing shale as a separate matrix). 44

Figure 3.23. Sonic response prediction from Neutron logs. Green (DT): Measured sonic log; Red (DT_NPHIa): PredictiOn from Wylie's Time Average Equations; Blue (DT_NPHIb): Modified equation (I). (a) Well A, (b) Well B (c) Well C 46

Figure 3.24. Bar graph describing the frequency of RMS error (of 46 randomly separated wells) between the pseudo-sonic log and the measured sonic log (a) Wylie's Time Average Equation before accounting for dolomite effect (b) Modified Equation correcting for dolomite. 47

Figure 3.25. Crossplot showing the error in predicted sonic log for Well B from Wylie.s Time Average Equation (a) before correcting for secondary porosity (b) after correcting for secondary porosity. Color indicates the dolomite fraction and clay content is along $\mathrm{x}$-axis while and error is along $\mathrm{y}$-axis with zero line at center (marked with black line). 48

Figure 3.26. Plot between DTshl and the corresponding average error, used to estimate the most appropriate DTshl for the use in sonic log prediction from average porosity. Zero line is marked with the black line. 50

Figure 3.27. Predicted logs by using average of neutron and density porosity. The prediction is much better than that of the neutron and density porosities alone. vii 
In the figure Green Curve: Measured Sonic log Red: From Wylie's Time Average Equation (one matrix), Purple: Modified Time Average Equation (two lithologies) Blue: From Modified Equation (II) (two lithologies plus dolomite correction) (a) Well A, (b) Well B and (c) Well C..........................51

Figure 3.28. Bar-graph explaining the frequency of root mean square error of 46 wells in predicting the sonic response from average porosity. (a) Wylie's Time Average Equation, (b) Modified Time Average Equation (c) Modified

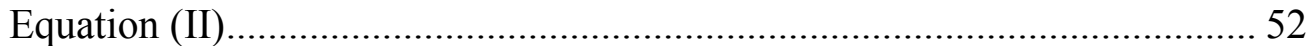

Figure 3.29 Crossplots between error and dolomite fraction colored with shale volume displaying the results of sonic log prediction in Well B by (a) Simple Wylie's Time Average Equation (b) Modified Time Average Equation (two lithologies; clay + shale) (c) Modified equation (two lithologies + dolomite correction). Dolomite fraction is along X-axis; Error is along Y-axis and the data points are colored with respect to shale fraction. 54

Figure 30. Prediction of sonic $\log$ with the results of mineral identification. Red:4mineral identification clay inclusive, Blue: Modified 3-mineral identification clay exclusive, Green: Measured Sonic log. (a) Well A (b) Well B (c) Well C. 56

Figure 3.31. Cross plot describing error in sonic prediction in Well B versus dolomite and shale fractions. (a) Mineral fractions used were calculated by 4-Mineral Identification clay inclusive (b) Mineral fractions used were calculated by Modified 3- Mineral Identification clay exclusive.

Figure 32. Bar graph presenting the root mean square error in sonic prediction by the use of individual mineral fraction in Wylie's Time Average Equation. (a) Mineral fractions calculated from 4-mineral Identification clay inclusive. (b) Mineral fractions calculated from Modified 3- Mineral Identification clay exclusive. 


\section{Acknowledgement}

I owe my deepest gratitude to my adviser, Dr. Wayne D. Pennington, for his guidance, patience and feedbacks to improve my work. He gave me an opportunity to develop my own individuality and self-sufficiency by allowing me to work independently in a very relaxed and friendly environment. His strong encouragement, golden pieces of advice, sound ideas and expert thoughts made this work done. His guidance helped me in all the time of my research work, and especially in writing the thesis. For everything you have done for me, I am very grateful to you, Dr. Pennington. I would also like to say thanks to Dr. Roger Turpening for providing me an opportunity to attend his weekly meetings where I learnt a lot. I got a lot of ideas and expert opinions from those meetings. He also made his support available for me in number of ways; the references, the books, the journals and other stuff provided by Dr. Turpening improved my knowledge and abilities. My words could not complete without paying my gratitude to Dr. Gregory P. Waite and Dr. Tamara Olson for their insightful comments and constructive suggestions.

I would like to say my cordial thanks to University of Engineering and Technology (UET), Lahore, Government of Pakistan and people of Pakistan for sponsoring my graduate studies at Michigan Tech. My sincere thanks and regards are due to Dr. Syed Tahir Ali Gillani (Chair, Department of Geological Engineering, UET, Lahore) and Dr. Muhammad Akram Khan (Vice Chancellor, University of Engineering and Technology, Lahore) for having confidence in me and granting me the scholarship.

My warm thanks to Buddy Wylie who digitized the data I used, and made it available for Tech students. I am also thankful to Carol J. Asiala for helping me to get the data and guiding me about the software packages used in my work. I am very grateful to Amie Ledgerwood for her help and guidance in completing all necessary documentation during my whole graduate program. I would like to extend my gratitude to Michigan State Office for providing the data for this work.

I would like to pay my heartily gratitude to Munsif Ahmed Madni for his time and guidance in formatting my work according to the standards. Very special thanks to 
Youngchul Yu, Joshua P. Richardson, Ryan Banas, Mohammad Ali Ezawie and my other friends at Michigan Tech who discussed my work and guided me at various stages.

I am indebted to Muhammad Imran Aslam, my most special friend at MTU, for helping me get through the difficult times, and for all the emotional support and entertainment he provided me. I am, in particular, grateful to him for the time and caring, he made to me during my illness.

The last but the most important my parents, Liaqat Ali and Sajida Liaqat, I could not be able to get this work done without their prayers and love. I pay my very especial regards to them. I do not have words to say thanks to them. I am very thankful to Madiha Liaqat (my sister), Abid Ali (my brother) and also to my all other family members for their love and support. 


\begin{abstract}
This work is conducted to study the complications associated with the sonic log prediction in carbonate logs and to investigate the possible solutions to accurately predict the sonic logs in Traverse Limestone. Well logs from fifty different wells were analyzed to define the mineralogy of the Traverse Limestone by using conventional 4-mineral and 3-mineral identification approaches. We modified the conventional 3-mineral identification approach (that completely neglects the gamma ray response) to correct the shale effects on the basis of gamma ray log before employing the 3-mineral identification. This modification helped to get the meaningful insight of the data when a plot was made between DGA (dry grain density) and UMA (Photoelectric Volumetric Cross-section) with the characteristic ternary diagram of the quartz, calcite and dolomite. The results were then compared with the 4-mineral identification approach. Contour maps of the average mineral fractions present in the Traverse Limestone were prepared to see the basin wide mineralogy of Traverse Limestone.

In the second part, sonic response of Traverse Limestone was predicted in fifty randomly distributed wells. We used the modified time average equation that accounts for the shale effects on the basis of gamma ray log, and used it to predict the sonic behavior from density porosity and average porosity. To account for the secondary porosity of dolomite, we subtracted the dolomitic fraction of clean porosity from the total porosity. The pseudo-sonic logs were then compared with the measured sonic logs on the root mean square (RMS) basis. Addition of dolomite correction in modified time average equation improved the results of sonic prediction from neutron porosity and average porosity. The results demonstrated that sonic logs could be predicted in carbonate rocks with a root mean square error of about $4 \mu \mathrm{sec} / \mathrm{ft}$. We also attempted the use of individual mineral components for sonic log prediction but the ambiguities in mineral fractions and in the sonic properties of the minerals limited the accuracy of the results.
\end{abstract}




\section{Introduction}

Detailed knowledge of seismic velocities is essential for an effective interpretation of seismic data and its relationship to rock properties of interest. Sonic logging is one of the most commonly used sources of seismic velocity information, and is often used with density logging to generate synthetic seismograms that help to improve the well-tie, seismic interpretation, lithology identification, geopressure determination, and rock strength evaluation. However, the primary original purpose of sonic logging was to determine the porosity, but after the advancement of density and neutron logging techniques, it is rarely used for that purpose. The result is we do not have the sonic logs, nor the resultant velocity-depth models, for many areas.

Considering the increasing importance and involvement of sonic logs in seismological and petrophysical analysis, many attempts have been made to determine the seismic velocities from other available data. Previous work involved sonic prediction on the basis of rock physics models, petrophysical properties of cores, and logging data. Neural networks provide one of the many approaches that have proven useful to generate the synthetic logs from other available logs [Du et al., 2008; Rolon et al., 2009], but fail to provide physical insight that may be useful for additional interpretation. Ojala demonstrated that relations from rock physics can be used to generate synthetic sonic logs from resistivity and porosity determined from other logs [Ojala, 2009]. Relations have also been developed that relate sonic transit time to resistivity, depth and porosity data [Adcock, 1993; Faust, 1951; Lee, 1999; Ojala, 2009] and their relative accuracy 
have been compared by many. Almost all these methodologies are based on porosity and its effects on different types of logs [Hacikoylu et al., 2006].

One thing common in the previous work is that all the attempts made for synthetic logging were in clastic sediments while a few reasonable attempts were made in carbonates. We assume that the prediction of sonic log in clean limestone is easy as all tools often detect the same porosity in clean limestone as is detected by sonic log but the shaliness, dolomitization and other complications can control the sonic response in carbonates, and knowledge of those controlling factors may be very useful in interpretation of available data.

In this work, an attempt was made to study these complications and to predict the sonic behavior on the basis of petrophysical analysis. About fifty randomly separated wells were selected in Michigan basin to study the Traverse Limestone. This formation consists of limestone with shale as significant lithology while local dolomitization and chert play a role in some areas. We used different conventional approaches to determine the lithology both in terms of quality and quantity, and attempted some modifications in these approaches. We also applied the results from lithological analysis to porosity logs, correcting for shale or secondary porosity to generate pseudo-sonic logs. In particular, Wylie's Time Average equation was modified to account for the shale volume, dolomite volume, porosity, secondary porosity and other physical properties of the rock. Sonic response was predicted by using different conventional and modified equations. The results from different approaches were compared using root mean square error with known sonic $\log$ values. 
The basic principle of the logs used, and working of their respective tool is given in Appendix (VI). 


\section{Traverse Group Geology}

N.H. Winchell first used the name "Traverse Group" for a sequence of buff granular limestone exposed around the Little Traverse Bay region of Charlevoix and Emmet counties in the northern part of Michigan's Lower Peninsula. Middle Devonian in age, it unconformably overlies the Dundee Limestone and is in turn overlain by the Late Devonian Antrim Shale. The Traverse Group has produced more than 105 million barrels of oil since first production in 1886 [Wylie and Huntoon, 2003].

The Middle Devonian Traverse Group is a sequence of limestone varieties with the shale progressively dominating the section upward. This sequence of interbedded carbonates and shales represent multiple phases of transgression and regression during the Middle Devonian. Traverse Group has its maximum thickness of $900 \mathrm{ft}$ in the northeastern and central part of the Michigan state and it thins out to a minimum thickness of $80 \mathrm{ft}$ in the southwestern part of the basin. It has been divided into thirteen different formations in outcrops but this outcrop terminology is not used in subsurface stratigraphy as facies changes do not allow any certain correlation between outcrops and subsurface [Wylie and Huntoon, 2003].

In the subsurface, the Traverse Group is divided into three different formations: Traverse Formation, Traverse Limestone and Bell Shale. Bell Shale, the lower most formation of the Traverse Group is about $80 \mathrm{ft}$ thick and pinches out completely in the south western part of the basin [Catacosinos et al., 1990]. Bell Shale consists of a grayish shale and is fossil-rich in the upper zone. The middle formation of the Traverse Group is the Traverse Limestone that conformably overlies the Bell Shale in the central and western Michigan 
and unconformably overlies the Dundee Limestone in the eastern part of Michigan where Bell Shale is not present. Mineralogically, Traverse Limestone consists of finely crystalline gray or brown limestone of varying shades with some intervals of scattered dolomitic limestone and argillaceous limestone [Lilienthal, 1974]. Other than pure limestone, Traverse Limestone also contains chert, dolomite and evaporites in the western portion of the state and an increasing amount of shale in the eastern portion [Catacosinos et al., 1990; Dolton, 1995; Newman, 1936; Pringle, 1937]. Pringle reported that the Traverse Limestone has a $200 \mathrm{ft}$ thick bed of gray shale with lime and dolomite under the first layer of brown limestone in the Arenac County and also pointed out the presence of the chert in its basal portion. The presence of water, brine, oil and gas has been reported in wells at different levels and in different amounts.

The upper most formation of the Traverse Group is the Traverse Formation, consisting of gray calcarious shale and argillaceous limestone. The shale content progressively dominates upward in the section. It is present in the western and central portion of the Lower Peninsula with a maximum thickness of $80 \mathrm{ft}$ and thins out to a feather-edge in the eastern Michigan. Most authors consider it as transition zone between the underlying Traverse Limestone and the overlying Antrim Shale.

A significant amount of oil and gas has been produced from the Traverse Limestone [Dolton, 1995]. The source rock for these reservoirs has not been identified yet but is presumed to be Ordovician or Devonian. Almost all of the Traverse fields are in the central and western portion of the Michigan basin. Traverse Limestone has intervals of porous and dolomitized limestone that make it suitable for reservoir rock. Devonian 
formations exhibit the presence of the crimps of various magnitudes in the outcrops and in the subsurface [Milstein, 1988]. These folds provide suitable enclosures and structures to trap the oil. In addition, accumulation of hydrocarbons is supported by stratigraphic traps developed by the stratigraphic and diagenetic variations in the Traverse Group. 


\section{Methodology}

The seismic velocity for any rock unit depends on its constituting mineral types and their fractions, on the porosity and porosity types, and fluid types in pores. To establish relationships for the determination of sonic velocities, it is necessary to have a reasonable understanding of lithology, porosity and fluid content. The Traverse Limestone is very complex in its nature as it has huge lateral and vertical variations in mineralogy. To get the detailed lithological information of the unit, petrophysical analysis of the logging data from fifty different wells was done. The techniques used, their corresponding results and the comparison of these results is described in the coming sections.

\subsection{Picking the Formation Tops}

In order to conduct systematic studies of the formation, the tops of the units were picked on logs. The Traverse Limestone everywhere in the Michigan Basin is overlain by Antrim Shale with a layer of Traverse Formation between them in the central and western parts of the basin. Antrim Shale is highly radioactive because of the presence of Uranium; and gamma ray logs for Antrim show values that are frequently far higher than 150 API. We picked the top of Traverse Group at the base of the Antrim Shale where the gamma ray dropped below 100 API. In central and western portions of the basin, this represents the top of the Traverse Formation, the upper most formation of the Traverse Group. Traverse Formation shows decreasing trend on gamma ray log with increase in depth and ultimately stabilizes with a very low value. We marked this stable point as the top of the Traverse Limestone. The sudden increase in gamma ray response made it very easy to mark the base of the Traverse Limestone at the top of the Bell Shale, in the northwestern Michigan. In the northeastern part of the state, the base of the Traverse 
Limestone has thick beds (up to $200 \mathrm{ft}$ ) of shale that can be confused with Bell Shale. Errors were identified from isopach maps initiating a repick for the top of Bell Shale. In these areas, top of the Bell Shale was marked with a sudden and reasonable drop in gamma ray while moving upward from the base of the Bell Shale. In the eastern and southern parts of the state it was difficult to mark the base of the Traverse Limestone because there it overlies directly the Dundee Limestone with little or no shale. In these areas, neutron porosity and density logs were used in addition to the gamma ray log. The base of the Traverse Limestone was, then, marked by a slight downward decrease in gamma ray along with an increase in neutron porosity and/or slight decrease in density. In some wells, resistivity logs also helped to mark the base with a decrease in resistivity.

In Figure 3.1, open-hole logs from two wells are displayed; one describes the formation picks in the Eaton County where Bell Shale is absent and the other presents a well from Clare County where Bell Shale is thick. The first track shows solid red line of gamma ray $\log$ with black dotted line of caliper log. The second track displays the resistivity logs and the third track has porosity logs (blue: neutron log, red: density log, green: sonic $\log$ ). 


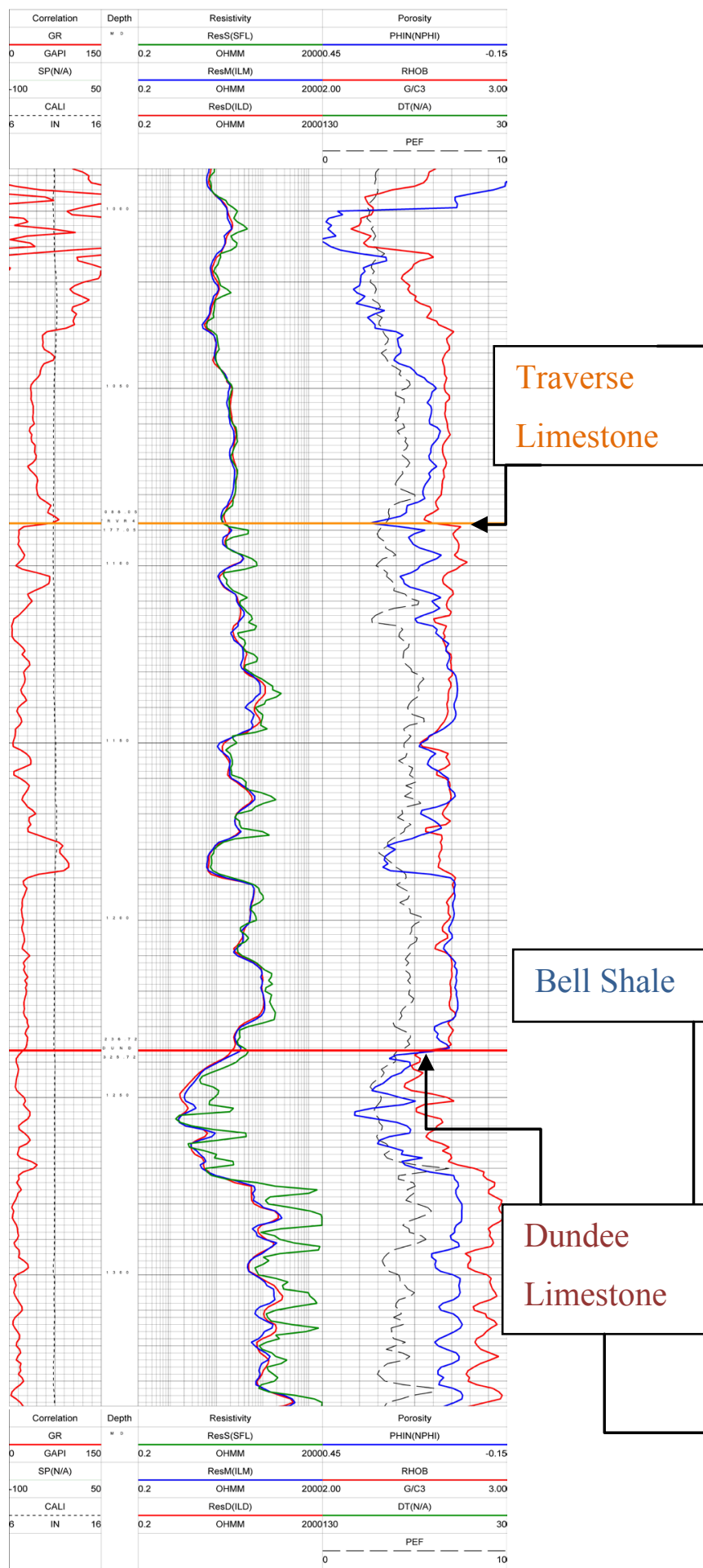

(a)

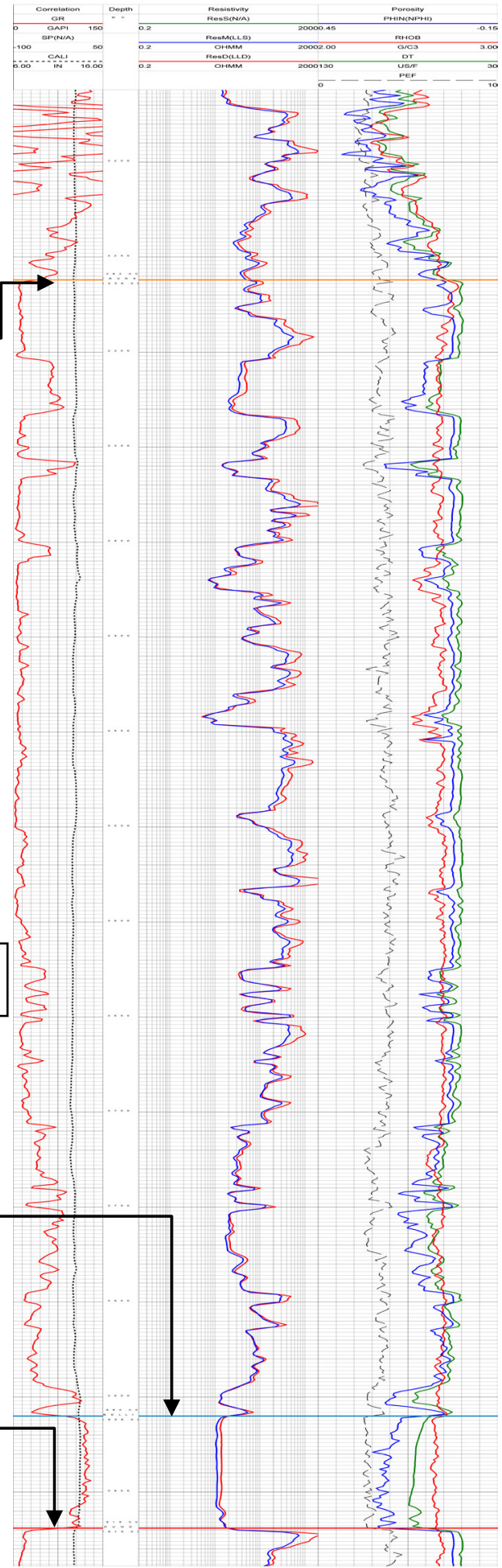

(b)

Figure 3.1. Well logs presenting the tops of Traverse Limestone, Bell Shale and Dundee Limeston. (a) From Eaton (b) From Clare 
About 160 randomly spaced wells were selected and the formation tops marked for Traverse Limestone, Dundee Limestone and Bell Shale. We prepared isopach and topographic maps of the Traverse Group (Traverse Limestone plus Bell Shale) excluding Traverse Formation to see the basin wide trend of the Traverse thickness and depth, shown in Figure 3.2. The ispoach (thickness) map and the depth contour map of the Traverse Limestone confirm the trend of the formation proposed in earlier studies [Catacosinos et al., 1990; Howell and van der Pluijm, 1999; Wylie and Huntoon, 2003]. Figure 3.2 shows that the Traverse Limestone has maximum thickness in the northeastern part of the basin and decreases gradually in the south-west direction. The background color of the traverse topography reveals that the maximum thickness of the formation is not at the center of the basin but is in its north-east.

An isopach map of the Bell Shale was also prepared and is presented in Figure 3.3 in color scale. We can see in Figure 3.3 that the Bell Shale has its maximum thickness in the northwestern part of the basin and thins out to complete absence in the southern part and eastern parts of Michigan basin. The green central region shows about constant thickness in that region. We did not have wells in the north part of the state. The contours and topography in that region was plotted by interpolation from the nearest point so the figure does not present the true picture in that region. 


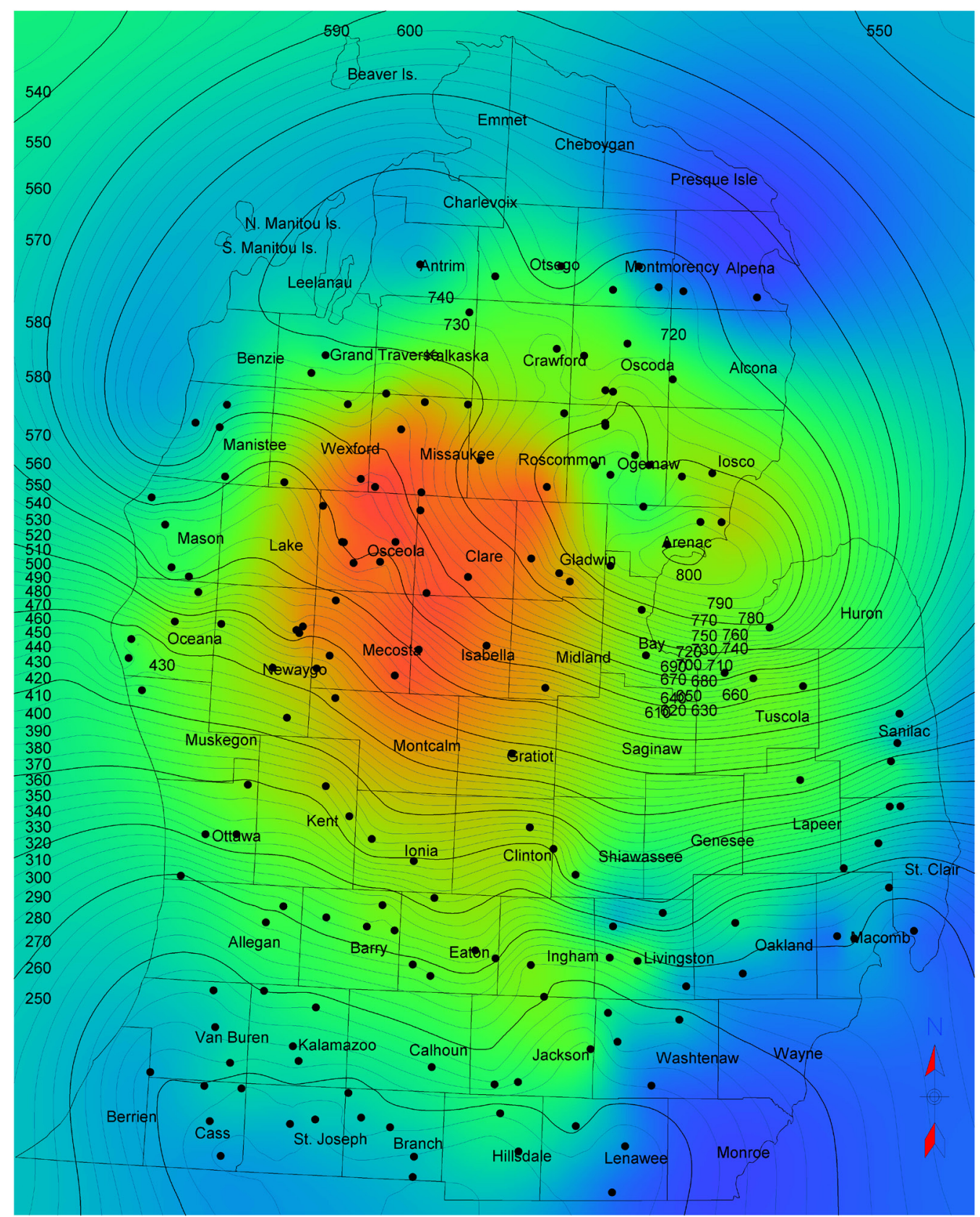

TRVR-DUND Isopach

Data Point

Data Point
TRVR Top Contour

IsoMap Surface Grid Mesh

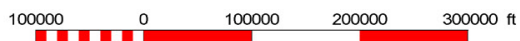

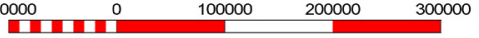

Grid

2640

3449

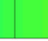




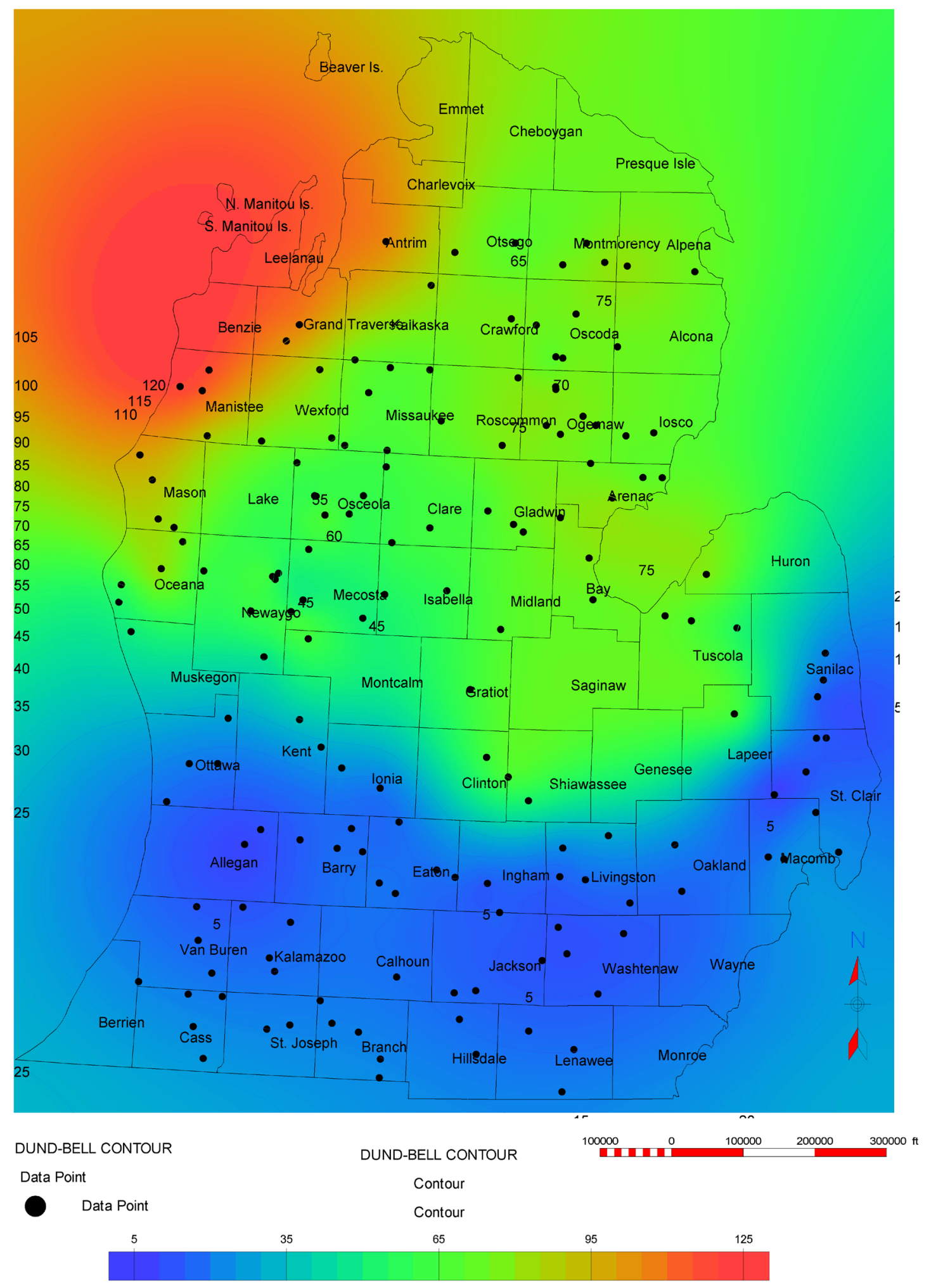

Figure 3.3. Isopach map of the Bell Shale. Color-bar indicates the thickness of the Bell Shale in $\mathrm{ft}$. 


\subsection{Petrophysical Analysis}

We presumed that the most important thing in sonic response prediction is to have the detailed mineral composition of the rock. We selected fifty randomly distributed wells from the 160 wells used above. Figure 3.4 shows the locations of these wells. Detailed petrophysical analysis was carried out on the open-hole log data (provided by the Michigan State Department) to determine the mineral compositions and porosities. Shale fraction was determined on the basis of the gamma ray log. Fractions of other minerals were calculated by using data from gamma, density, neutron and (Photoelectric Absorption Factor) PEF logs. Conventional mineral identification approaches were used to interpret the logging data for qualitative and quantitative evaluation of lithology.

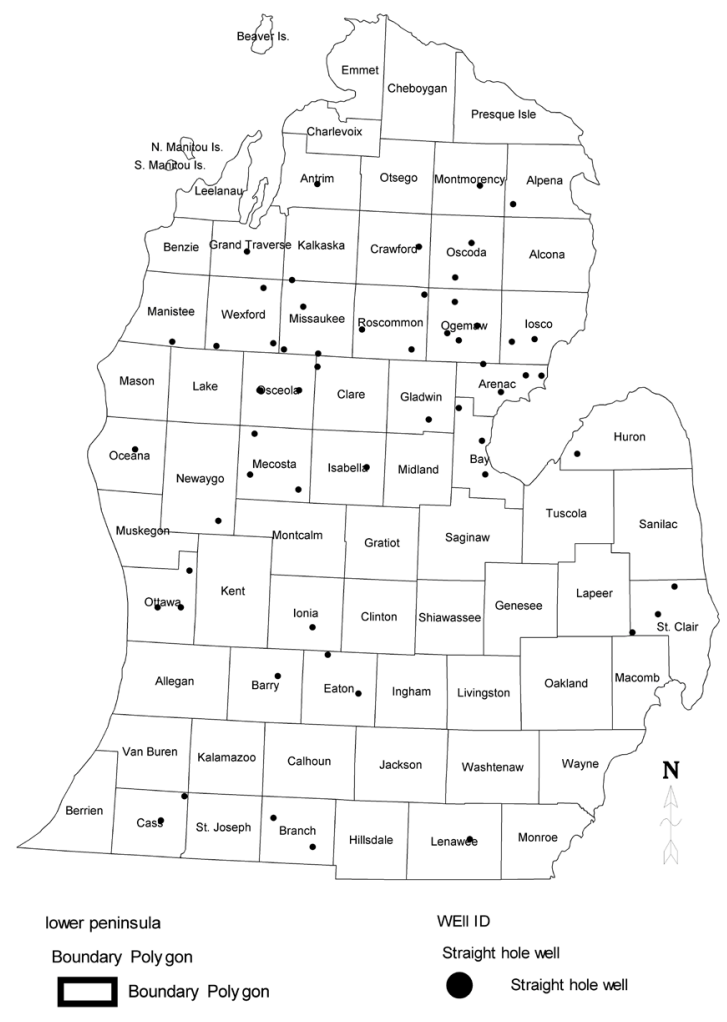

Figure 3.4. Map of Michigan's Lower Peninsula showing the locations of wells used in this work. 


\subsubsection{Crossplot between Neutron Porosity and Bulk Density}

We prepared the Crossplot between Neutron Porosity and Bulk Density (neutron-density crossplots) for all the wells to yield the qualitative description of lithology. Neutrondensity crossplots gave three quite different results in Traverse Limestone. In some cases the neutron density cross plots indicated pure limestone. We selected well\#21107402420000 (A) as an example for this category and its neutron-density crossplot is shown in Figure 3.5. The second type of response described the presence of significant amount of dolomite in addition to the limestone. Well \#21113361730000 (B) presented in Figure 3.6 is an example of this category. There were very few wells displaying this kind of trend.

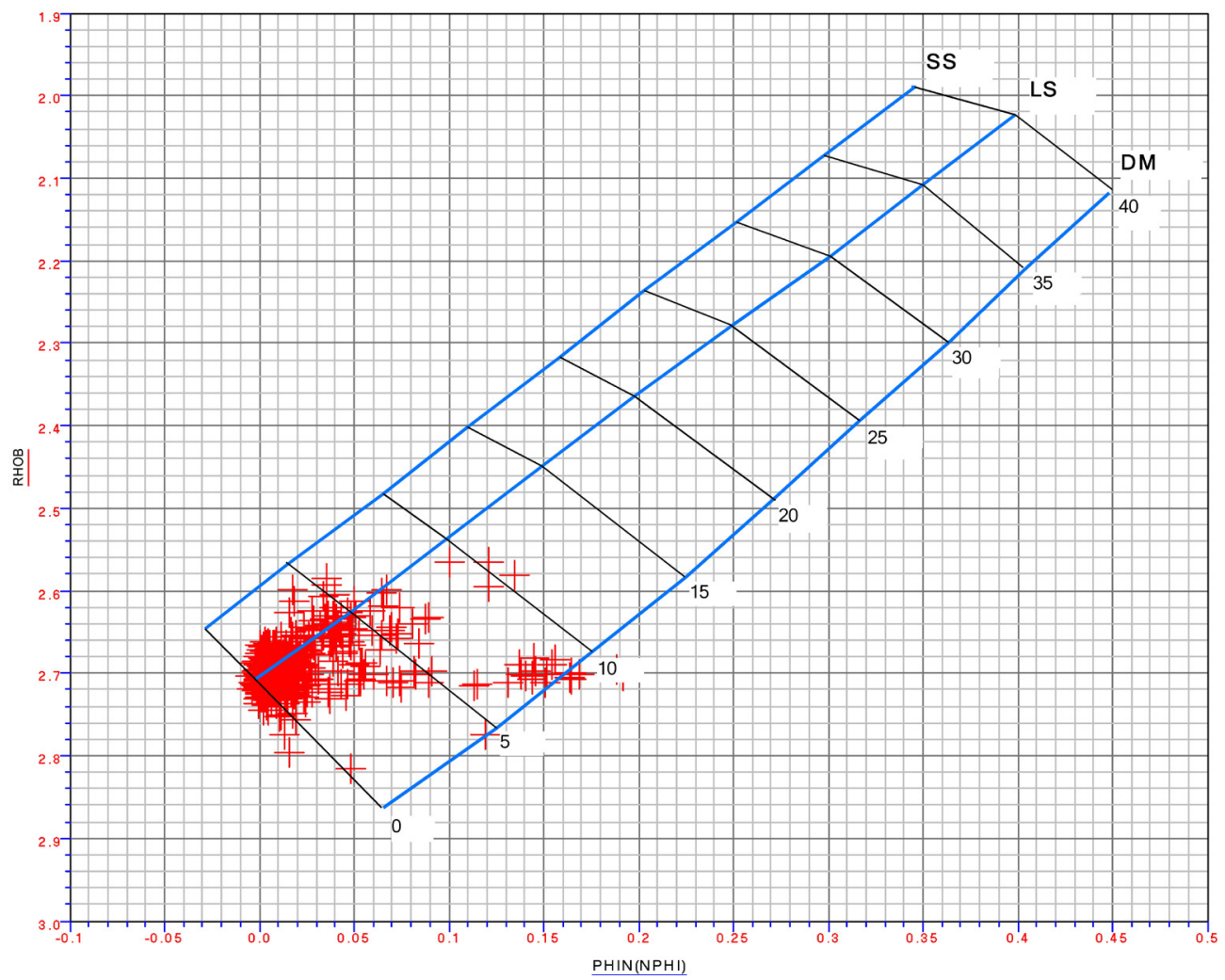

Figure 3.5. Neutron-Density Crossplot of Well A indicating pure limestone. 


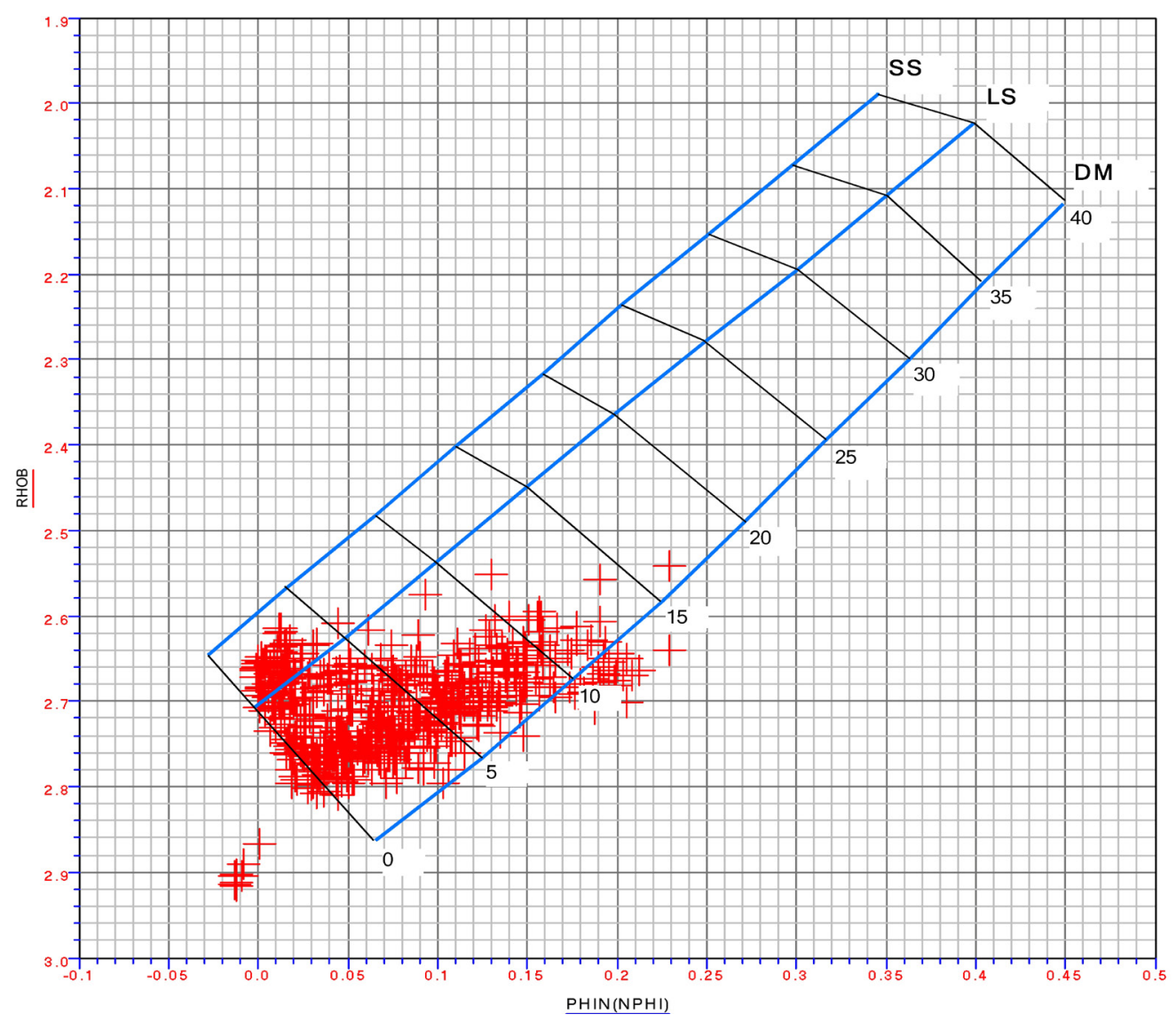

Figure 3.6. Neutron-Density crossplot of Well B indicating the presence of dolomite and limestone.

Third and the most confusing response was where neutron porosity increased without any significant change in density values. One of the examples shown in Figure 3.7(a) displays the data from Well \#21135406510000 (C). We show gamma ray log on the third axis and colored the data points suspecting that gamma ray indicated clay with its bound water as the potential source of high neutron response. The plot is displayed in Figure 3.7(b) and it shows that our assumption was reasonably correct. For the remaining part of our work, we will call these wells A, B and C respectively. 

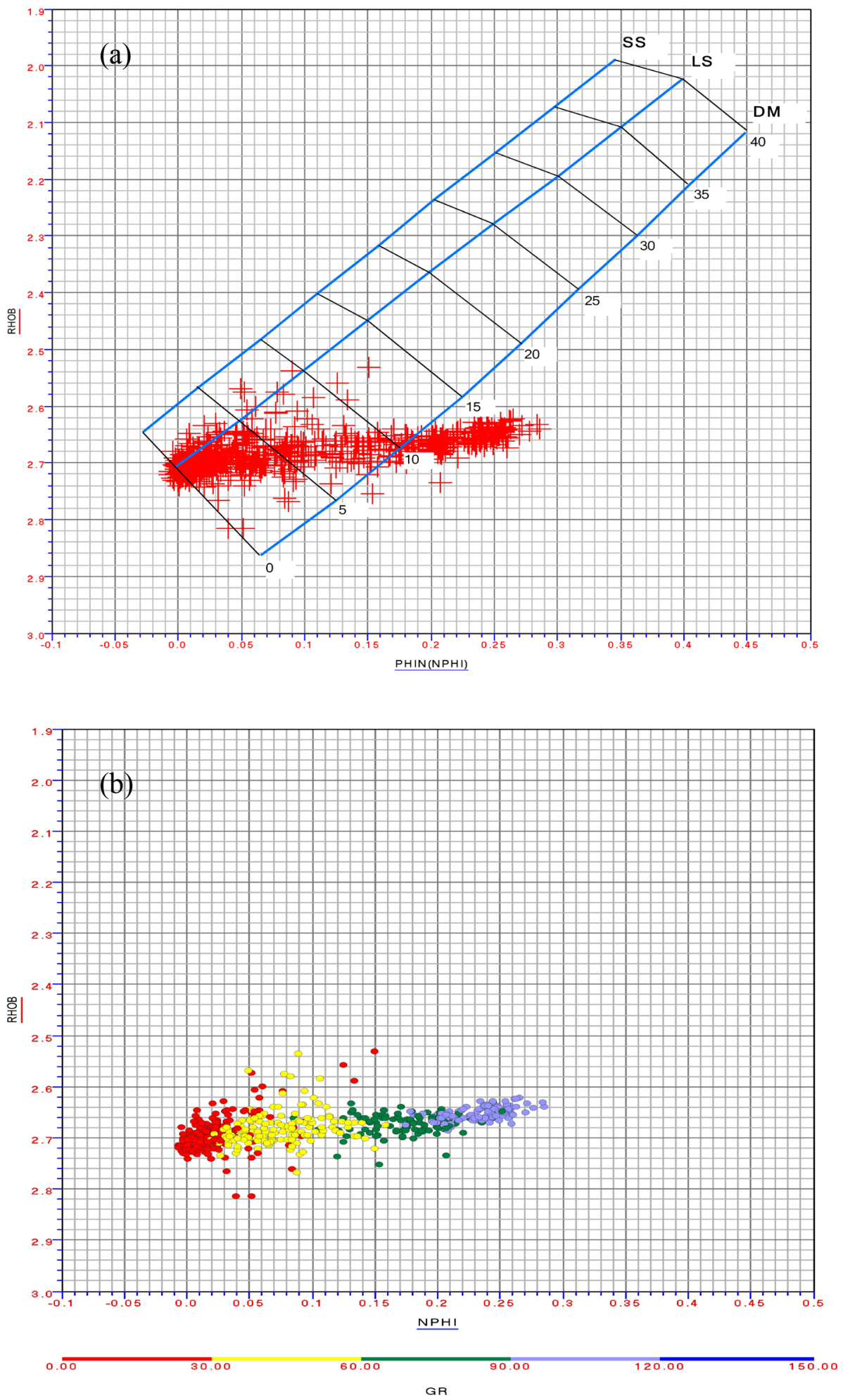

Figure 3.7. (a) Neutron Density cross plot of Well C displaying complex response before shale correction. (b) Neutron-Density crossplot colored according to gamma ray response before shale correction. 
In the next step, we applied some shale corrections and tried to remove the clay effects from the density and neutron data in order to determine the "clean" mineral content and porosity. Equations used for this process are given in Appendix (I). We used $2.65 \mathrm{gm} / \mathrm{cc}$ for shale density, 15API for gamma ray log in clean formation and 110 API for gamma ray in shale, and conventional properties for limestone (calcite) matrix. Our correction moved most of data points to limestone matrix line. The respective "clean" neutron density crossplot is shown in Figure 3.8 after shale correction. Some of data points displayed abnormally high $(\rho>3.00 \mathrm{~g} / \mathrm{cc})$ or abnormally low $(\rho<2.00 \mathrm{~g} / \mathrm{cc})$ density values after shale correction. It could be because of some bad data points, bed-boundary effects, or other causes, and will be investigated further in future work; these points occur at very high GR values, and have undergone the greatest "correction".

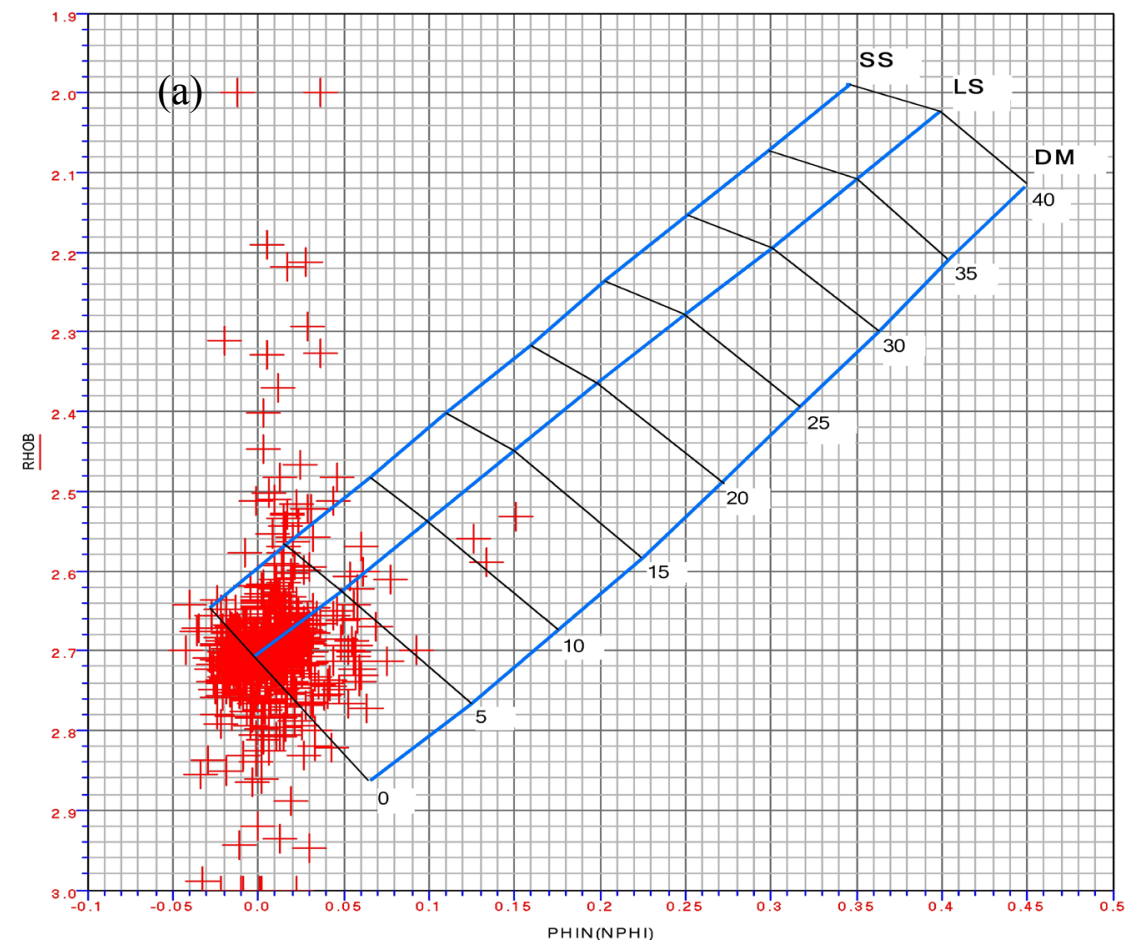




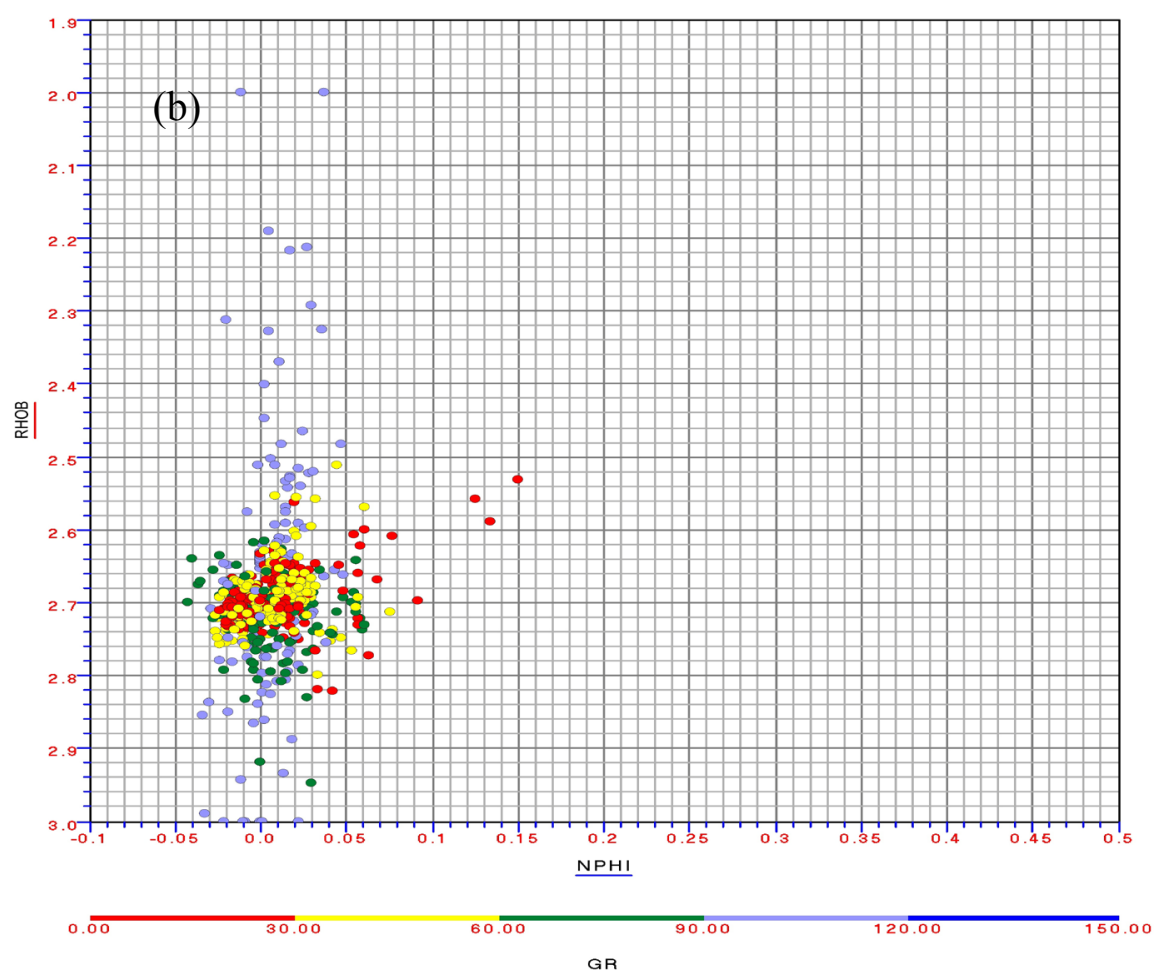

Figure 3.8. (a) Neutron-density crossplot of Well C after applying shale correction. (b) Colored with respect to the gamma ray log to make it compareable with Figure 3.7 (b).

From the neutron density cross-plots we conclude that the Traverse Limestone is not a simple pure limestone, but is complex in its mineralogical composition. It has a mixture of limestone and shale with, locally, addition of dolomite. Crossplots also indicate the traces of chert at some places. These crossplots also helped to decide the parameters for future use (e.g., GR for shale and clean lithology, neutron porosity for shale and density value for shale). Neutron density crossplots gave us the qualitative description of the mineral composition. Synthetic sonic velocities require the precise knowledge of all mineral fractions. For this purpose we used the mineral identification approach. 


\subsubsection{4- Mineral Identification}

Conventional mineral identification techniques involve the use of the gamma ray log, density $\log$, neutron porosity $\log$ and Photoelectic Absorption Factor (PEF log). With these four logs, it is possible to determine four mineral components under most conditions.

Assuming the presence of four minerals (Quartz, calcite, dolomite and clay), we used the 4-mineral identification technique implemented in commercially available software PRIZM $^{\mathrm{TM}}$ (Petrophysical Log Analysis Software) to determine the volumetric fraction of each component. It involves the use of dry grain density (DGA) and matrix volumetric factor (UMA) of rocks to solve for the constituent minerals. Conventional 4-mineral identification approach is explained in Appendix II with all the parameters, equations and solutions we used in this work.

From mineral identification, we obtained a reasonably good estimate of each constituent mineral. Again the results were categorized into three different types. Some of the wells displayed reasonably pure limestone, while others were displayed a large amount of clay content with the limestone. In a few wells a significant amount of dolomite was also observed with localized traces of chert.

We made the crossplots between DGA and UMA (two parameters derived from the porosity, density and PEF logs - Appendix II) with the characteristic ternary diagram. These crossplots give visual description of the quantitative results of mineral identification. 
Figure 3.9(a) displays the ternary diagram for Well A. Ternary diagram is consistent with the results of the neutron density crossplot. It demonstrates that the Traverse Limestone is nearly a pure limestone in this well. To see the lithological column in the well, a litho-log was prepared from the mineral identification results and some portion from the middle depths of the log is presented in Figure 3.9(b).
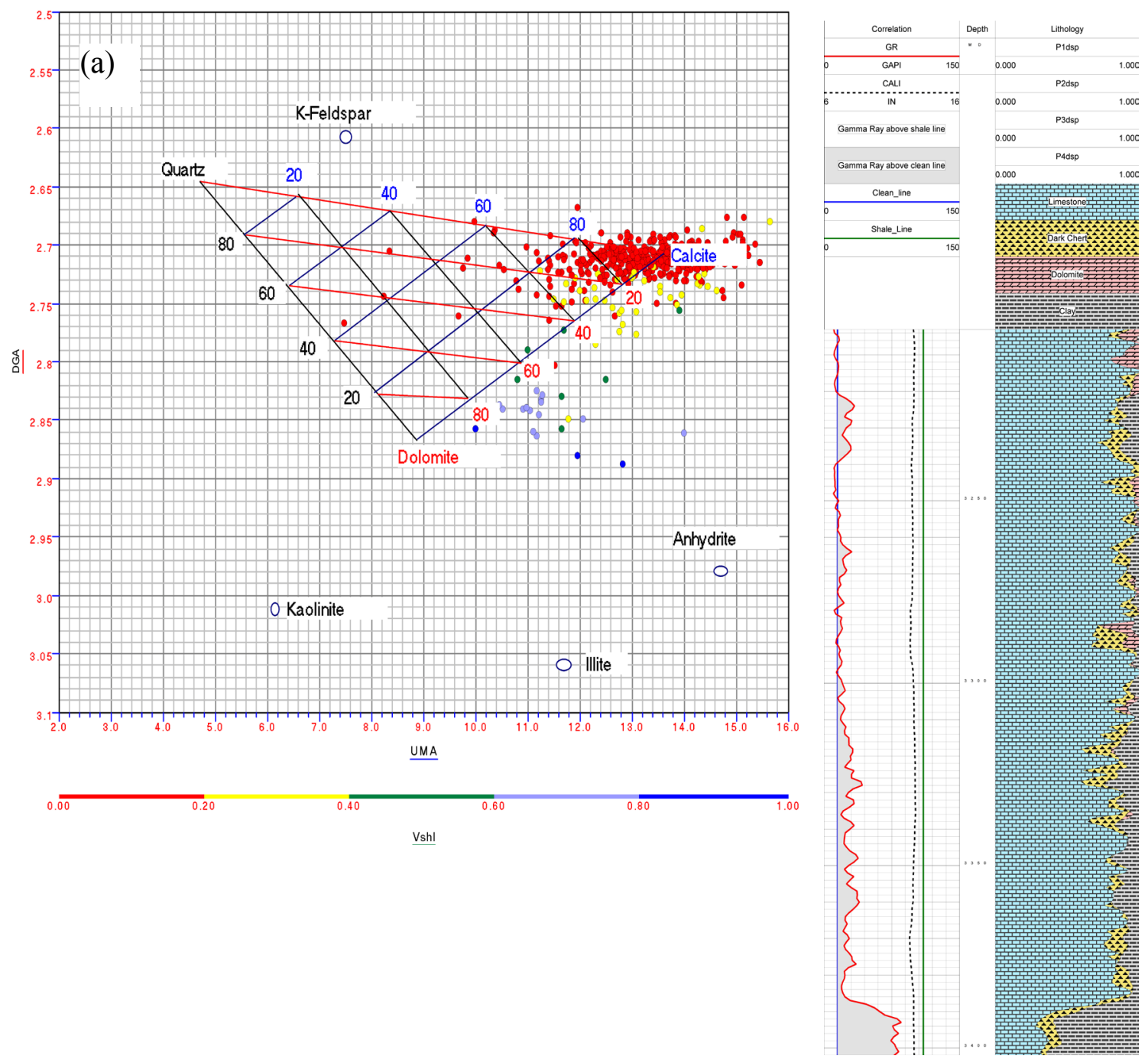

(b)

Figure 3.9. (a)- Cross-plot between DGA and UMA presenting the data from Traverse Limestone of Well A. (b)- A part of respective lithology log. Red Line in first track show the gamma ray response, blue line is the clean line and green line is the shale line. 
Similarly ternary diagrams for Well B and Well C were prepared with their respective lithologs and their images are displayed in Figure 3.10 and 3.11 respectively. Figure 3.10 indicates the presence of significant amount of chert with dolomite in Well B, yet we could not see any clear indication of chert in the neutron-density crossplot of Figure 3.6. This disagreement led us to perform 3-mineral clay-inclusive identification procedure that is described in a later section.
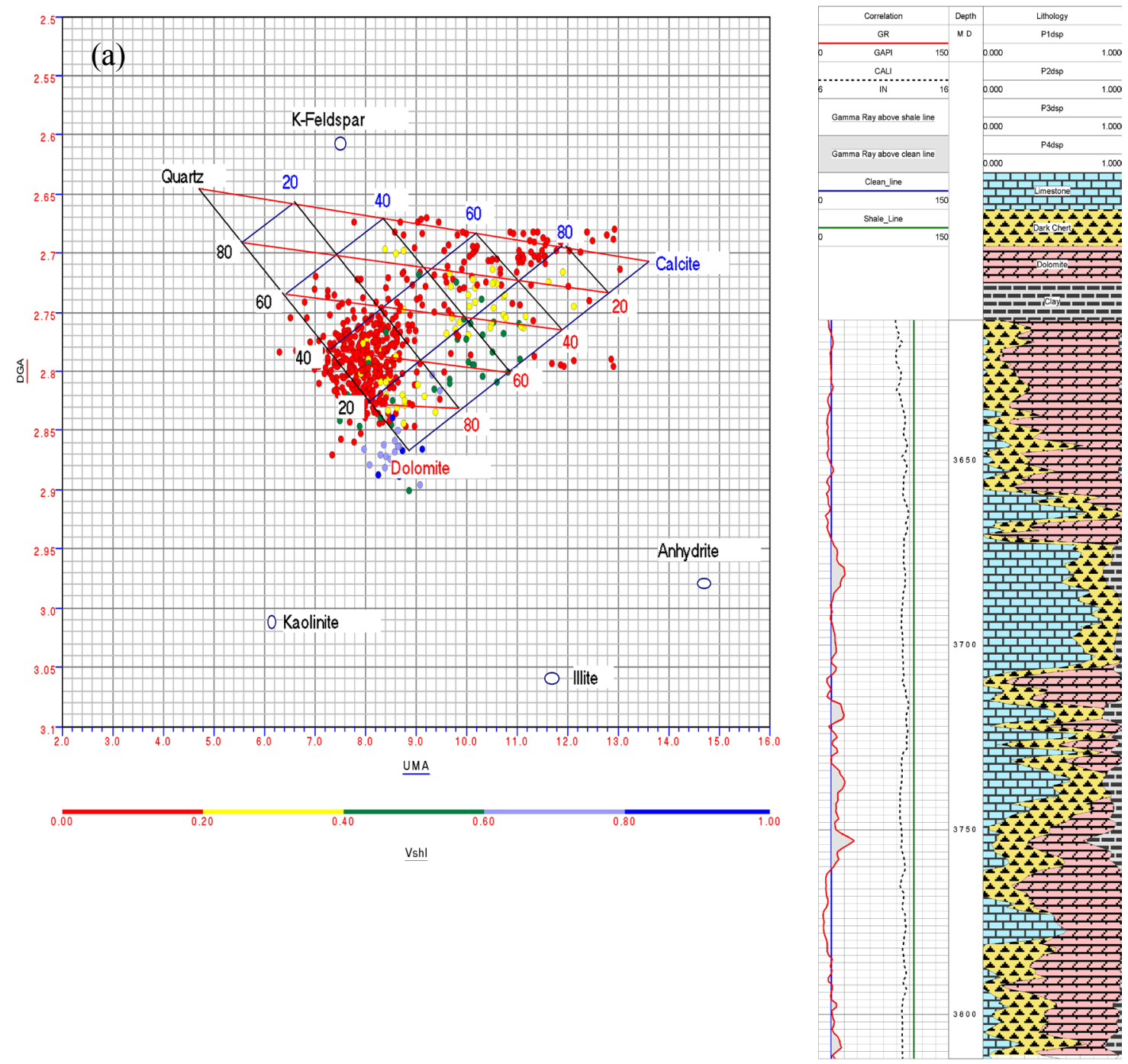

(b)

Figure 3.10. (a) Cross-plot between DGA and UMA presenting the data from Traverse Limestone of Well B. (b) Respective Litholog prepared by 4-mineral identification. Red 
Line in first track show the gamma ray response, blue line is the clean line and green line is the shale line.

Figure 3.11 displays the ternary diagram for Well $\mathrm{C}$ and its lithology, having used the 4mineral solution. The ternary diagram is again a little confusing as some of our data points are out of the characteristic ternary diagram of calcite, dolomite and quartz. These points trend towards illite (a type of clay mineral) and suggest the presence of clay. The color of the data points indicates shaliness (from gamma ray) where red describes no shale and dark blue indicates pure shale. But the question here is what the mineral fraction of each component is? The Ternary diagram does not clearly answer this question. However, the mathematical approach of 4-mineral identification quantifies each component and gives us numbers. We prepared the litholog for Well C by calculating the mineral constituents of each point. Lithology log of Well C displays thick beds of shale in the well with small amount of chert and dolomite. 


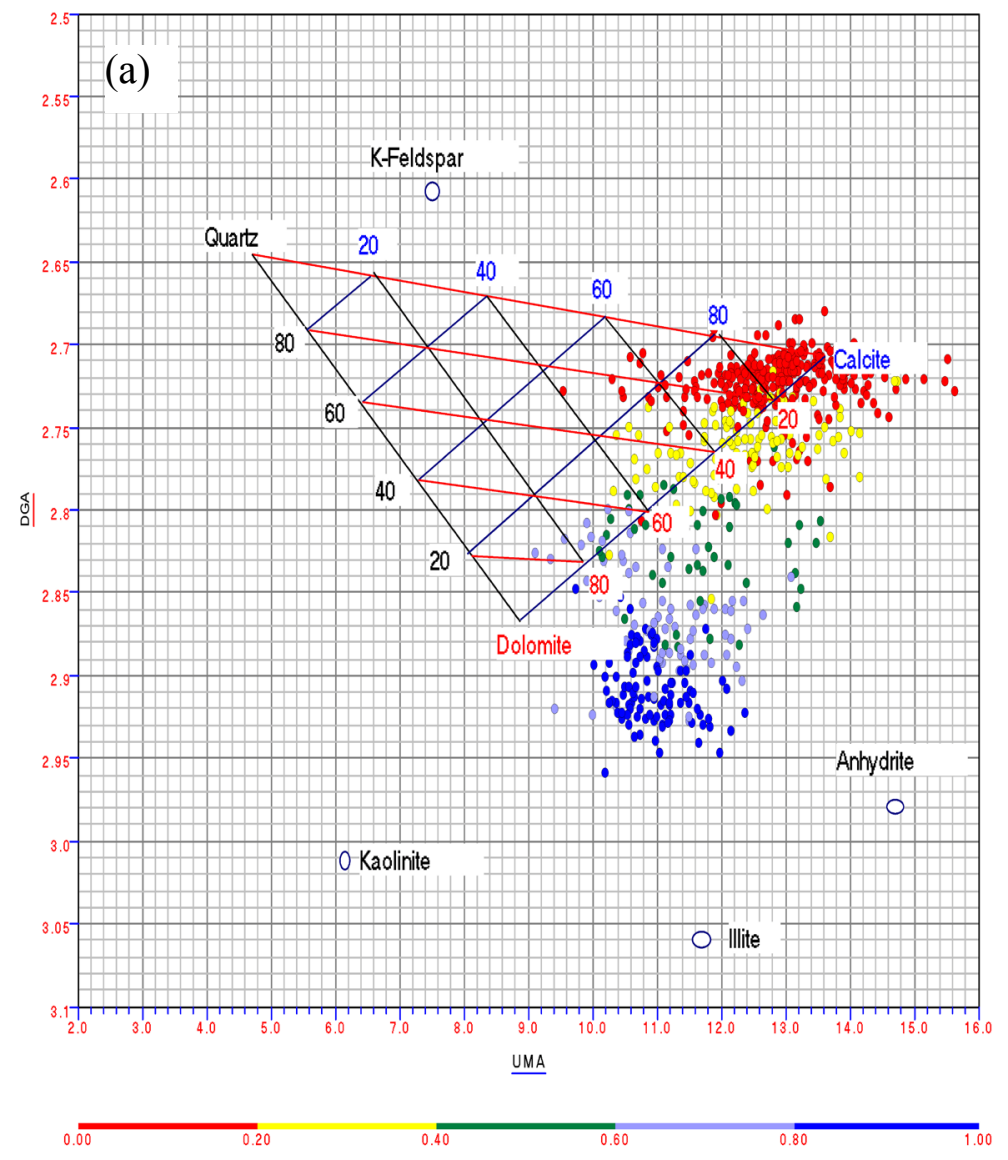

$\underline{\text { Vshl }}$

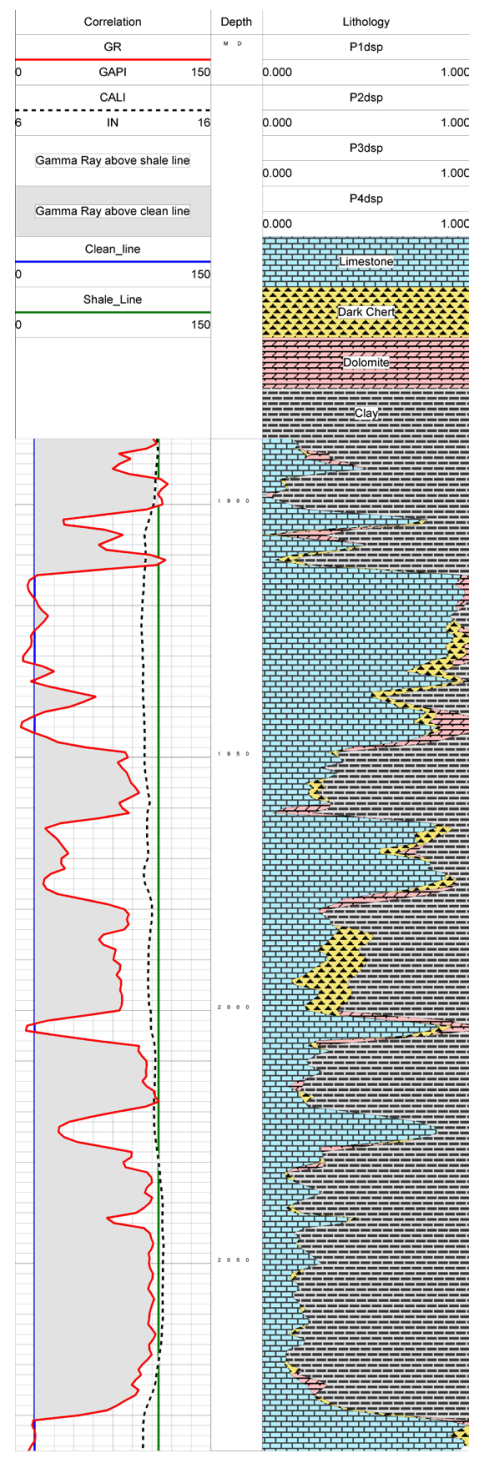

(b)

Figure 3.11. (a) UMA-DGA Plot of Well $\mathrm{C}$ for Traverse IImestone before shale correction (b) Respective Litholog describing the lithology. Red Line in first track show the gamma ray response, blue line is the clean line and green line is the shale line.

The 4-mineral identification approach deals equally with the shale volume as it deals with other fractions, after having initially estimated the shale volume from gamma ray log. The mineral fraction of non-clay minerals are estimated from the other (density, neutron porosity, and PEF) logs, while accounting for the shale contribution to these other logs. 
However, because the typical approach divides the porosity equally (using a volumeweighted approach) among all mineral constituents, the effect of shale content (which may include most of the porosity) is minimized. To fix the clay-bound water volume using shale content determined from gamma ray log, we modified the mineral identification approach as discussed in a later section: "Modified Mineral Identification".

\subsubsection{3-Mineral Identification}

Neutron density crossplot and ternary diagram of Well B did not agree on the amount of chert present in the well. Neutron density crossplot did not show any indication of chert in the well but ternary diagram described a significant amount of chert. Both approaches have some factor of doubt in them as these are indirect measurements made with certain assumptions. To see the results from a different angle, we used 3-mineral identification approach assuming that there was no chert in the wells, while including clay (shale) as one of the three components and ignoring the gamma ray log. 3-mineral identification was applied to all the wells to get the mineral fractions of clay, dolomite and calcite. The results of 3-mineral identification for Well A, B and C are displayed in Figure 3.12 in the form of litholog. 


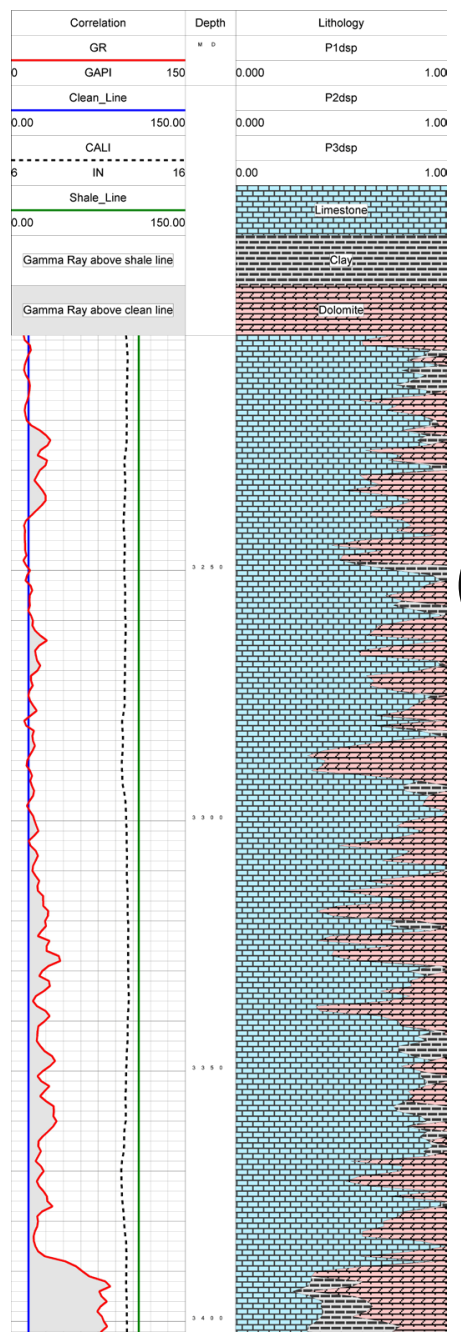

(a)

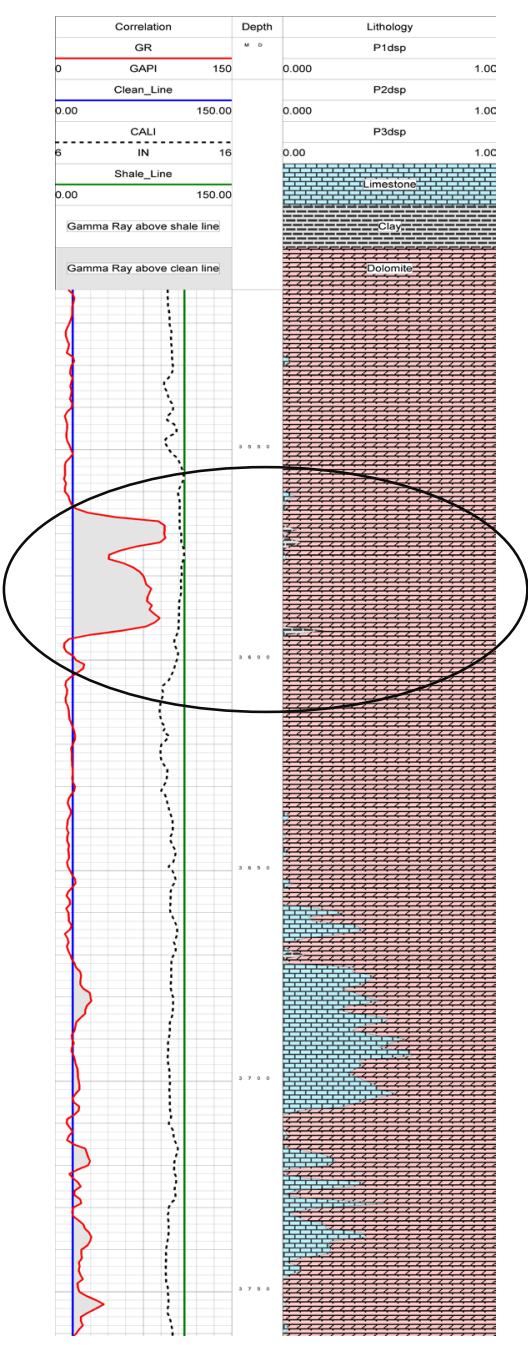

(b)

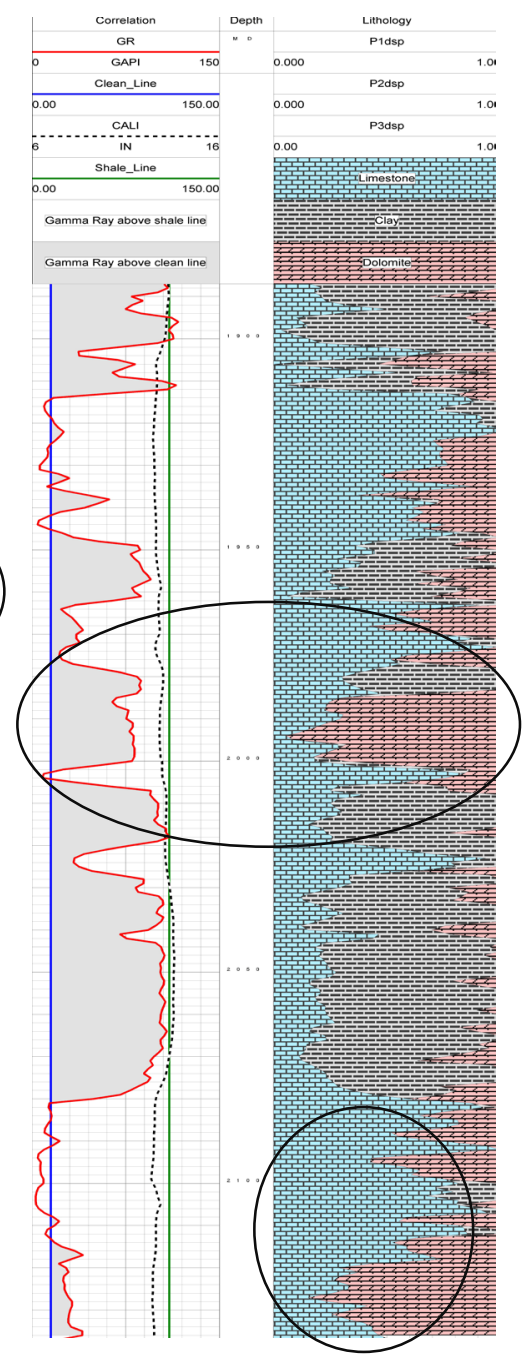

(c)

Figure 3.12. Lithologs prepared from 3-mineral clay inclusive identification. (a) Well A (b) Well B (c) Well C. Note the circled areas displaying disagreement with the gamma ray $\log$ (Red line in the first track). Red Line in first track show the gamma ray response.

Figure 3.12 shows that most of the chert was replaced by dolomite in 3-mineral identification. But the most interesting part was that it often replaced limestone and clay content with dolomite. Some examples are circled in Figure 3.12.

The reason that the solution found dolomite where clay likely exists is that 3-mineral approach completely neglects the GR $\log$ and processes the data only on the basis of DGA and UMA. Details of 3-mineral approach are given in Appendix (III). 
The replacement of limestone with dolomite can be explained on the basis of UMA and DGA values. Chert has the lowest UMA and DGA values among all the four constituents, with UMA about half that of dolomite. Limestone, on the other hand, has the highest UMA value. Removal of chert unbalanced the UMA equation and to rebalance the equation amount of dolomite was increased and the amount of limestone was decreased. All this work resulted into unbalanced grain density equation as both limestone and dolomite have higher densities than chert. To make the space for increased density, clay fraction was reduced. This whole process resulted into an increase in dolomite and decrease in limestone and clay content.

We concluded that 3-mineral identification is not a good tool for mineral identification in shaly formations as it completely neglects the gamma ray response.

\subsubsection{Modified Mineral Identification}

We modified the mineral identification approach by combining aspects from both 3mineral and 4-mineral identification approach.

In 4-mineral identification, shale volume determined from gamma ray response is changed to balance the DGA and UMA response and in 3-mineral identification approach gamma ray response is completely neglected.

In our modified approach, we fixed the shale volume on the basis of gamma ray response. We did it by removing the effect of shale content from all the logs, including the presumed porosity associated with the shale component. We "corrected" the density, porosity and PEF values by assuming linear law of volumetric mixing and then shale free data was used for 3-mineral (calcite, dolomite and chert) identification. The porosity associated with the shale content was estimated from the log data, and was included as part of the "correction" process. This way, if most of the porosity of the bulk rock was in fact associated with the shale fraction, even though that may have been a minor component, it was no longer equally distributed among all the components, as it was in the original 4-mineral method. The equations developed, parameters used, and other details are given in Appendix IV. 
This approach improved the ternary diagrams for shale bearing formations over the other approaches, without any significant ill effects on clean formations. Figure 3.13 shows the ternary diagram generated by modified approach. Data points circled in Figure 3.11 are now reasonably within the triangle and give some meaningful information. The points are still colored with respect to previous shale fraction just to make them visible for comparison with the Figure 3.11, even though all these data points are plotted using the shale free values.

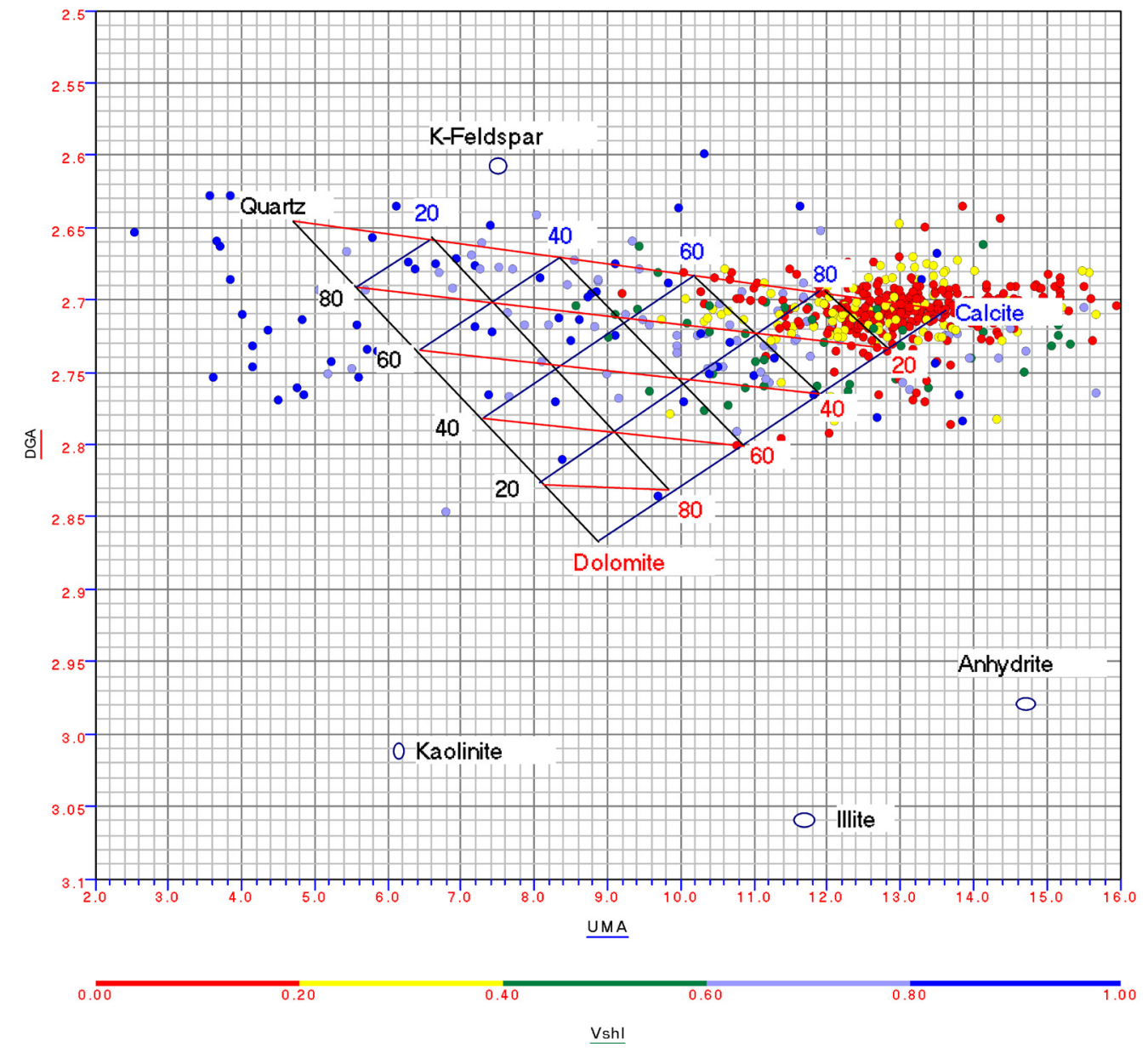

Figure 3.13. UMA-DGA crossplot after removing the shale fractions with characteristic ternary diagram of Well $\mathrm{C}$. 
Because we fixed the shale fraction on the basis of gamma ray response in the modified approach, there should be some changes in volume fractions of other minerals. To see the difference, we displayed the lithologs of Well A, B and C in Figure 3.14.

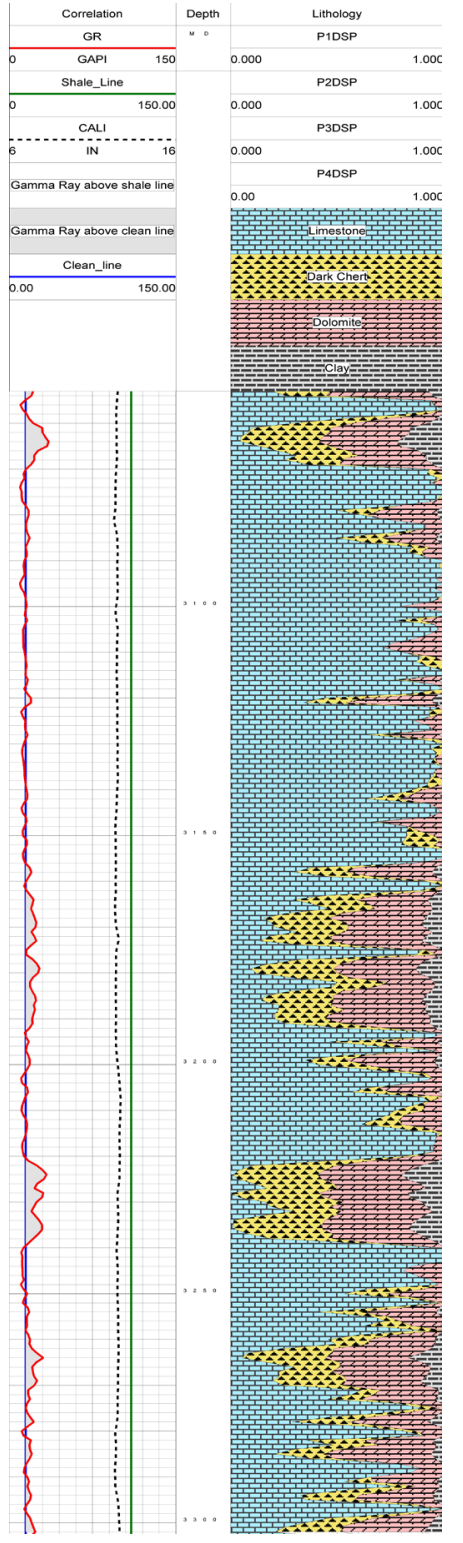

(a)

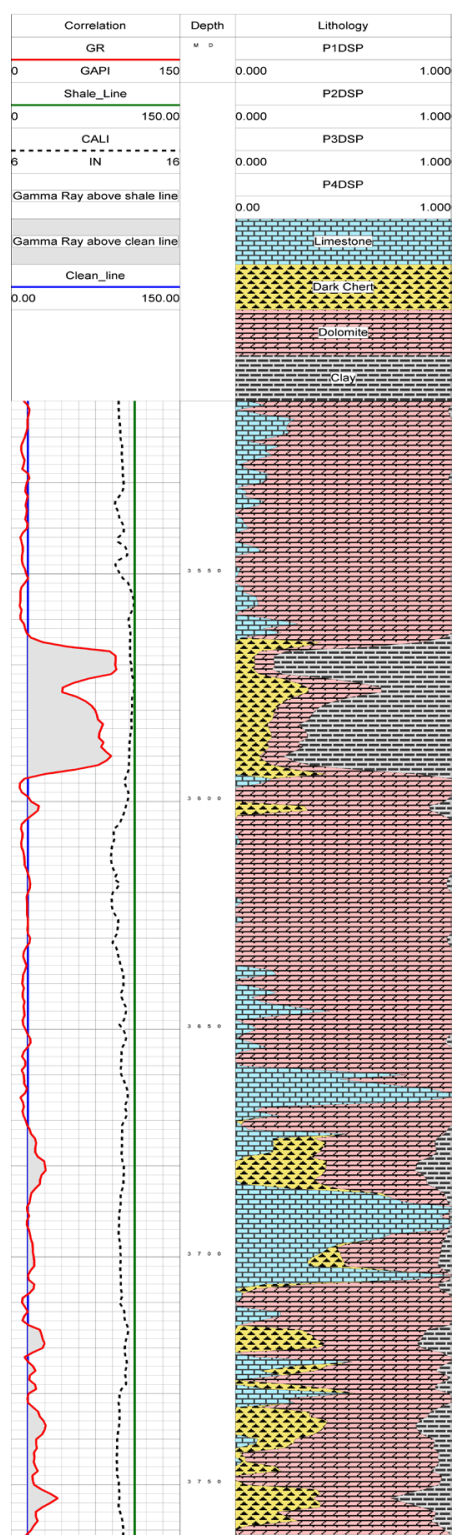

(b)

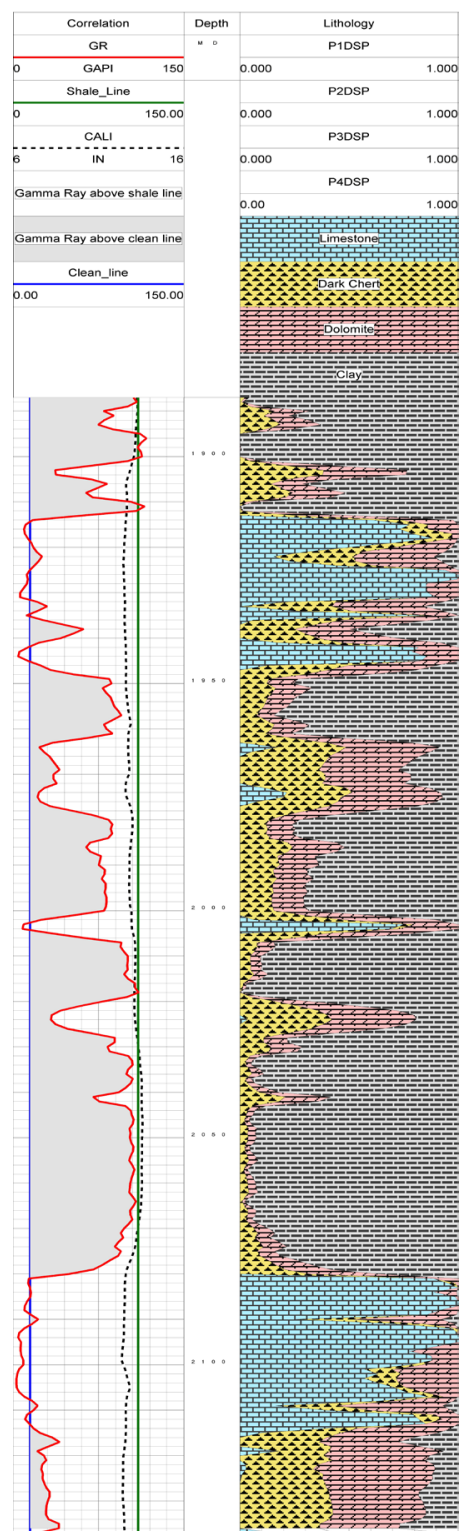

(c)

Figure 3.14. Lithologs from Modified 3- Mineral Identification clay exclusive performed on the data after correcting for the shale effects. (a) Well A (b) Well B (c) Well C. Red Line in first track show the gamma ray response, blue line is the clean line and green line is the shale line.

In general there was no significant difference between the 4-mineral identification and modified mineral identification for shale free formations. But some changes were 
observed in shaly units, as is expected because the two approaches deal with the shale content differently, particularly the porosity associated with the shale component. The minor differences in clean formations were associated with limits employed by the algorithms: (1) in modified approach we applied some limits to neutron porosity, density and PEF value while correcting for shale, and that introduced some factor of uncertainty; (2) in 4-mineral identification approach all limits were applied to the calculated mineral fractions by applying unity constraint to the sum of volume. The difference of limits and their applications changed the results.

We do not know which approach is best beause we do not have any core or quantitative lithological data to verify the results. As we had observed that 3-mineral approach is not appropriate in shaly formations, we did not use any of the results derived from it. The results generated by 4-mineral identification and modified mineral identification were used for predicting the sonic response in the next section.

We also prepared contour maps of the average of volume fractions calculated from both approaches. In detail, these contour maps showed significant differences between the results of the two approaches. Overall, however, the maps display increasing shale content from south-west to north-east and an increase in limestone content towards the center of the basin. Comparing these maps with the Figure 3.2, we conclude that increase in thickness of Traverse Limestone towards the northeast of the basin is because of the shale beds deposited just below the Antrim.

Both approaches show similar degree of dolomitization and its trend in the basin but with different values. One interesting aspect observed in the dolomite trend was that the maximum degree of dolomitization was in the northwest direction where the thickness of Bell Shale was also maximum as displayed in Figure 3.3.

Distribution of chert is somewhat random in the basin. Fraction of dolomite calculated by modified mineral identification is quite different from the one calculated by 4-mineral identification. 
Contour maps describing the volume fraction of each component are displayed in the Figures 3.15 to 3.18. We can see in Figure 3.15 that both approaches show same results for the distribution of clay fractions in the Michigan basin. The reason for the mismatch in the trend of other mineral fractions, as shown in figure 3.16 to 3.18 , is the approximations made in modified approach to fix the clean density and clean PEF values within certain ranges. 


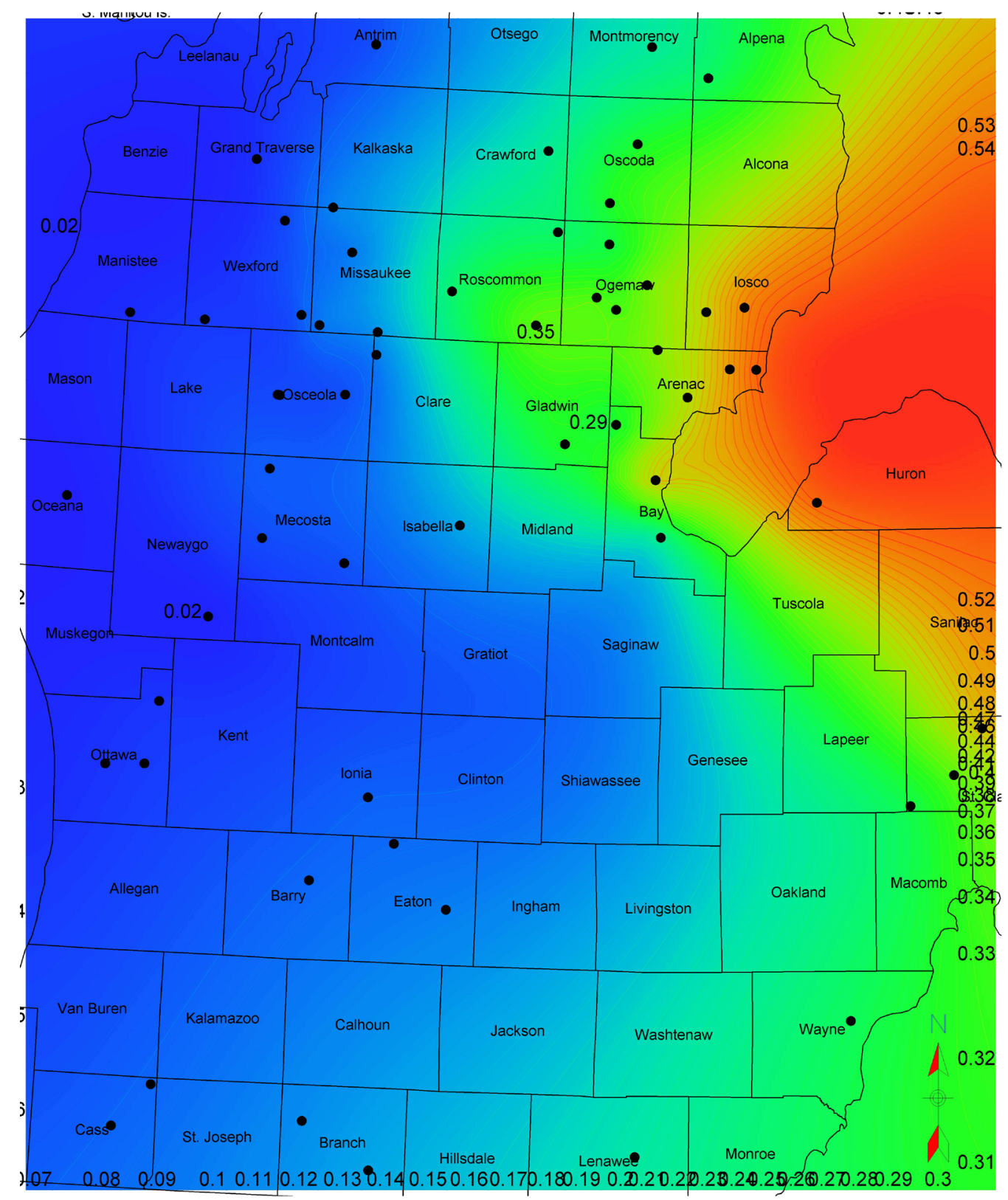

Well ID

Straight hole well

Straight hole well

PRIZM Curve Data P4aveTRVR

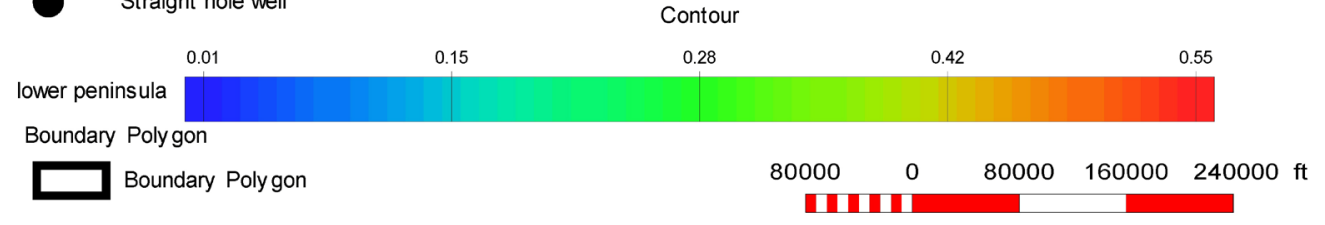

(a) Shale fraction from 4-mineral identification 


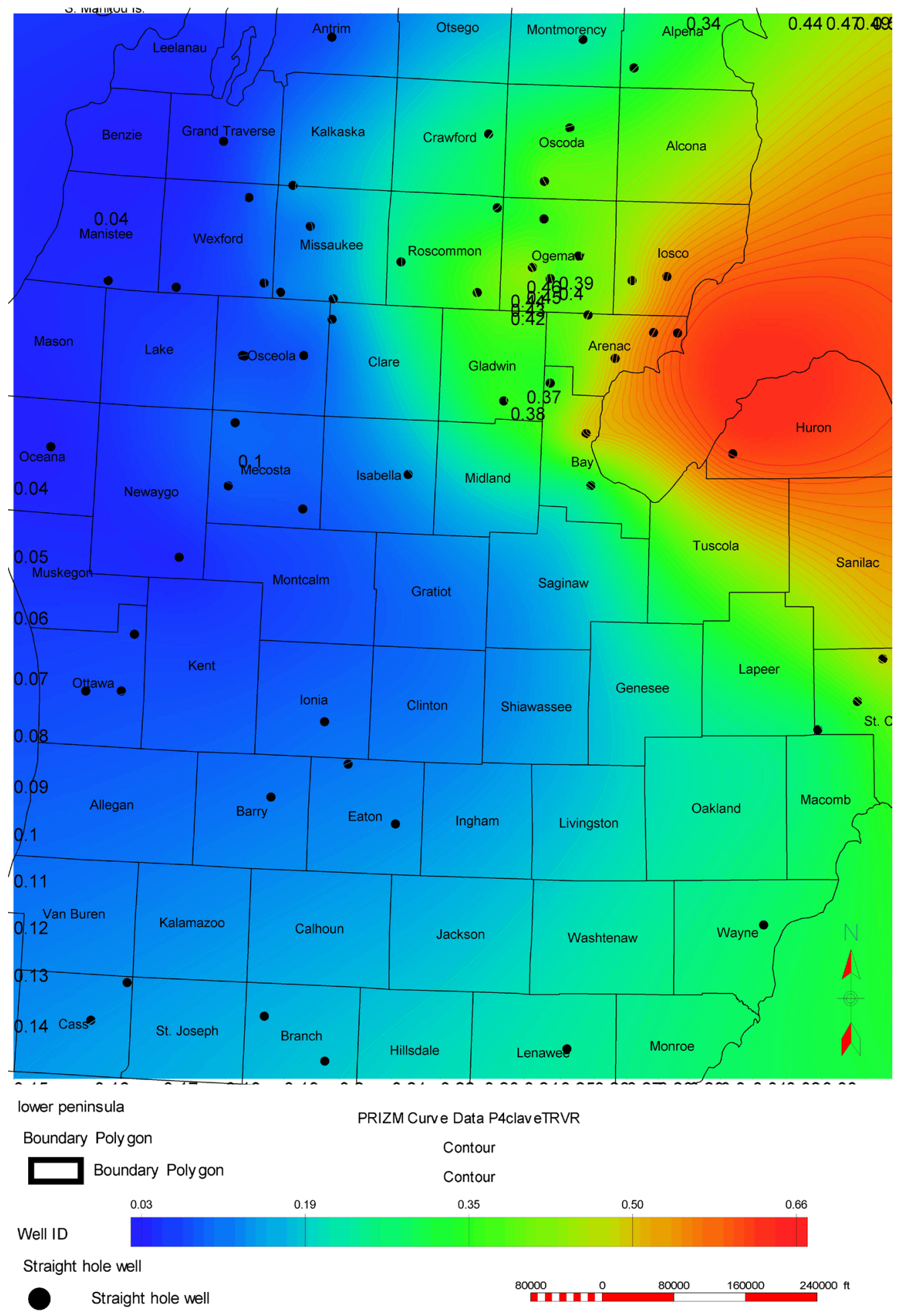

(b) Shale fraction from modified 3-mineral clay-exclusive approach

Figure 3.15. Basin wide distribution of Shale fraction in Trvaerse Limestone. (a) Calculated by 4-mineral identification. (b) Calculated by Modified 3-mineral clay exclusive approach 


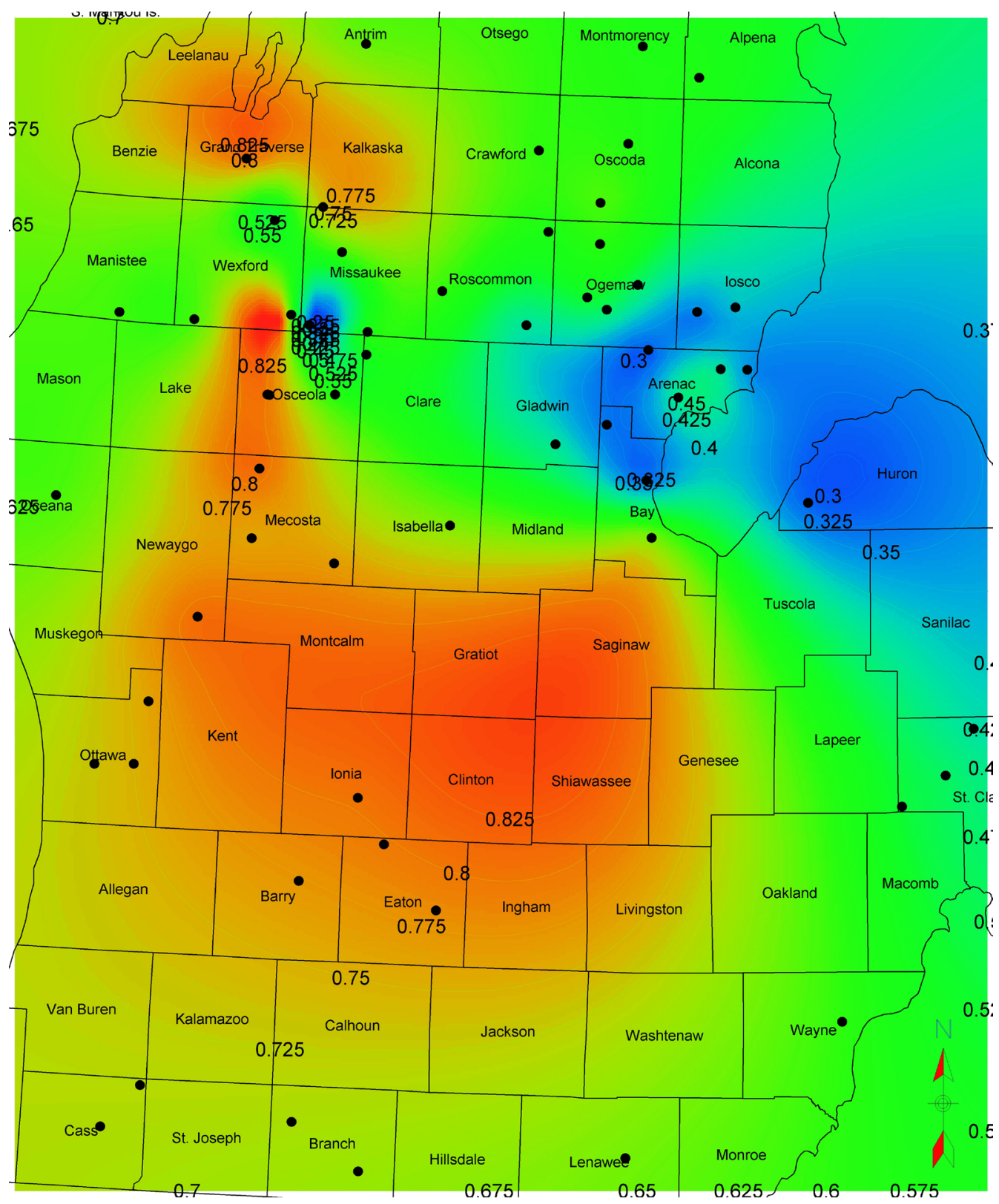

Well ID

Straight hole well

Straight hole well

PRIZM Curve Data P1aveTRVR

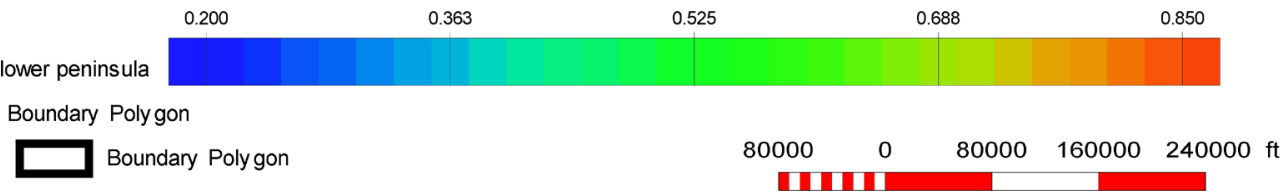

(a) Limestone fraction from 4-mineral identification approach. 


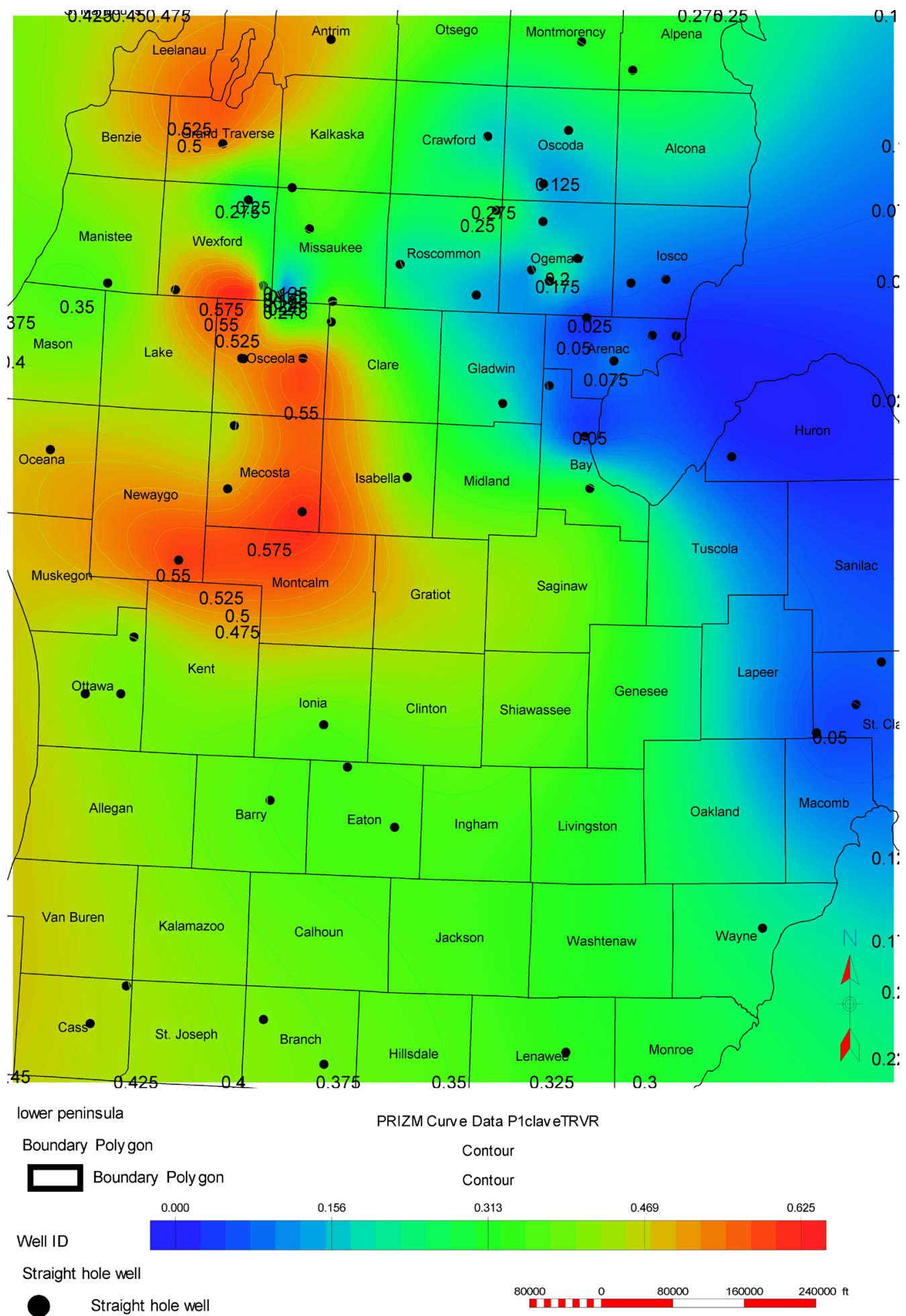

(b) Limestone fraction from modified 3-mineral clay-exclusive

Figure 3.16. Basin wide distribution of limestone fraction in Traverse Limestone (a) Calculated by 4-mineral identification. (b) Calculated by Modified 3-mineral clay exclusive approach 


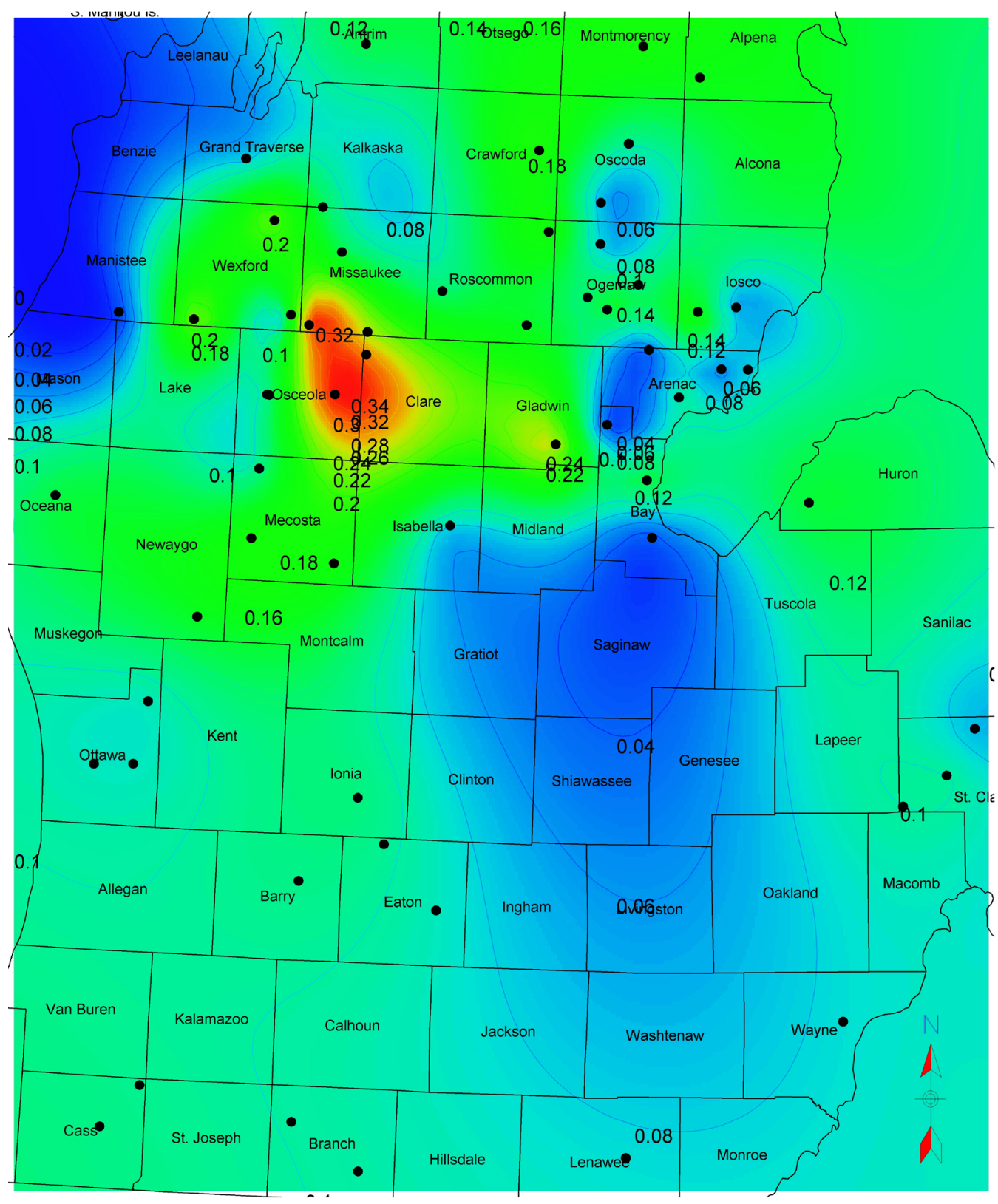

Well ID

PRIZM Curve Data P2ave eTRVR

Straight hole well

Straight hole well

Contour

Contour

0.00

0.09

0.18

0.27

0.36

lower peninsula

Boundary Polygon

Boundary Polygon

$80000 \quad 0 \quad 80000 \quad 160000 \quad 240000 \mathrm{ft}$

(a) Chert fraction from 4-mineral identification approach. 


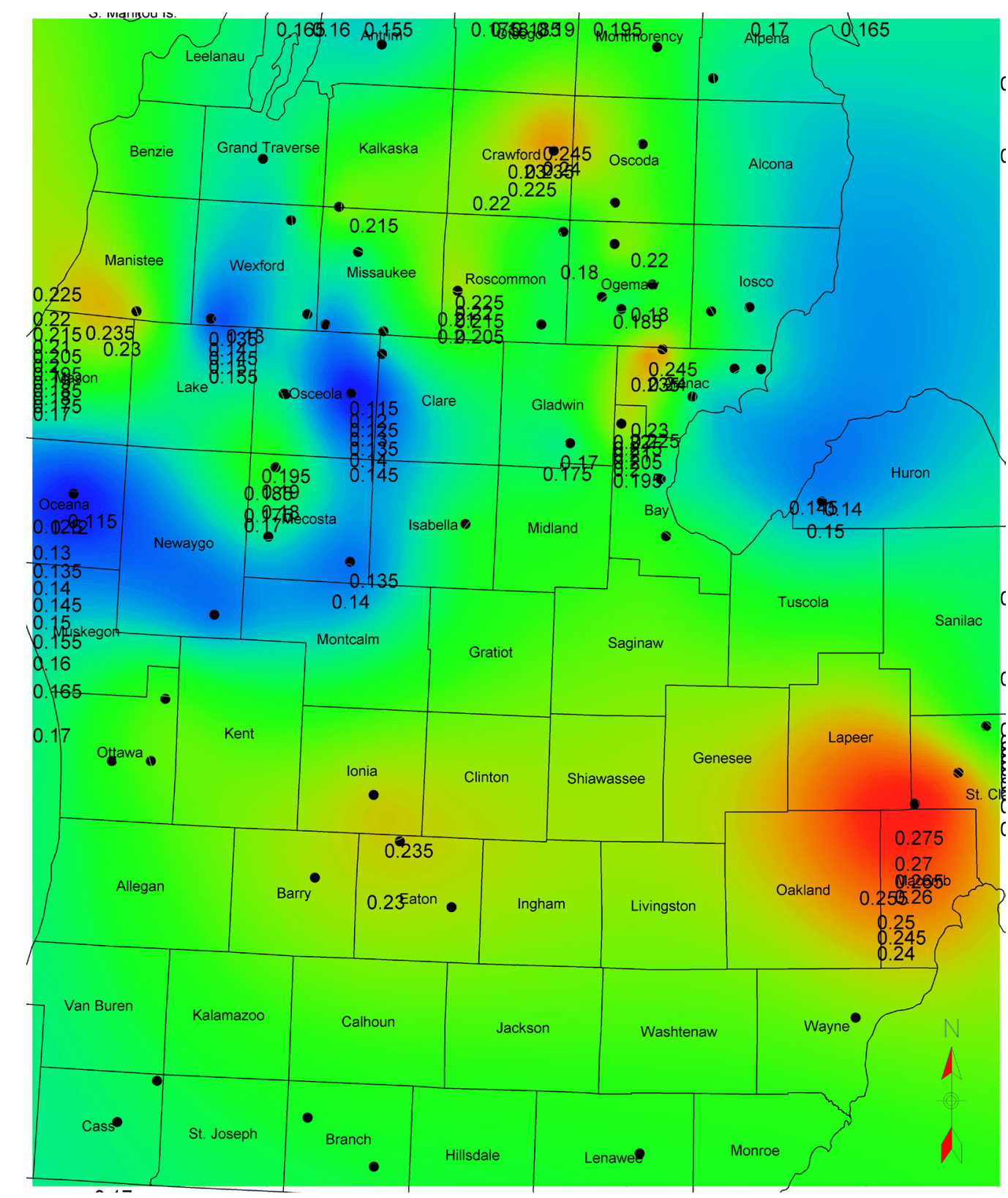

lower peninsula

Boundary Polygon

Boundary Polygon

0.105
PRIZM Curve Data P2claveTRVR

Contour

Contour

Well ID

Straight hole well

Straight hole well

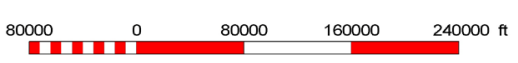

(b) Chert fraction from modified 3-mineral clay exclusive approach.

Figure 3.17. Basin wide distribution of chert fraction in Traverse Limestone (a) Calculated by 4-mineral identification (b) Calculated by Modified 3-Mineral clay Exclusive approach. 


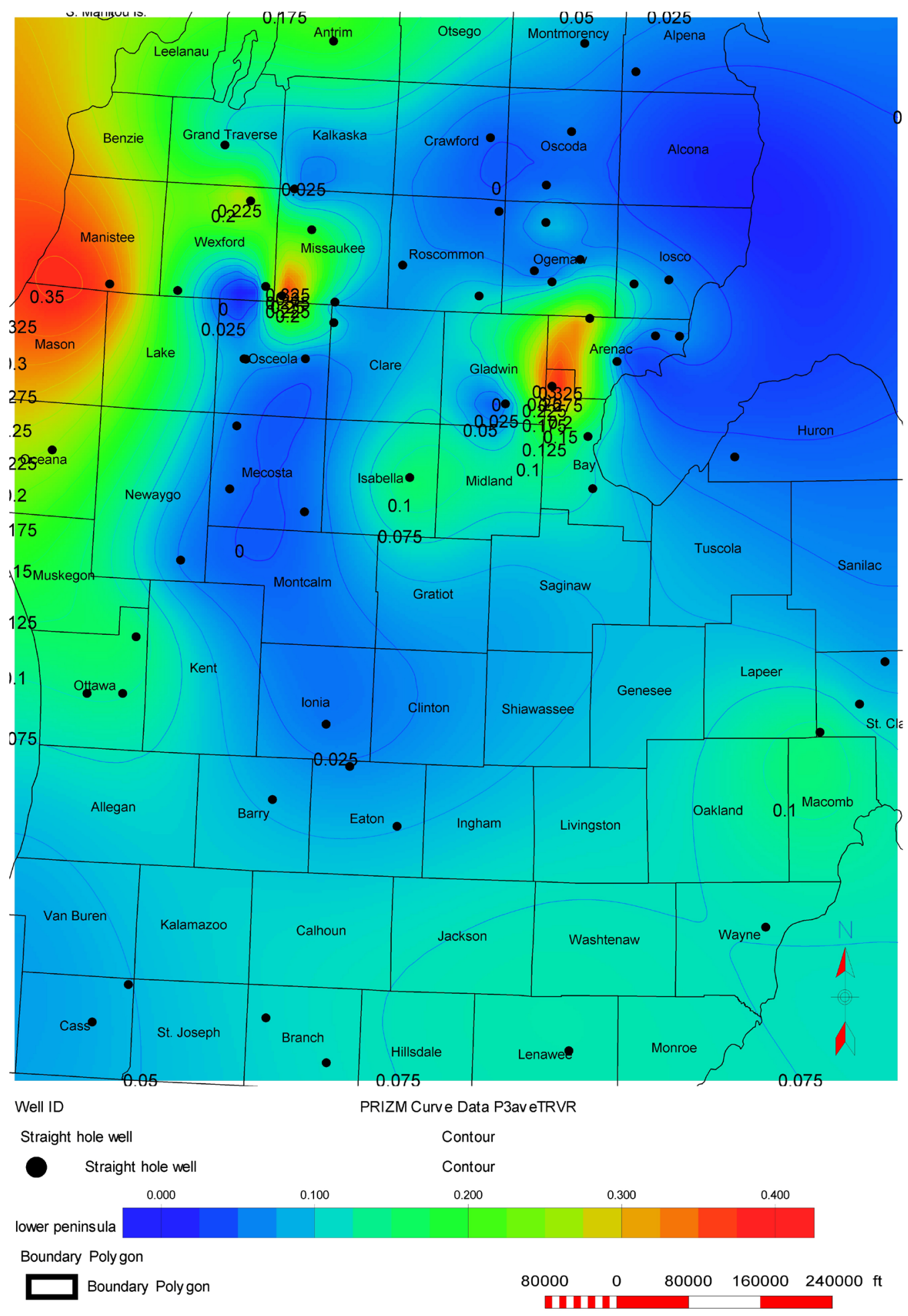

(a) Dolomite fraction from 4-mineral identification approach 


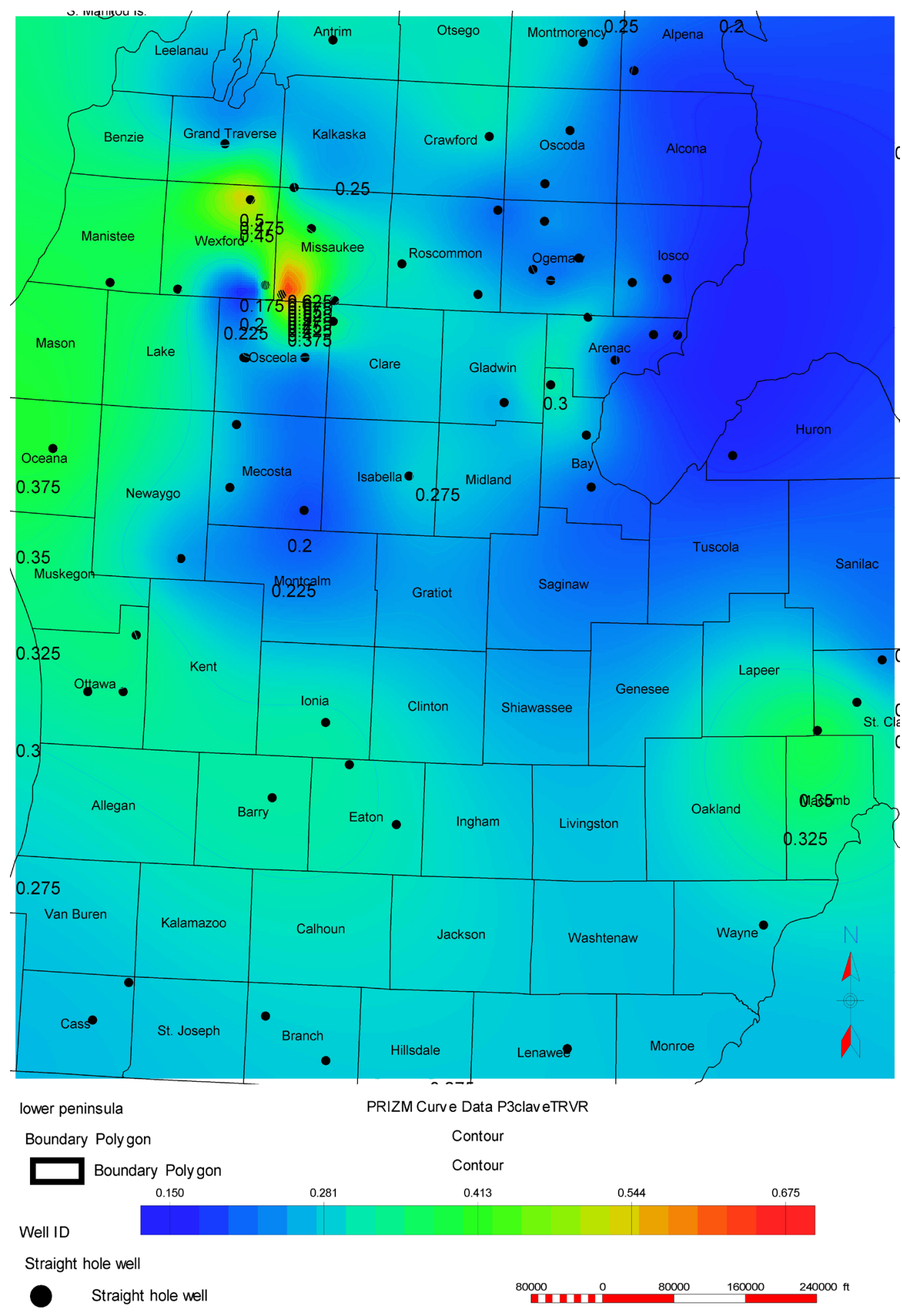

(b) Dolomite fraction from modified 3-mineral clay-exclusive approach.

Figure 3.18. Basin wide distribution of dolomite fraction in Traverse Limestone (a) Calculated by 4-mineral identification (b) Calculated by Modified 3-Mineral clay Exclusive Approach. 


\subsection{Sonic Response Prediction}

To predict the sonic response, we use the lithology, porosity and the fluid content, while assuming reasonable estimates for sonic properties of each component mineral. We used simple approaches such as using porosities from density and neutron porosity logs in Wylie's Time Average Equation to predict the sonic response for Traverse Limestone, assuming fresh water as the fluid content. The water in Traverse is considered quite salty we neglected it to keep the calculations simple and easy. This assumption did not introduce any significant error as the travel time of brine is $179 \mu \mathrm{sec} / \mathrm{ft}$ and for fresh water it is $189 \mu \mathrm{sec} / \mathrm{ft}$. The maximum error possibly caused by this $10 \mu \mathrm{sec} / \mathrm{ft}$ difference in $15 \%$ porosity rock is about $0.75 \%$. We then used different mineral content and porosities, based on our final lithology determinations, and used various approaches in our search for the best synthetic sonic response. The results were compared with the measured sonic logs on a root-mean-square (RMS) basis. In general, the discrepancy between predicted and actual sonic was related to the shale and dolomite content, which we then attempted to account for. The data having extremely bad caliper response were deleted to avoid the effect of bad data points.

\subsubsection{From Density Porosity}

In the very first case we assumed that we have only density log for the prediction of sonic response. We used Wylie's Time average equation to calculate the transit time from density porosity considering limestone matrix and fresh water (for the equation see Appendix (V), Equation 1).

The response was reasonably good in limestone units but in shale-prone zones the error was large. Shale has much more porosity and associated bound water. The porosity determined from density logs did not treat that porosity uniquely from limestone porosity. This fact resulted in a lower transit time (higher velocity) prediction in shale units.

To remove the effect of shale, we separated the shale fraction from the clean rock by using gamma ray $\log$ to determine the shale volume (Vshl), and then applied modified time average equation to calculate the sonic transit time. Modified time average equation, taken from Adcock 1993 [Adcock, 1993], considers the shale as a separate unit. The 
equation is given in Appendix (V), Equation 2. We need shale transit time to use in this equation, and it is important to use the transit time of wet shale, not dry, in modified time average equation as density porosity does not account for shale porosity. References generally cite a transit time for shale that varies between $50-150 \mu \mathrm{s} / \mathrm{ft}$ depending upon the amount of bound water for seismic acoustic waves $(\mathrm{Vp})$. We used the data from all wells and calculated the respective average for different shale transit times. We then plotted the average of the error versus the shale transit time (DTshl), and DTshl was selected for minimum value of the average of the error. The plot generated is shown in Figure 3.19. Depending on the plot, we selected a transit time of $83 \mu \mathrm{s} / \mathrm{ft}$ for wet shale to calculate the pseudo-sonic log from density porosity.

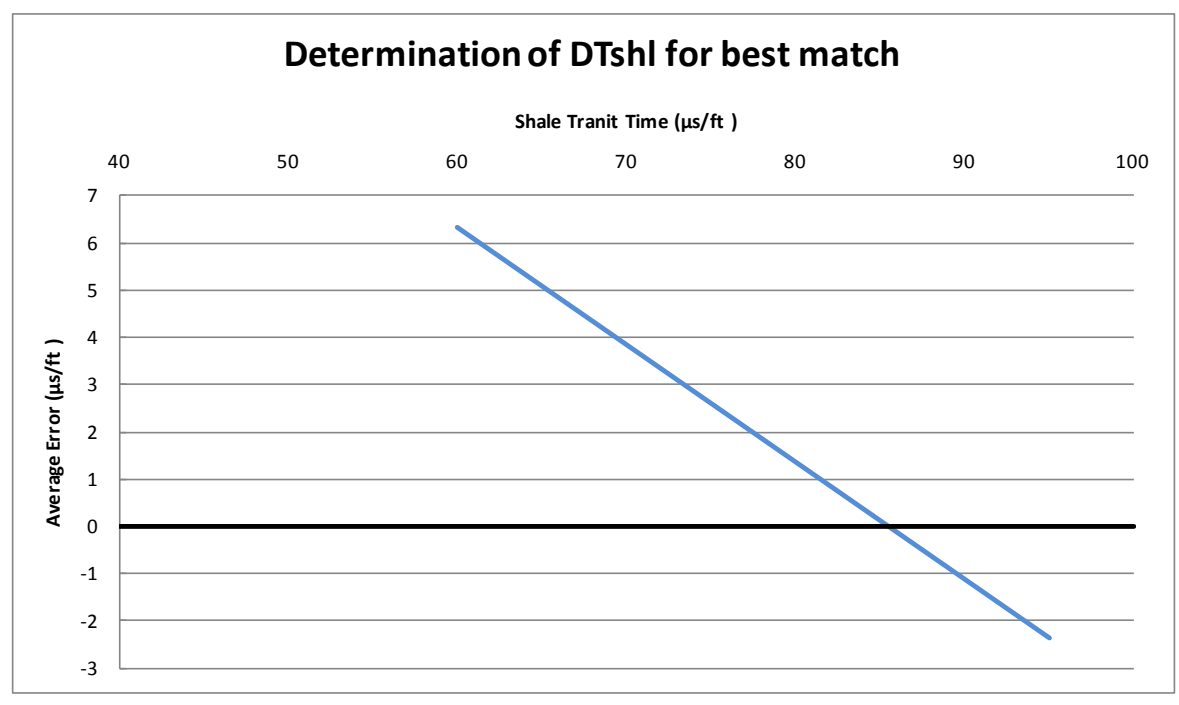

Figure 3.19. Plot of average error (between predicted and actual sonic $\operatorname{logs}$ ) versus respective assumed DTshl (Shale Transit Time) to determine the value of DTshl for minimum error. Zero line is marked with the black line.

Figure 3.20 presents the logs predicted from Well A, Well B and Well C. There were small errors in estimating sonic properties where dolomite was present. We conclude that these errors are introduced by secondary porosity, which is measured by the density log, but which usually does not affect the sonic log. We can also see small errors introduced by the presence of chert (quartz), which has a density different from that of limestone (calcite). 


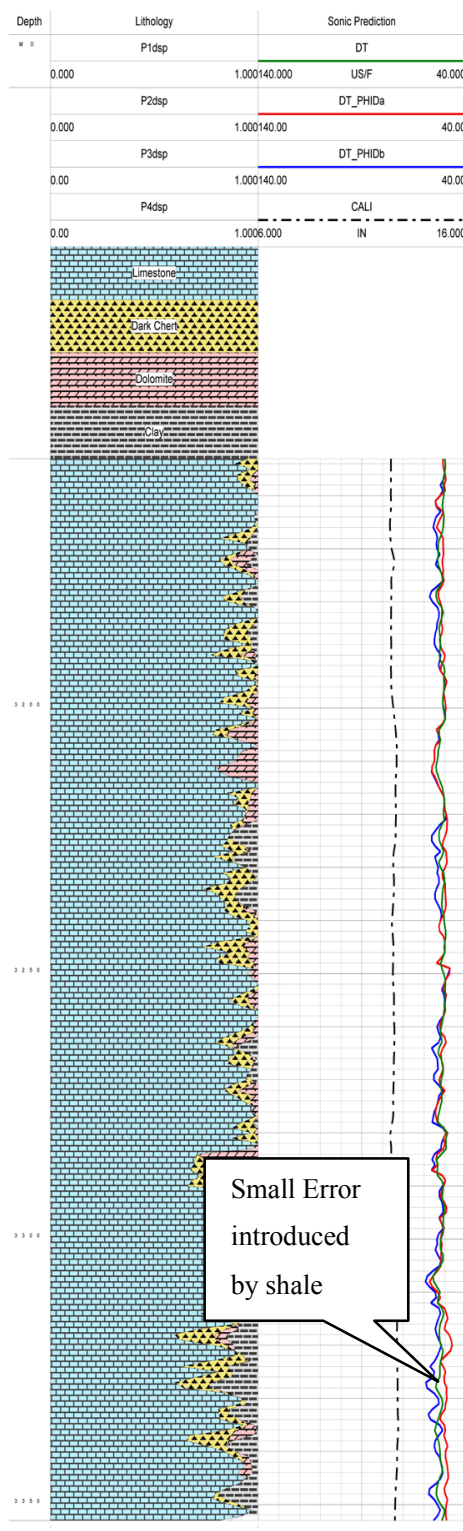

(a) Well A

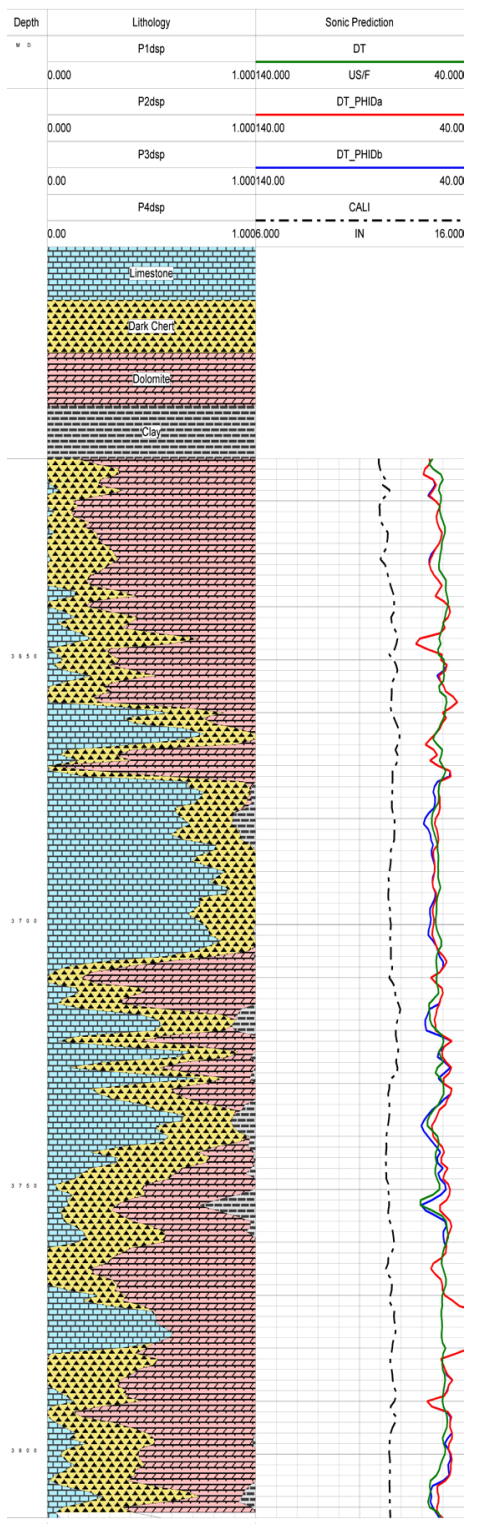

(b) Well B

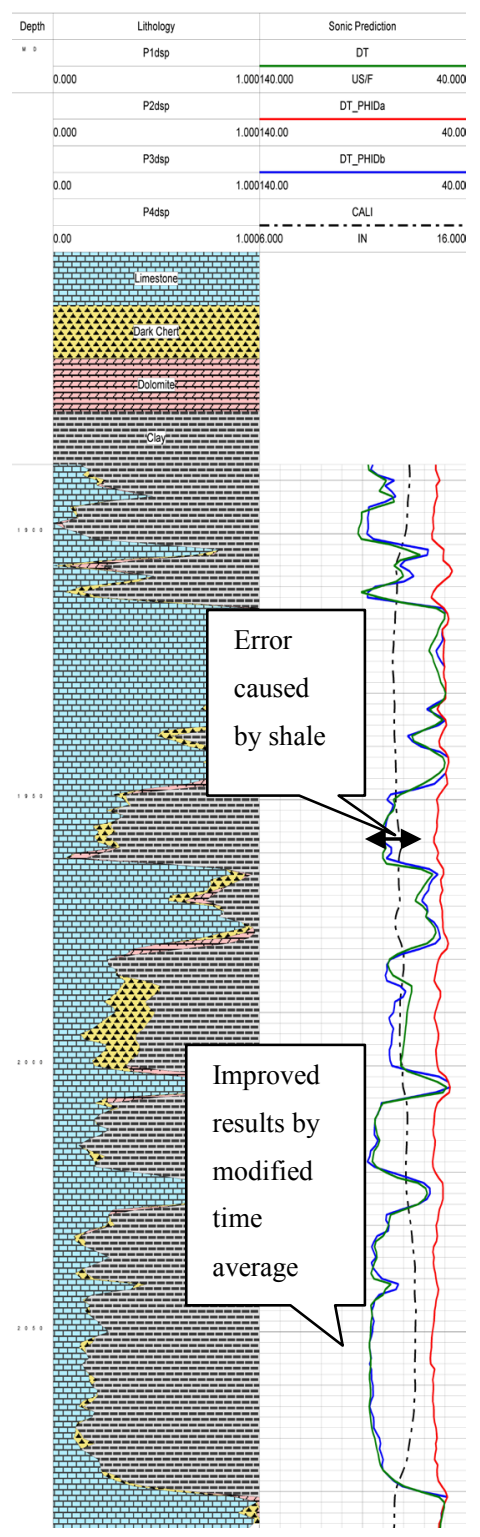

(c) Well C

Figure 3.20. Logs displaying sonic prediction from density log. Green (DT): Measured Log; Red (PHIDa): Predicted by using Wylie's Time Average Equation; and Blue (PHIDb): Predicted by using Modified Time Average Equation including the effect of shale. Note the very nice fit in clean formations of Well A. Also see the error in prediction in Well B because of dolomite fraction. Well C presents the huge error in red caused by shale while modified equation in blue gave reasonable results. (a) Well A, (b) Well B (c) Well C

Figure 3.21 presents crossplots between errors in sonic prediction versus clay fractions in Well B and Well C. 

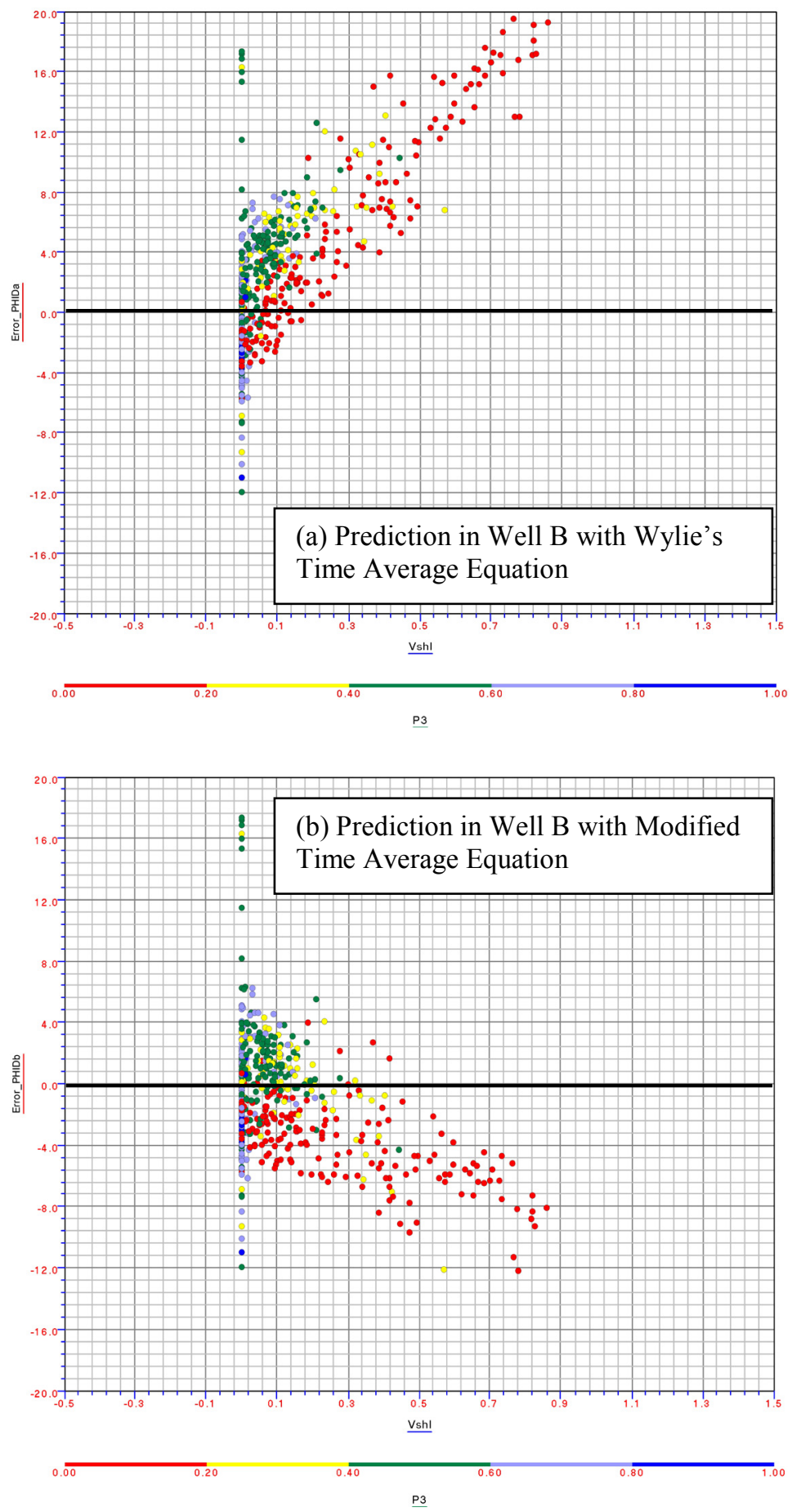

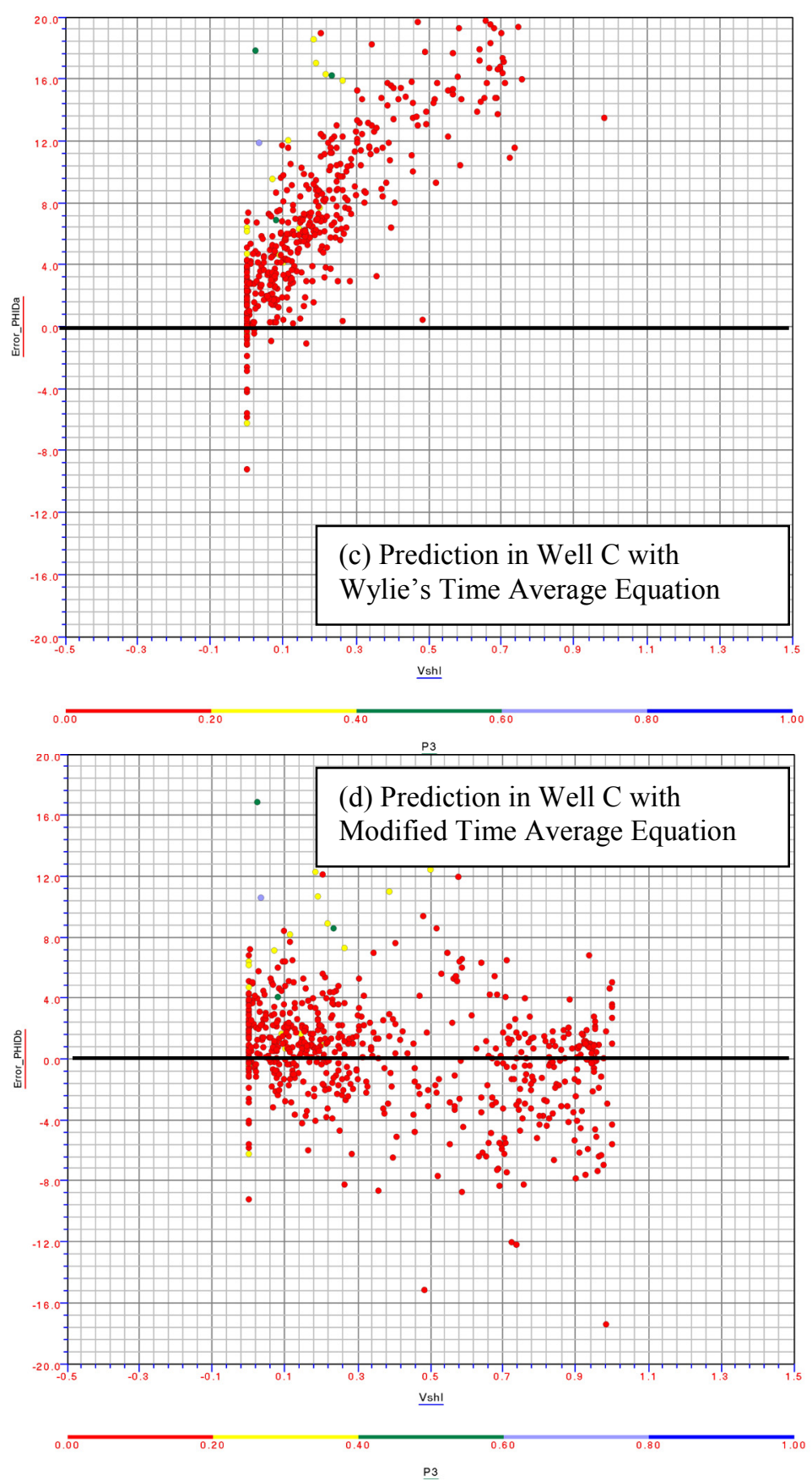

Figure 3.21. Crossplots describing error in sonic prediction with the increase in clay volume and dolomite fraction. Shale volume is shown along the $\mathrm{x}$-axis, and error is shown in the y-axis ( 0.0 is in the center and is marked with black line). Color of dots indicates dolomite content. (a) and (b) present the data from Well B. (c) and (d) present the data from Well C 
Figure 3.21(a) and 3.21(b) demonstrate the error caused by dolomite content. Figure 3.21(b) also indicates the results of shale over-correction in Well B caused by the higher shale transit time used in that well. On the other hand, figure 3.21(d) shows the reasonable correction corresponds to the use of the same transit time. This reveals the problems associated with non-uniform data acquisition practices in the field. This factor limits the accuracy of the prediction. Some other wells from one single county also showed the similar behavior.

Figure 3.22 shows a bar graph describing the frequency of root mean square error in different wells before and after using the shale correction, and demonstrates that the consideration of shale as a separate matrix has improved the results significantly.

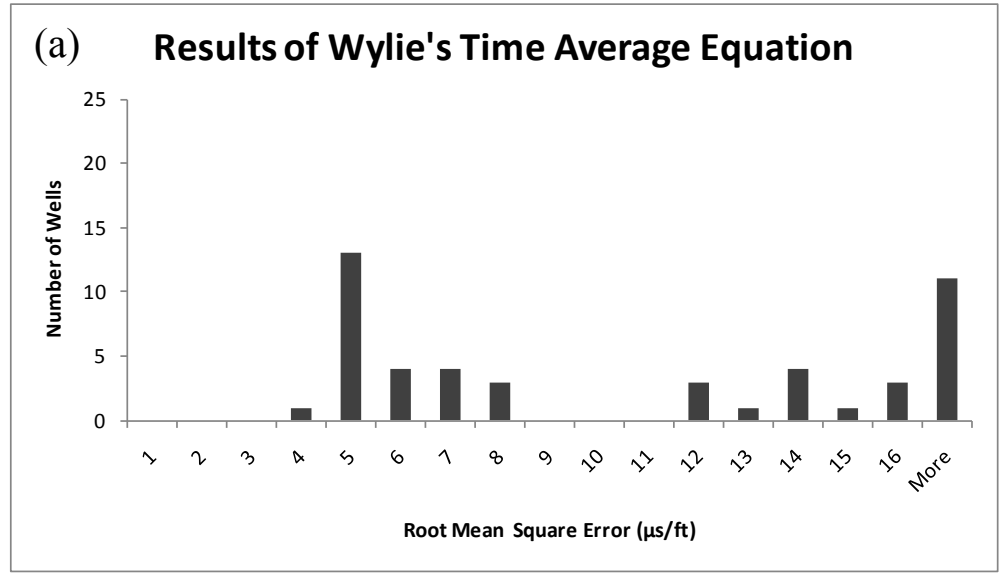

(b) Results of Modified Time Average Equation

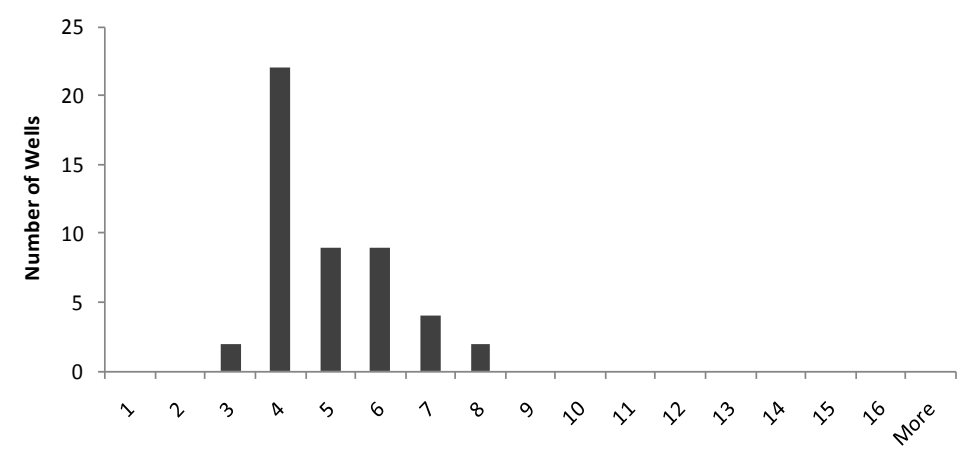

Root Mean Square Error ( $\mu \mathrm{s} / \mathrm{ft})$

Figure 3.22. Frequency of RMS error observed in sonic prediction (in 46 wells) from density porosity using (a) Wylie's Time Average Equation (Without Shale correction), (b) Modified Time Average Equation (Dealing shale as a separate matrix). 
Figures 3.20-3.22 reveal that the addition of the as a separate matrix in Wylie's time average equation significantly improves the results. It is important to use the transit time of wet shale (DTshl), not dry, in modified time average equation. The transit time for wet shale can be determined by using the sonic logs from the surrounding wells. We also observed that because of lack of logging standards, single value of DTshl was not possible for all the wells that in turn decreased the accuracy of the pseudo-sonic logs. The accuracy of the prediction could be enhanced by standardizing the logging techniques.

\subsubsection{From Neutron Porosity}

After density porosity, we used the neutron porosity in Wylie's Time average equation. The results obtained are shown in Figure 3.23 in the form of litho log.

We can see in Figure 3.23 that neutron porosity can be used in Wylie's Time average equation to predict the acoustic velocities in pure limestone with a reasonable accuracy. Neutron porosity is not affected by shale volume as neutron tools nicely detect the clay bound water and give the total porosity of the rock, including the shale fraction.

In Well B, dolomite fraction has affected the results badly. It is not because of neutron tool but because of sonic log. Sonic tools do not detect the vugs and channels which may be large compared with the wavelengths of the sonic signal used; on the other hand, surface seismic observations are often assumed to include these effects. For the purposes of synthetic sonic log generation, we want to remove the effects of such secondary porosity. However, the knowledge of such secondary porosity is useful for petrophysical interpretation, and in logging practices it is calculated by subtracting the sonic porosity from the average of neutron and density porosity. 


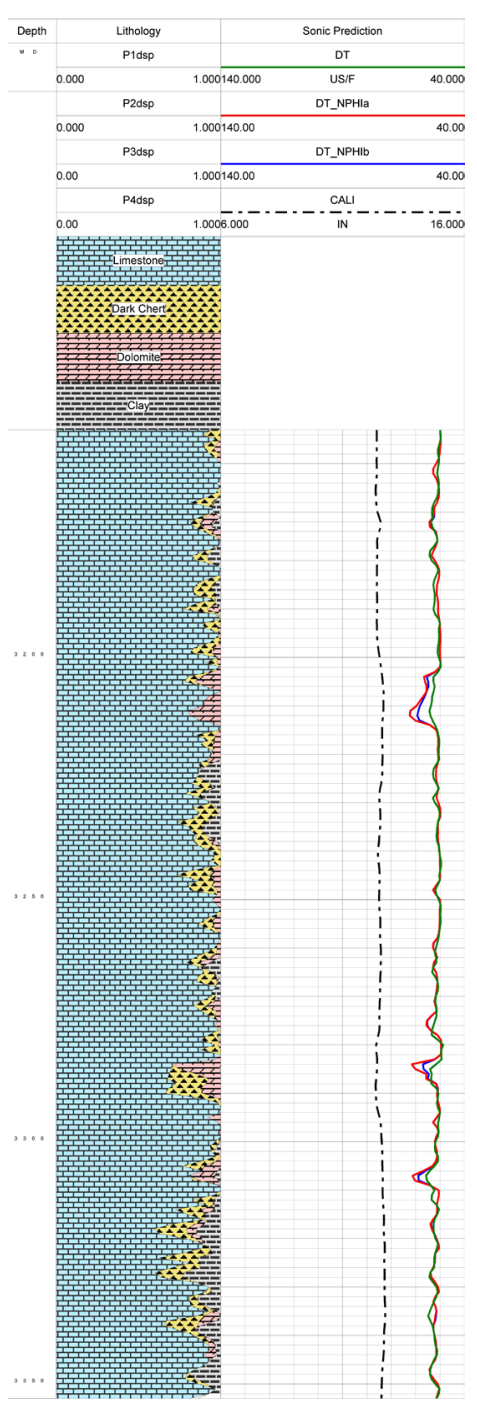

(a) Well A

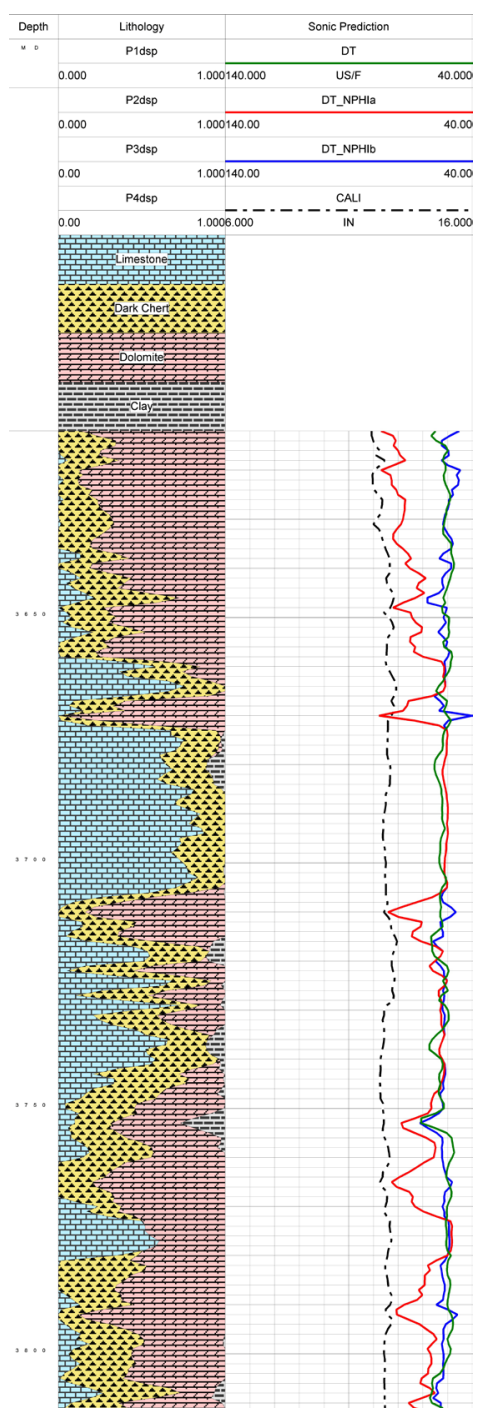

(b) Well B

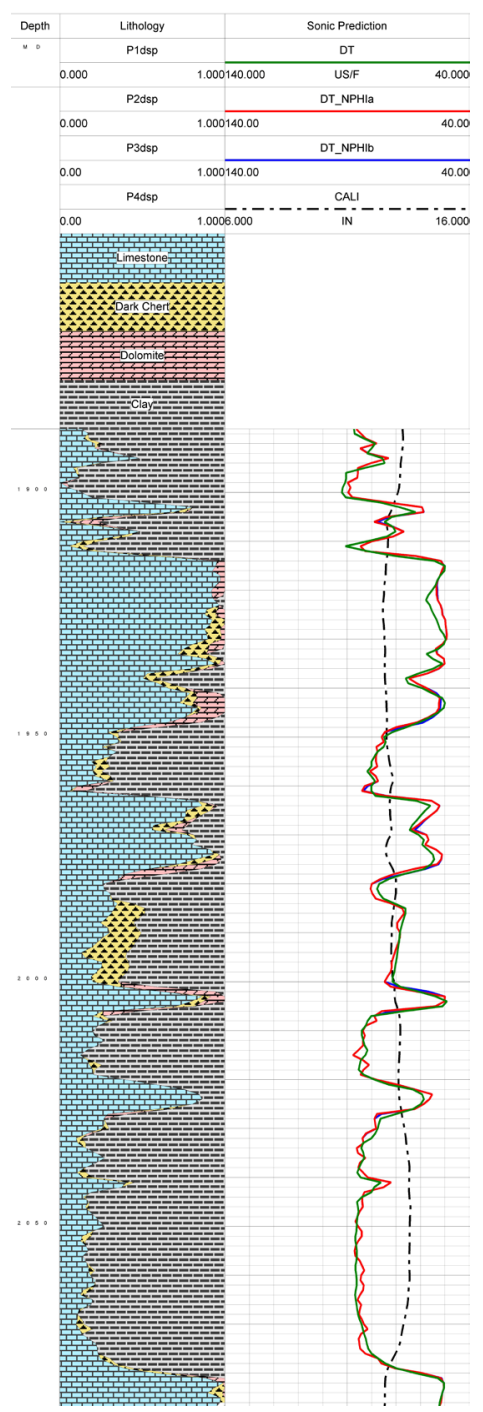

(c) Well C

Figure 3.23. Sonic response prediction from Neutron logs. Green (DT): Measured sonic log; Red (DT_NPHIa): PredictiOn from Wylie's Time Average Equations; Blue (DT_NPHIb): Modified equation (I). (a) Well A, (b) Well B (c) Well C

To account for the effect of secondary porosity associated with dolomite, we modified the time average equation to remove the effect of dolomite porosity, which is assumed to be the dolomite volume fraction of the clean porosity (calculated as part of the lithology determination). The equation developed is given in Appendix (V) and is named Modified Equation (I). This modification improved the results. In field applications, one can get an estimate of dolomite fraction by a calcium test, often reported in mud-logs, and calibrate 
this correction for different conditions. Figure 3.24 shows the bar graph describing the error (a) before and (b) after dolomite correction. It shows that our modification has decreased the error in prediction from about $5.00 \mu \mathrm{s} / \mathrm{ft}$ to $4.00 \mu \mathrm{s} / \mathrm{ft}$.
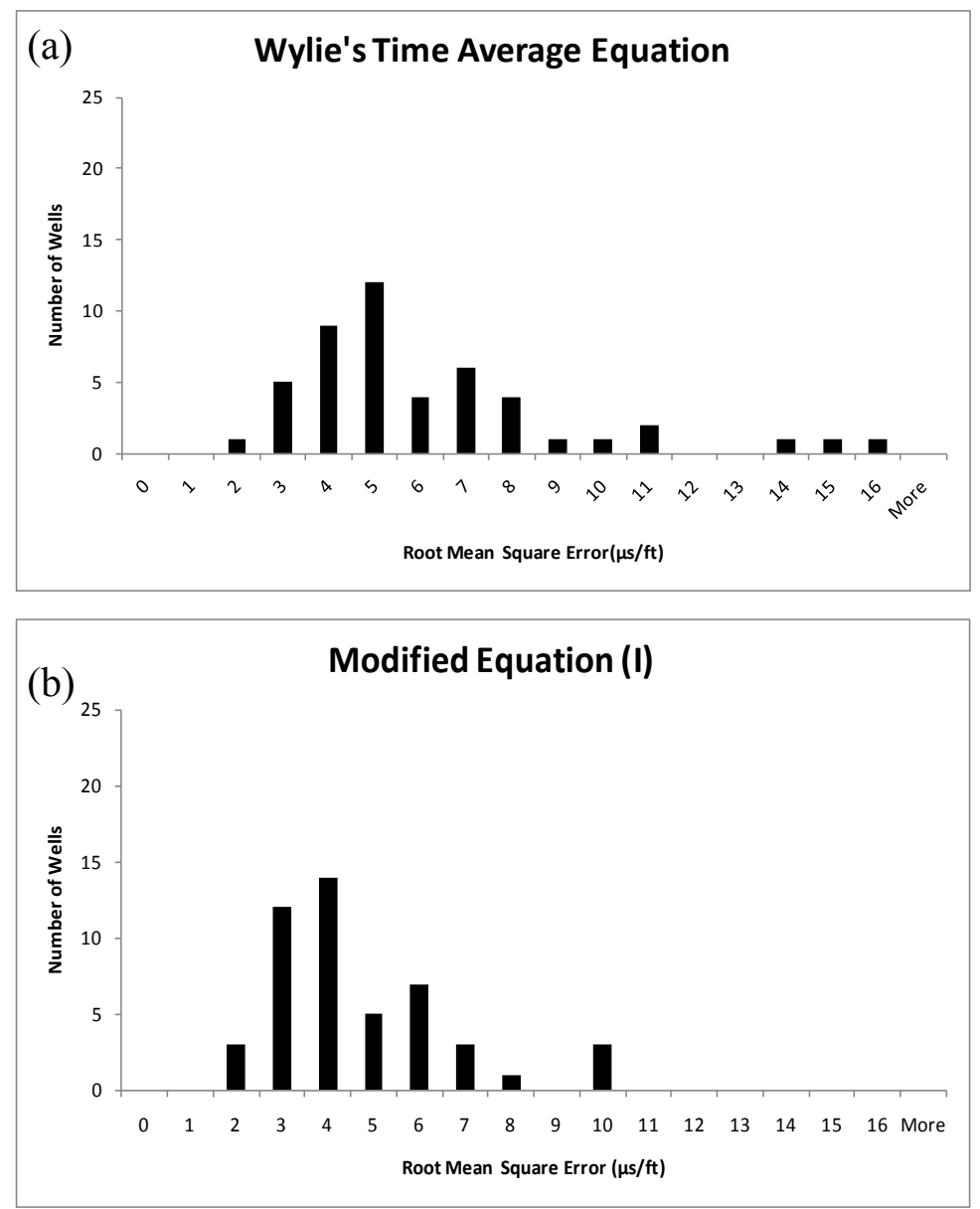

Figure 3.24. Bar graph describing the frequency of RMS error (of 46 randomly separated wells) between the pseudo-sonic log and the measured sonic log (a) Wylie's Time Average Equation before accounting for dolomite effect (b) Modified Equation correcting for dolomite.

Figure 3.25 shows the crossplots relating the error in sonic log prediction with the volume of clay and dolomite fractions. It also confirms that addition of dolomite corrections to Wylie's Time Average equations reduced the RMS error caused by dolomite fractions, and the data points with higher dolomite content were moved towards zero error line at the center. 

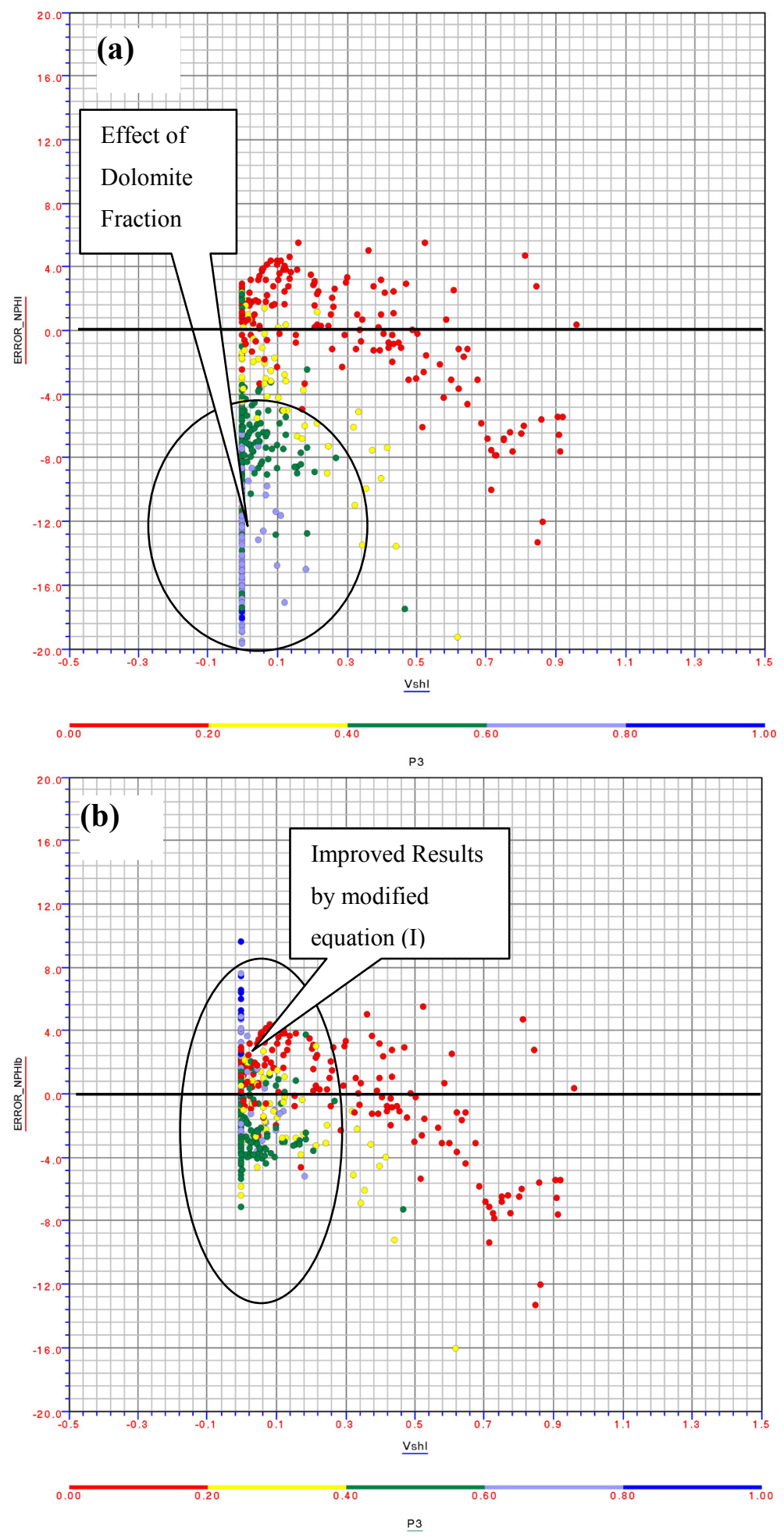

Figure 3.25. Crossplot showing the error in predicted sonic log for Well B from Wylie.s Time Average Equation (a) before correcting for secondary porosity (b) after correcting for secondary porosity. Color indicates the dolomite fraction and clay content is along $\mathrm{x}-$ axis while and error is along $y$-axis with zero line at center (marked with black line). 


\subsubsection{Sonic response from average porosity}

In the previous sections, we treated neutron and density porosities separately and found that neutron porosity could be corrected for dolomite-related secondary porosity, and that density porosity could be corrected for shale porosity. These corrections improved the sonic log prediction for those wells that contained either significant dolomite or shale zones. In this section, we investigate the use of average/apparent porosity to see if it can help us to improve our prediction results.

Initially, we used simple "Wylie's time average equation", where the porosity employed is the average of the density and neutron porosities, given in Appendix (V) equation 5. The predicted curve is displayed in Figure 3.27 in red color and is named as DT_PHIA.

The second prediction was made by using modified time average equation for two lithologies, shale and limestone. The equation is given in Appendix (V), equation 6 and named "Modified Time Average Equation". The curve is displayed in Figure 3.27 in purple color and is named DT_PHIAa. This equation is adopted from Adcock [Adcock, 1993].

Like neutron porosity and density porosity prediction curves, the curves from average porosity also exhibit the effect of dolomite. It caused the transit time higher than actual sonic measures. We edited the modified time average equation to remove the effects of dolomite and named it "Modified Equation (II)" (see - equation 7 in Appendix (V)). Dolomite has secondary porosity caused by vugs and channels and sonic tools do not detect them. Effective porosity in dolomite can be considered as the measure of secondary porosity. We edited the modified time average equation to subtract the fraction of effective porosity associated with dolomite from the total porosity. In our work, we successfully tested this equation. On the basis of the results, we applied certain limits to this modification. According to that limit $100 \%$ of secondary porosity in dolomite was removed if the fraction of dolomite was less than $75 \%$ otherwise $3 / 4$ of the effective porosity was removed. The predicted response from this equation is plotted in Figure 3.27 with blue color and is named as DT_PHIAb. 
To determine the most appropriate shale transit time for this equation, we made the plots of the average of the errors of each well versus shale transit time. The plot is attached in figure 3.26. The figure shows different best fitting DTshl values for modified time average equation (without dolomite correction (red line), $62.5 \mu \mathrm{sec} / \mathrm{ft}$ ) and modified time average equation (with dolomite correction (purple line), $67.5 \mu \mathrm{sec} / \mathrm{ft}$ ). We selected $65.00 \mu \mathrm{sec} / \mathrm{ft}$ for shale transit time. However, the shale transit time for some wells was selected a little higher or lower for best match but $70 \%$ of wells were treated with $65 \mu \mathrm{sec} / \mathrm{ft}$. The value of matrix transit time used was in the range of $50 \mu \mathrm{sec} / \mathrm{ft}$. The values were selected for the best fit and same values were then used for this whole part. The shale transit time used in prediction from density log was higher than the one used in prediction from average porosity. It is because the density logs totally ignore the claybound water but the addition of neutron porosity in average porosity partially accounts for the clay bound water. As average porosity is the average of density porosity and neutron porosity so it is not the shale transit time used with average porosity is neither for fully wet shale nor for fully dry shale but is for partially wet shale.

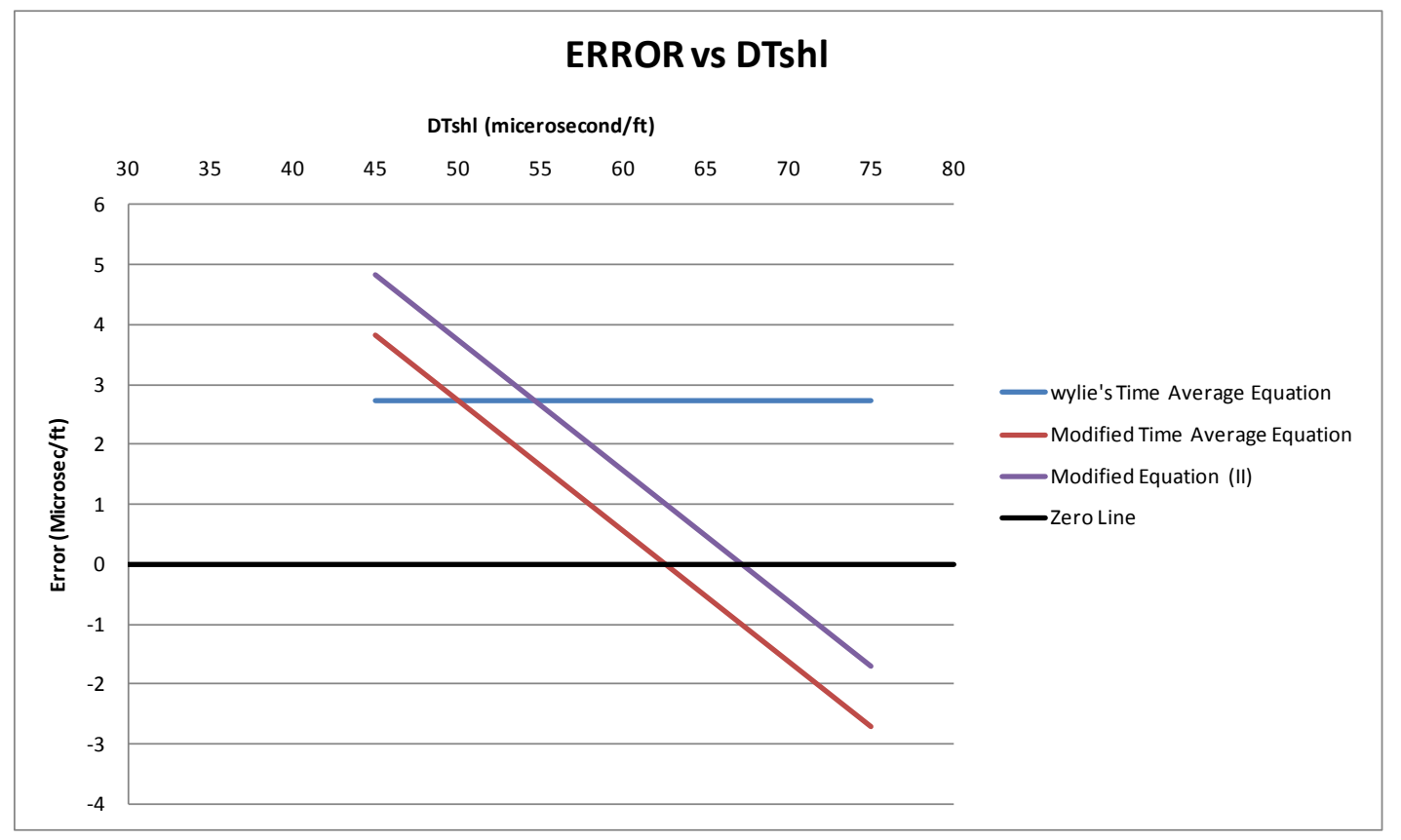

Figure 3.26. Plot between DTshl and the corresponding average error, used to estimate the most appropriate DTshl for the use in sonic log prediction from average porosity. Zero line is marked with the black line. 


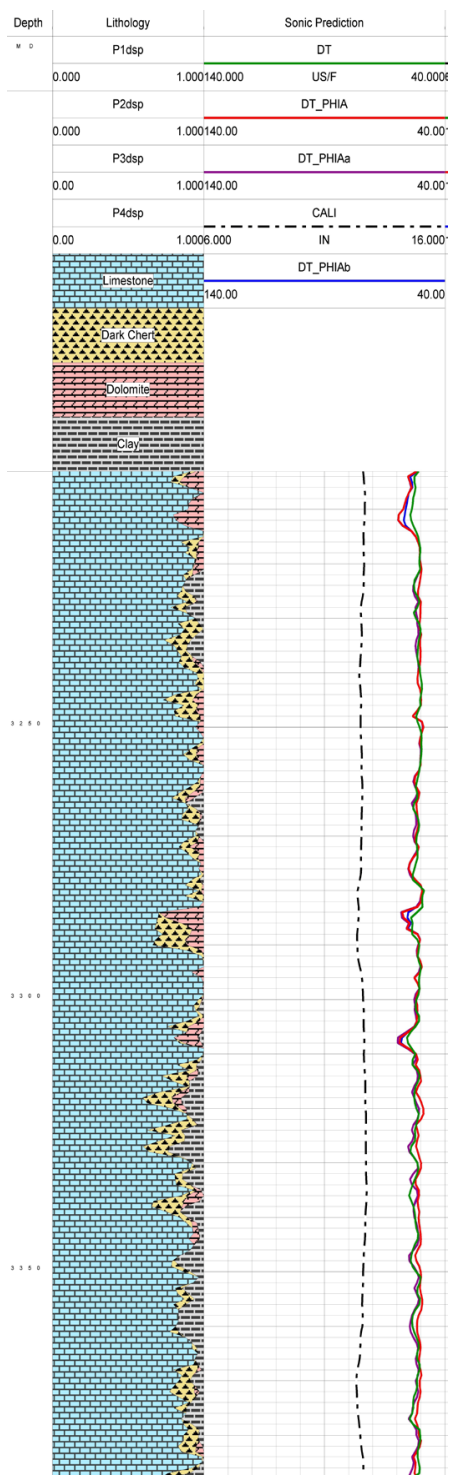

(a) Well A

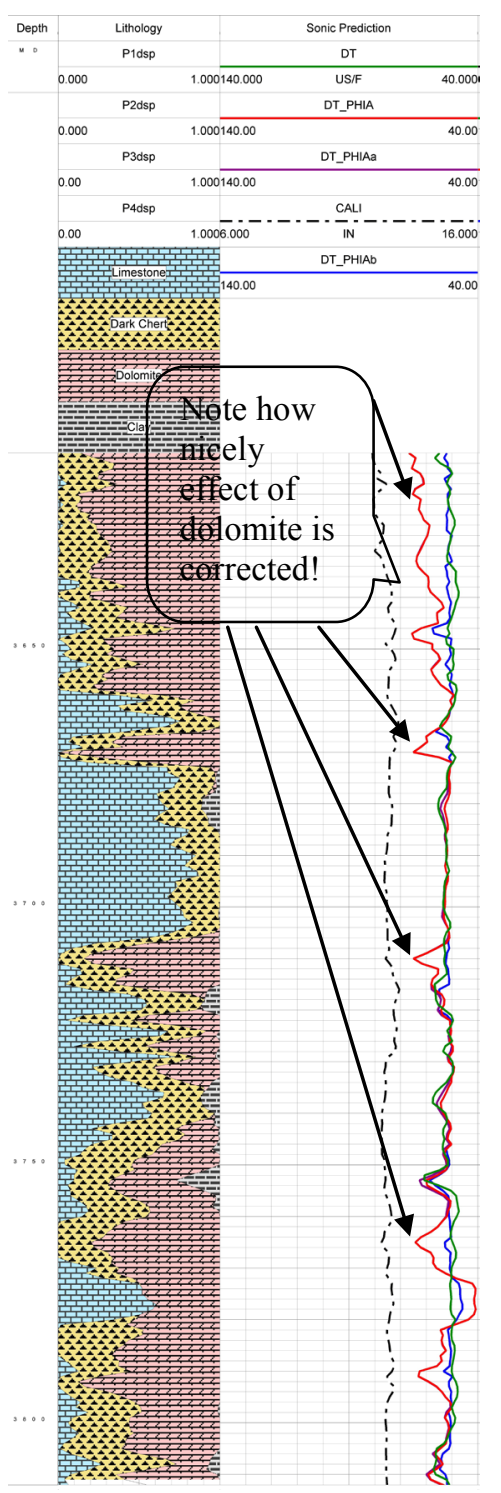

(b) Well B

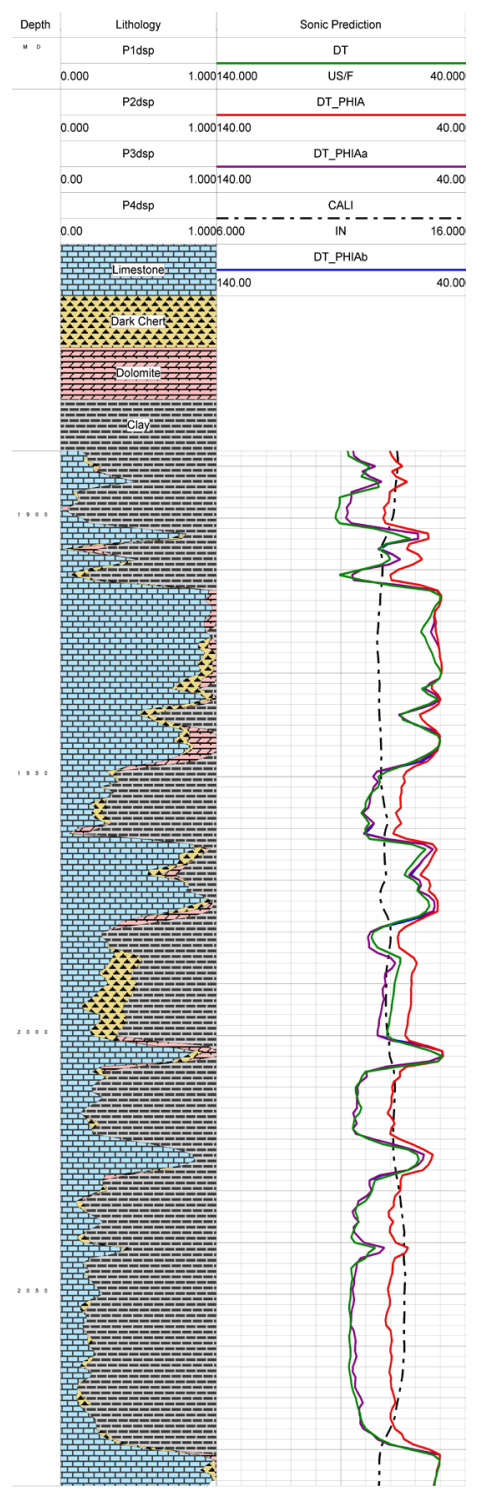

(c) Well C

Figure 3.27. Predicted logs by using average of neutron and density porosity. The prediction is much better than that of the neutron and density porosities alone. In the figure Green Curve: Measured Sonic log Red: From Wylie's Time Average Equation (one matrix), Purple: Modified Time Average Equation (two lithologies) Blue: From Modified Equation (II) (two lithologies plus dolomite correction) (a) Well A, (b) Well B and (c) Well C.

The results from average porosity were much better. Well A demonstrated almost best fit for all equations. Modified equation (II) gave the best results and fit. It also removed 
most of the dolomite effect. Figure 3.28 shows bar graphs presenting the frequency of root mean square error in 46 wells.

(a)

Wylie's Time Average Equation
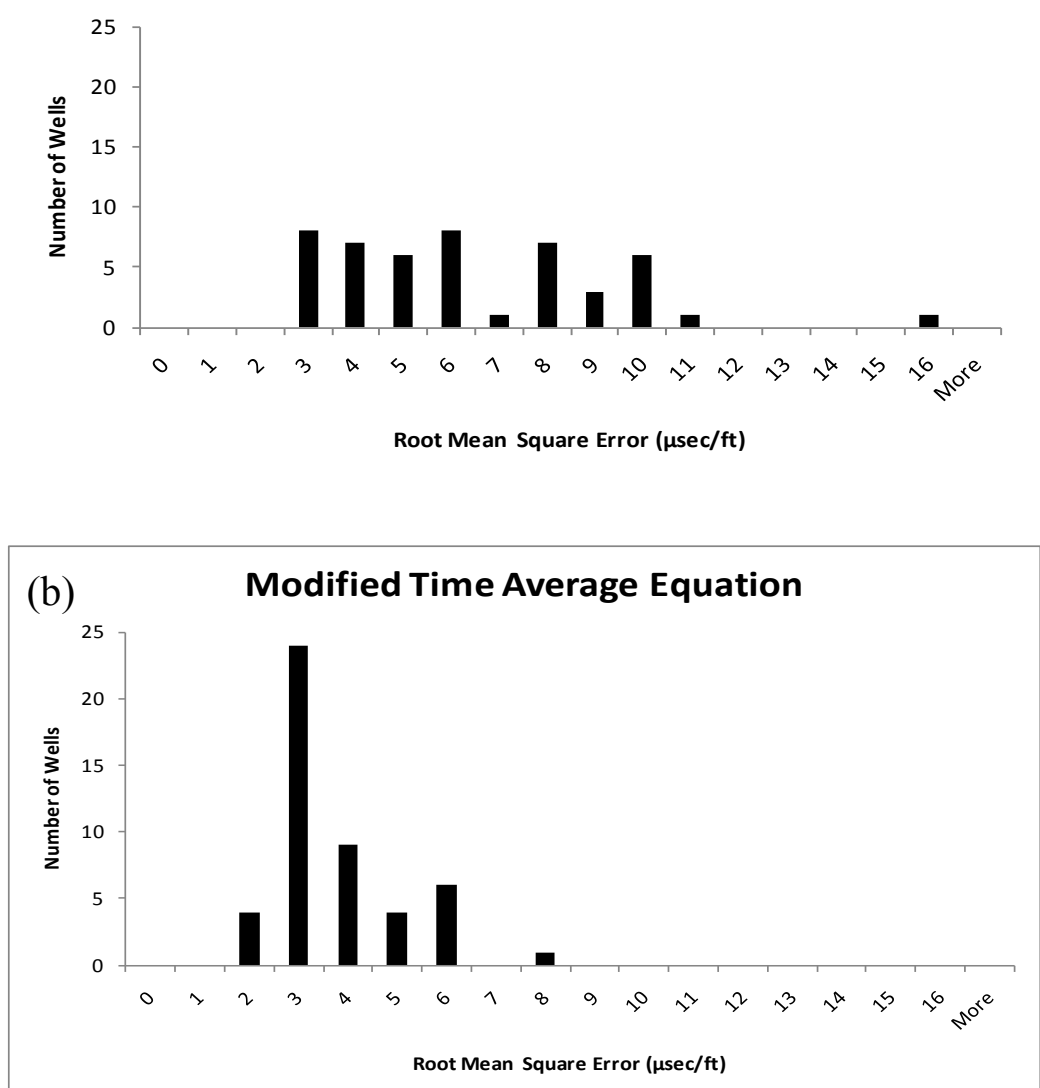

(c) Modified Equation (II)

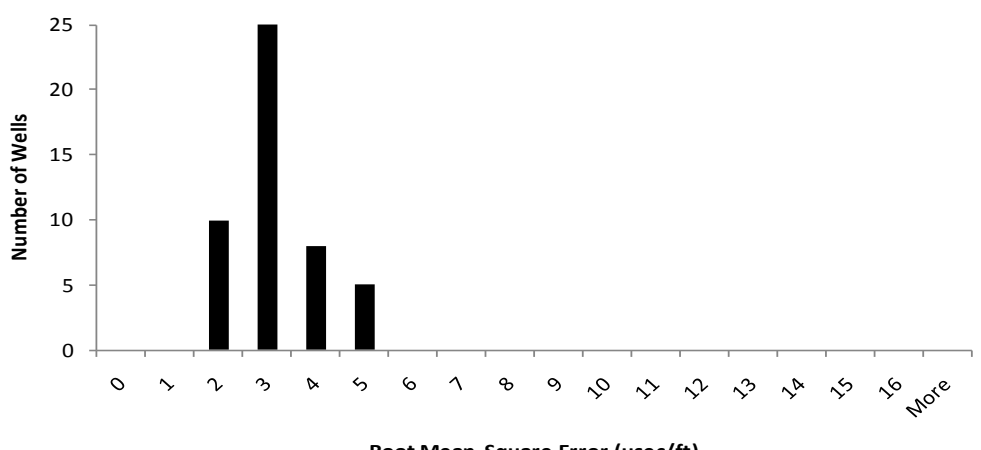

Root Mean Square Error $(\mu \mathrm{sec} / \mathrm{ft})$

Figure 3.28. Bar-graph explaining the frequency of root mean square error of 46 wells in predicting the sonic response from average porosity. (a) Wylie's Time Average Equation, (b) Modified Time Average Equation (c) Modified Equation (II) 
In Figure 3.29 shows the cross plot of Well B representing the effect of shale and dolomite content on the prediction of sonic log. Crossplots demonstrate the effectiveness of dolomite correction in modified equation (II). Figure 3.29(b) shows that the use of Modified time average equation has effectively decreased the errors introduced by the shale content but it does not correct the dolomite effects. Our modification equation (II) (Figure 3.29(c)) has, however, effectively reduced the dolomite effects and shifted all points to near zero error line. The effect of shale is removed equally as it is done in modified time average equation, so results in a better match.

The multiplying factor ' $a$ ' in modified equation (II) to remove the dolomite effects can be between 0.75-1.25 depending on the nature of the vugs, channels and fractures. Their exposure to sonic tools will also affect the response of sonic behavior. In our work, we used 1.00 for rocks having dolomite fraction less than $75 \%$ and 0.75 for those having dolomite fraction more than $75 \%$. These values were selected to get the best fit.

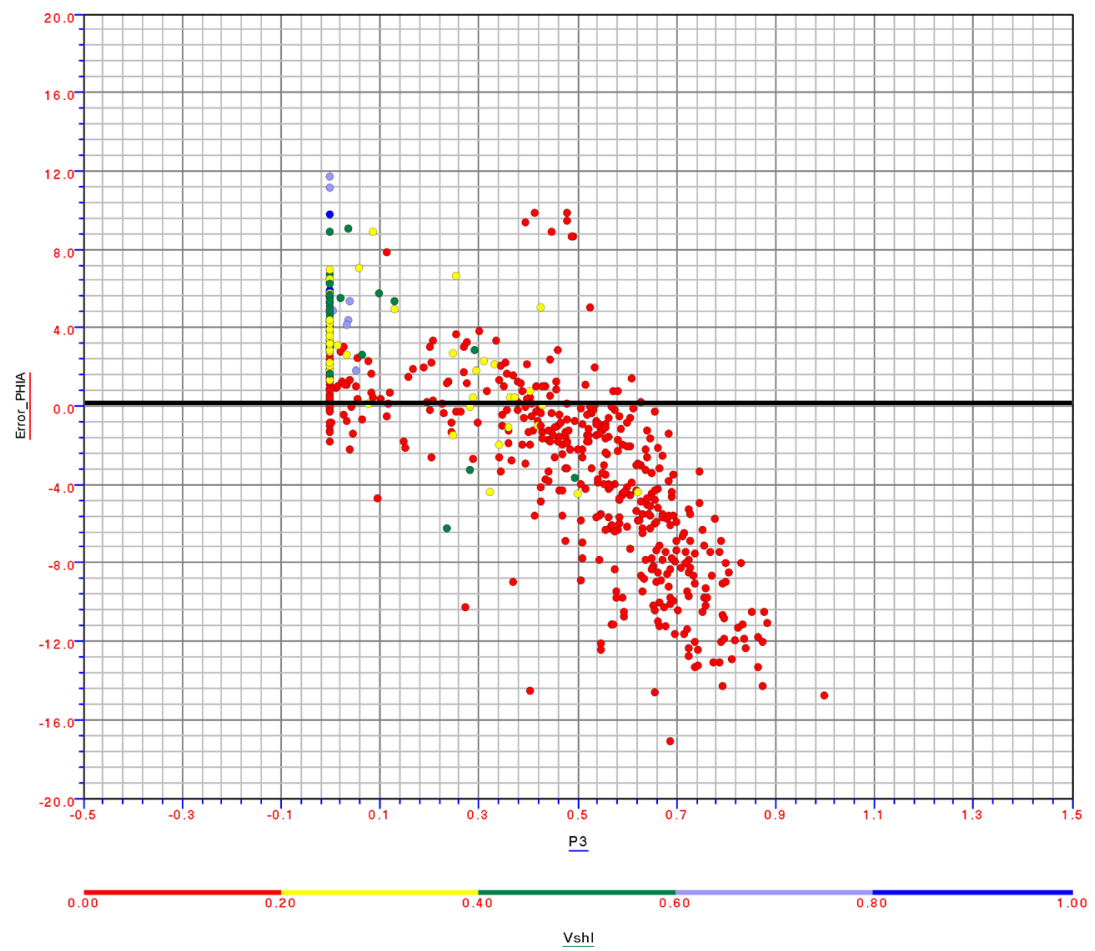

(a) Wylie's Time Average Equation 


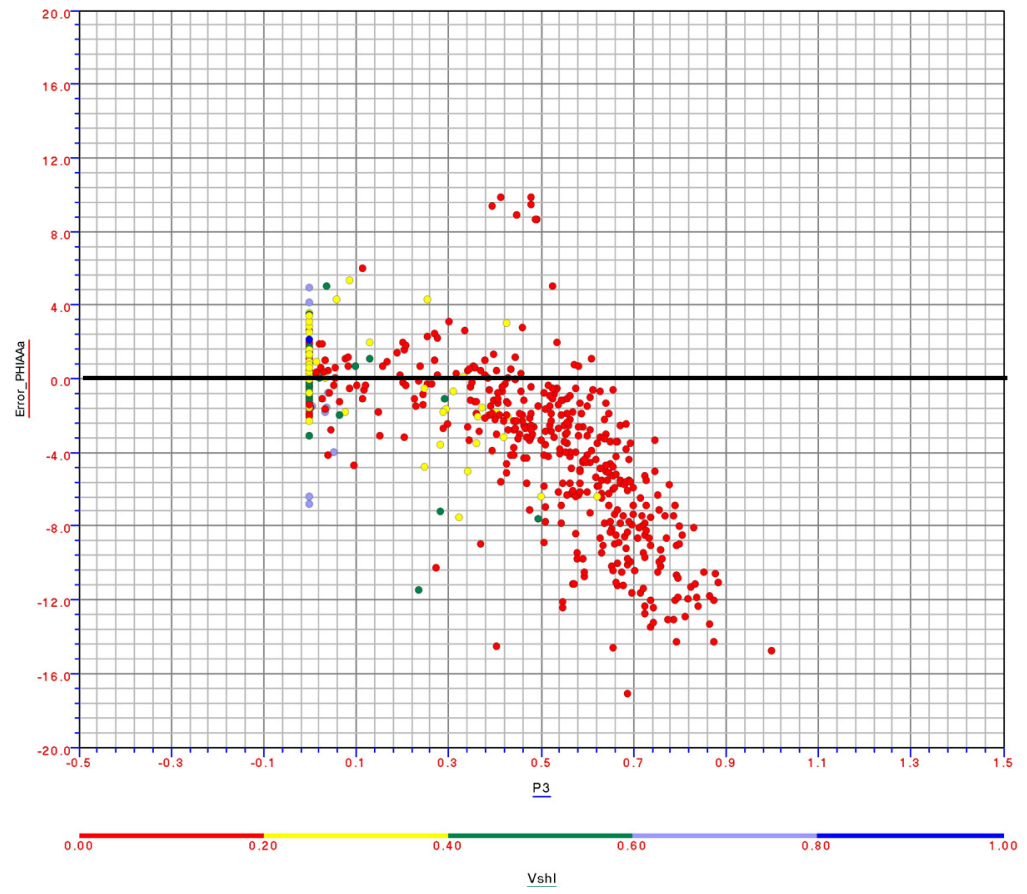

(b) Modified Time Average Equation

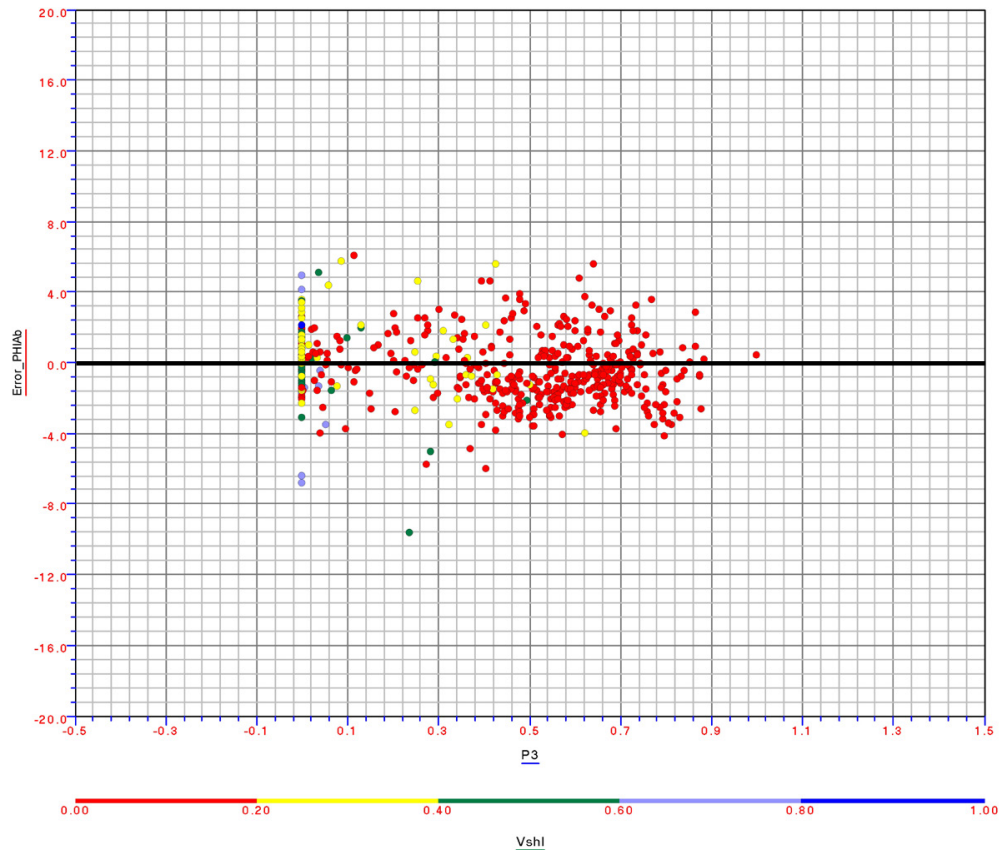

(c) Modified Equation (II)

Figure 3.29 Crossplots between error and dolomite fraction colored with shale volume displaying the results of sonic log prediction in Well B by (a) Simple Wylie's Time Average Equation (b) Modified Time Average Equation (two lithologies; clay + shale) (c) Modified equation (two lithologies + dolomite correction). Dolomite fraction is along $\mathrm{X}$-axis; Error is along $\mathrm{Y}$-axis and the data points are colored with respect to shale fraction. 


\subsubsection{From Mineral Identification results}

Sonic predictions made from density porosity, neutron porosity and average porosity shows the significant improvement in results with the use of two lithologies in Wylie's Time average equation. It led us to treat each mineral fraction separately in the Wylie's Time average equation so we used the results of mineral identifications discussed in section 3.2 .

From the petrophysical analysis of logging data, we were able to get the mineral fraction of the Traverse Limestone for all the wells. We split the Wylie's Time Average equation to deal each mineral component separately. The developed equation was named Modified equation (III) (see - Appendix (V) equation 8)

We used this equation for the mineral fractions calculated from modified mineral identification approach and also for the ones calculated by the conventional 4-mineral identification approach.

The results were worsened by the use of mineral identification results. In this approach the factors governing the transit time were increased too much, and the parameters relating mineral fractions were not known well. Also the fraction components by themselves were not well proven. In this part of the work, we used the text -book values for the sonic properties of chert, dolomite and calcite fractions, it can also cause an error. We expect that the use of well established sonic properties of these mineral fractions could have enhanced the results of pseudo-sonic logs. Because of the involvement of a lot of uncertain factors the results of this method were not good. In some wells, however, the results were very accurate and fit was the best of all approaches. The use of 4- mineral identification could have enhanced data accuracy if all the fractions were known and their respective transit times were established well. The results are shown in Figure 3.30. The spikes in well $\mathrm{C}$ are introduced by lithological identification. None of porosity logs and PEF exhibits this feature corresponding to these points. 


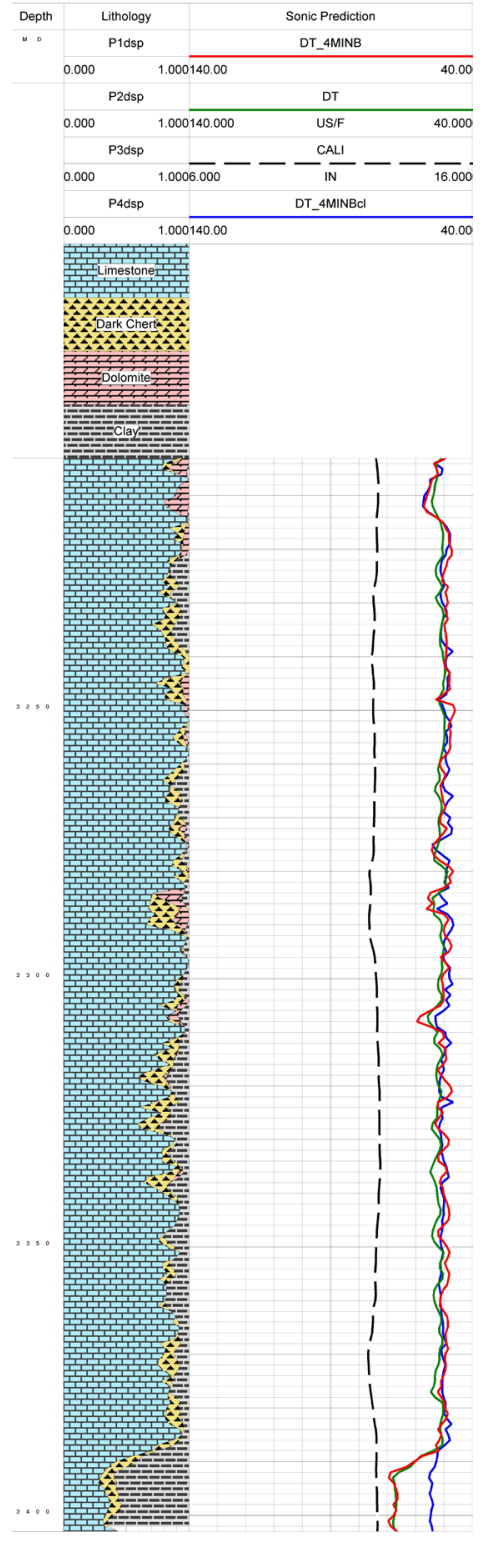

(a) Well A

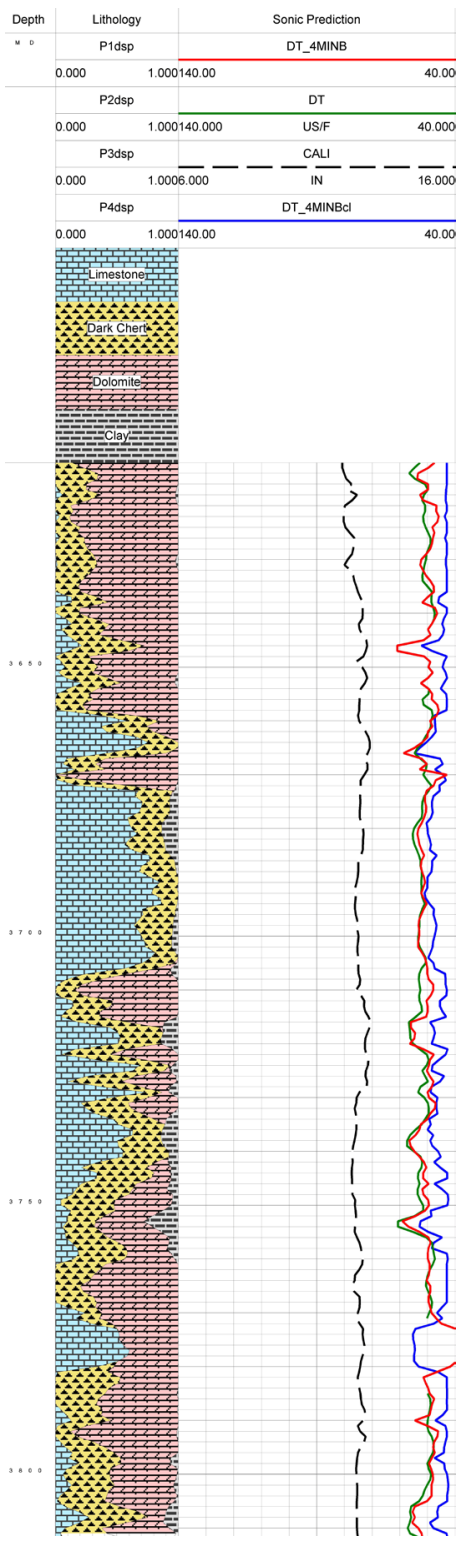

(b) Well B

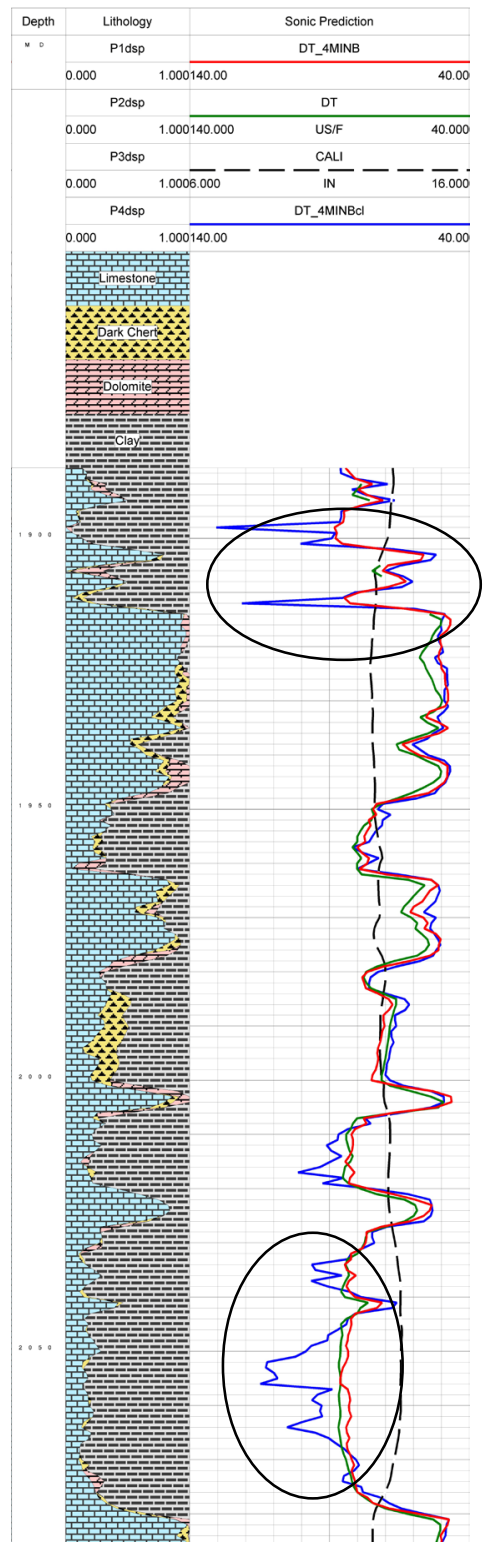

(c) Well C

Figure 30. Prediction of sonic $\log$ with the results of mineral identification. Red:4mineral identification clay inclusive, Blue: Modified 3-mineral identification clay exclusive, Green: Measured Sonic log. (a) Well A (b) Well B (c) Well C.

Figure 3.31 presents the crossplots of the error in the pseudo-sonic logs predicted in Well $B$ by the use of the results of mineral identification versus dolomite and shale fraction at corresponding points. 

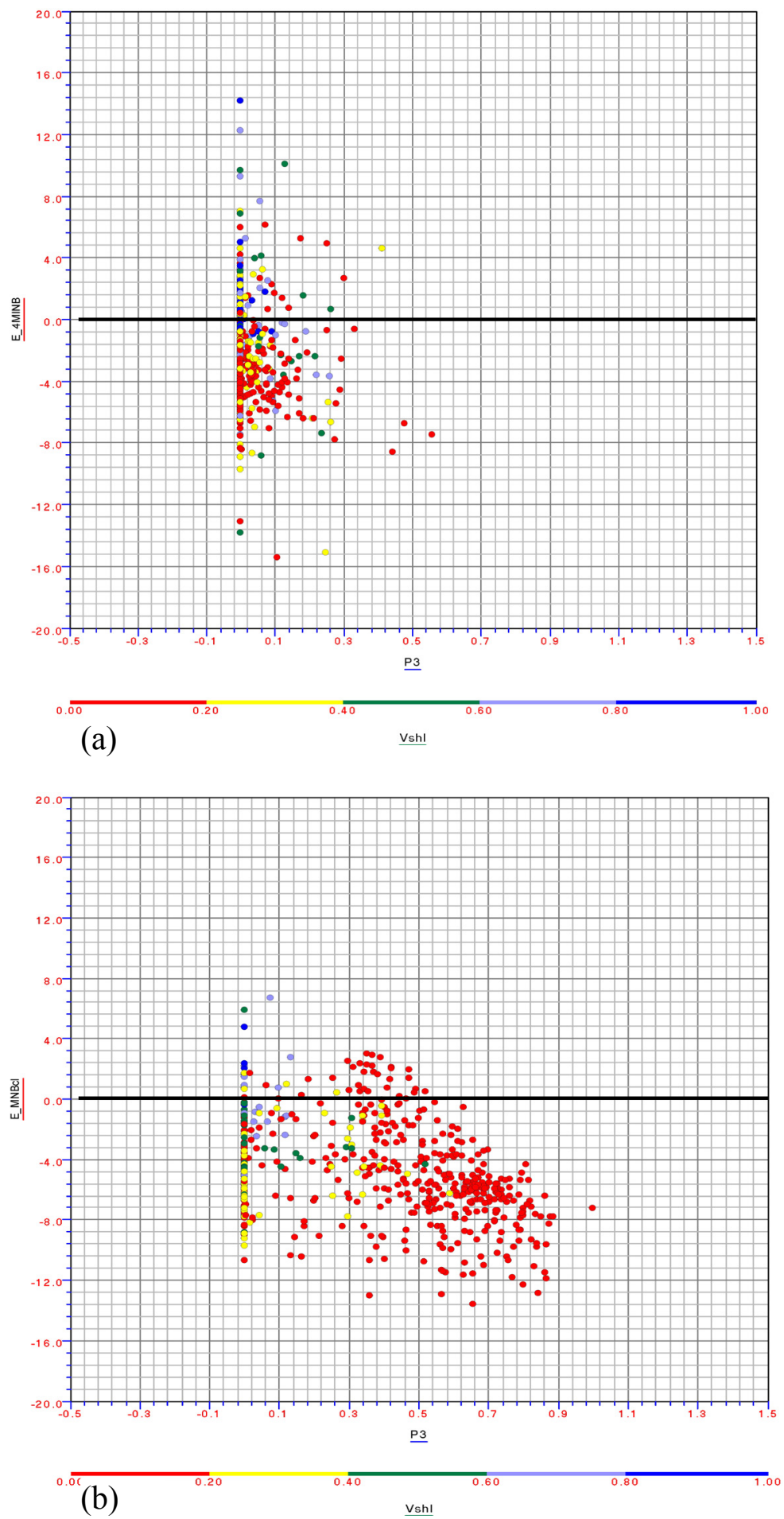

Figure 3.31. Cross plot describing error in sonic prediction in Well B versus dolomite and shale fractions. (a) Mineral fractions used were calculated by 4-Mineral Identification clay inclusive (b) Mineral fractions used were calculated by Modified 3- Mineral Identification clay exclusive. 
We also prepared the bar graph to see the frequency of root mean square error. The bar graphs are given below in Figure 3.32. We can see that the results of 4-mineral identification are better than density log response and neutron log response when used individually. But average porosity calculated by combining the neutron and density porosity gave the best results.

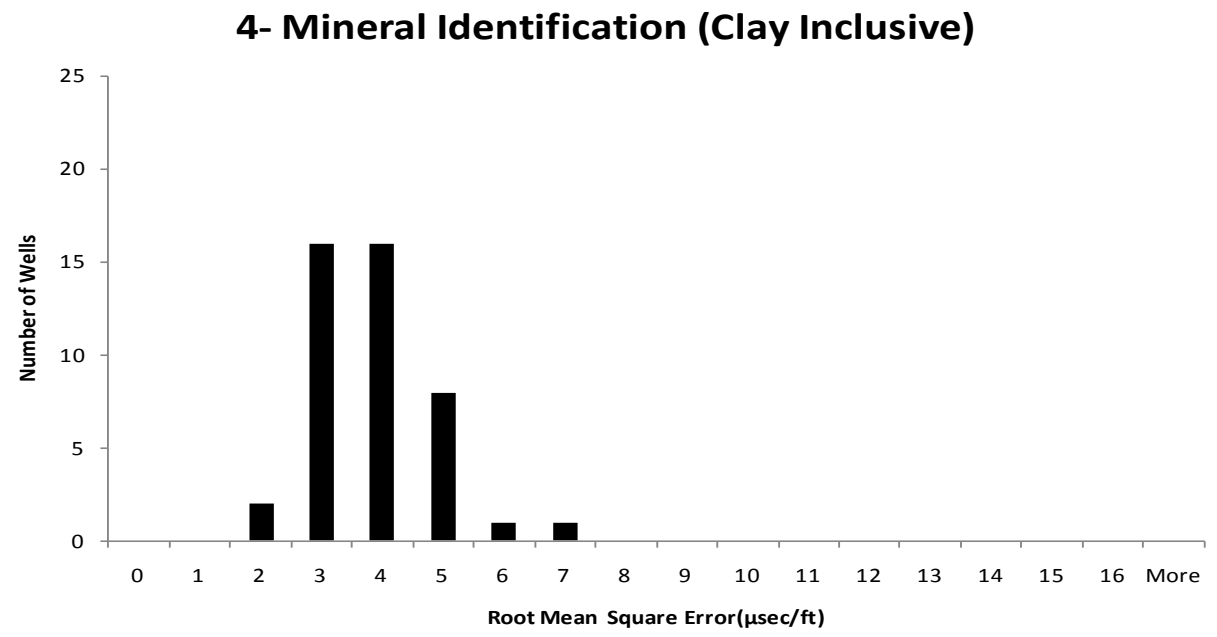

(a)

Modified 3-Mineral Identification (Clay Exclusive)

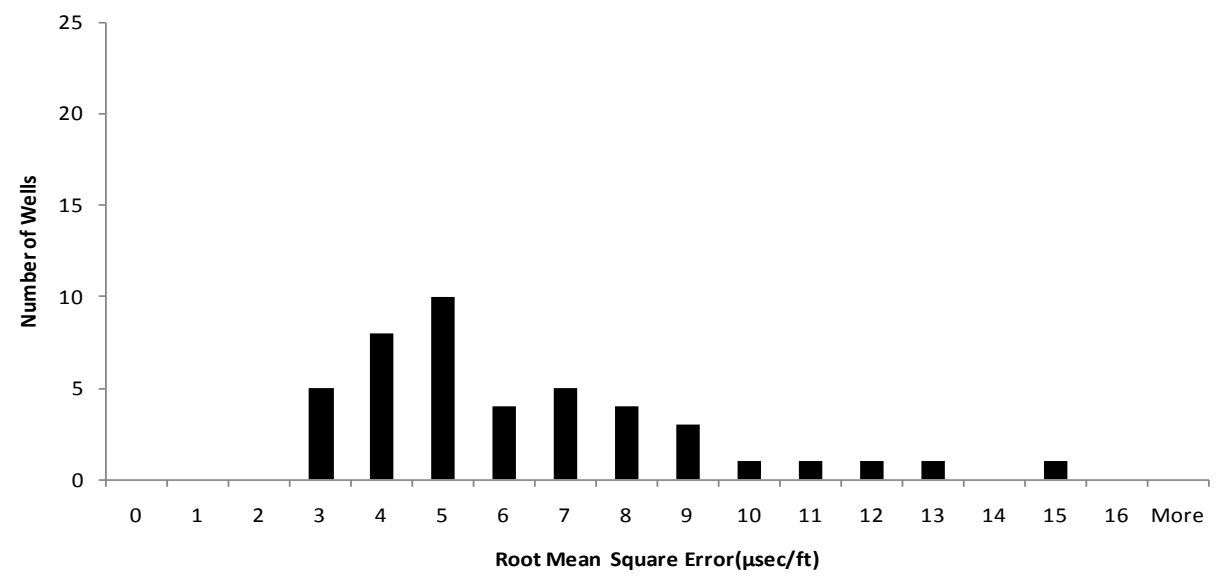

(b)

Figure 32. Bar graph presenting the root mean square error in sonic prediction by the use of individual mineral fraction in Wylie's Time Average Equation. (a) Mineral fractions calculated from 4-mineral Identification clay inclusive. (b) Mineral fractions calculated from Modified 3- Mineral Identification clay exclusive. 


\section{Results \& Discussion}

The work done has revealed that like clastic sediments, it is very difficult to predict carbonate velocities from other petrophysical properties. For best prediction we need the detailed knowledge of the lithology and porosity of the rock units. For lithology determination, we used the mineral identification.

The use of a conventional 4-mineral identification approach gave reasonably good results but there were some uncertainties, creating doubts about the results. The 4-mineral identification approach sometimes gives the negative fractions for some minerals and sometimes makes the total volume fraction greater than one. These effects can be because of the poor logging data or because of the poor control of logging data on the respective properties. We removed these effects by replacing the negative values with zeros and forcing the sum of volume fractions to one that ultimately causes some changes in the calculated mineral fractions. This makes the results of mineral identification unreliable. The 3-mineral identification, in addition, this totally neglects the gamma ray response for shale thereby increasing the error in the results.

Our modification to 3-mineral approach also has room for errors. In our modified approach, we corrected the data for shale using the gamma ray log before applying the mineral identification. This correction at various points caused too low or too high density and PEF values. These points were forced to corresponding minimum and maximum allowable values so caused uncertainty in results. In addition to this the limitations of mineral identification also introduces some errors.

The conventional approach fixes the data only once while applying the unity constraint and removing negative fractions. The limits used in our modified approach to fix the density, porosity, and PEF data caused higher level of uncertainty than the conventional approach. Because of the way both approaches work the results derived are different, but we cannot tell which one is better. Based on the number of uncertainties one can say that 4-mineral identification approach is the best among the three as it has least number of factors causing uncertainties. 
Prediction of sonic behavior from density porosity was fairly good in clean rocks. But in shaly formations, the density tool does not detect the clay-bound water and shale porosity. This factor caused error in the prediction of sonic log in shaly environments. However, the modified time average equation treats the shale content as a separate matrix and gives better results in shaly formations. But for the modified time average equation, we need to know the transit time of wet-shale that depends upon the amount of clay bound water and has a big range of values between $50-150 \mu \mathrm{sec} / \mathrm{ft}$. There is no logging tool or technology available other than sonic logs that can tell the sonic properties of insitu shale. However, the best approach is to use the sonic data from the surrounding wells and to make an estimate of shale transit time.

Neutron tools, on the other hand, detect the clay-bound water and give the correct porosity of shale so prediction of sonic logs from neutron porosity is good in shaly formations. The significant advantage of neutron porosity is that it treats the clay-bound water separately as fluid and allows the shale to be dealt as a part of matrix so we do not need to calculate the shale transit time to use in sonic log prediction. This fact makes the neutron porosity the best for the areas where we do not know the shale transit time. However in dolomites neutron logs show higher porosity than the sonic logs. The reason for this is the secondary porosity of dolomite caused by vugs, channels and fractures that are not detected by the sonic log. The subtraction of the dolomitic fraction of effective porosity from the total porosity while calculating the sonic response can improve the results significantly. Unfortunately we cannot get the dolomite fraction from logging data without PEF logs, and in most of the wells we do not have PEF logs. We often have mud logs and field results of cuttings and calcium tests. Those could be used to estimate the dolomite fraction for the use in log prediction.

As average porosity involves the use of both density logs and neutron logs, it is affected by the shale fraction as well as by the dolomite fraction. The use of modified time average equation with average porosity accounts for shale. To account for the effects of secondary porosity, neutron and density porosity with shale volume can be used to get effective porosity of the rock, and then the subtraction of dolomitic fraction of effective porosity from the average porosity improves the results. In dolomites effective porosity 
could be considered as the direct measure of the secondary porosity. The results derived by the use of average porosity in Wylie's Time Average equation after introducing the correction for shale and dolomite were the best ones and the root mean square error was about 3-4.0 $\mu \mathrm{sec} / \mathrm{ft}$ for most of the wells. The need of shale transit time again restricts the use of the average porosity in areas where shale transit time is not known.

The use of each individual constituent mineral to predict the log has not been shown to be as successful as expected. There are many reasons behind the failure of the use of mineral constituents in sonic prediction. One major reason is that we do not know the exact fraction of each mineral constituent because of the uncertainties in the mineral identification approach. Another reason can be that the sonic behavior of mineral components was not established accurately. The increase in number of factors controlling the sonic prediction and the ambiguities associated with those factors also increases the error in sonic response prediction. These factors make the use of mineral fractions unsuitable for sonic prediction.

The data quality was very poor in this work and it affected our results. Logs run by different companies or by different loggers were following different standards. This factor was a big hindrance in standardizing the transit time of the mineral components. In a couple of wells the shale transit time for the best fit was having a difference of 20$30 \mu \mathrm{sec} / \mathrm{ft}$ in the same unit and in the same county. That demonstrates the lack of data quality. Some error was also introduced by the assumption of fresh water, as the fluid in the pores of Traverse limestone is supposed to be salty. Our calculations show that the assumption of fresh water can cause a maximum error of $0.75 \%$ or $2 \mu \mathrm{sec} / \mathrm{ft}$. 


\section{Conclusion}

Wylie's Time Average Equation which is mostly used in the logging practice gives fairly good results when used for sonic response prediction in shale-free carbonate rocks. It divides the whole rock into two parts: pore free matrix and pore fluids. When there is shale in the rock as a part of the matrix, the travel time of matrix is strongly affected by the fraction of the shale present. This fact leads to treat the shale fraction separate from the other matrix constituents when using density data to calculate the sonic response from density porosity and from average porosity. Modified Time Average equation that deals with the shale as a separate matrix in the rock works fine to predict the sonic log in shaly carbonates.

On the other hand, the sonic tool does not give the true results in dolomites and neglects the secondary porosity of dolomite. We subtracted the effective porosity associated with volume fraction of dolomite from the average porosity to correct the effect of dolomite assuming the effective porosity as a direct measure of secondary porosity and then used in Modified Time Average equation.

The prediction of sonic transit times in the carbonates of the Traverse Limestone (including shaly and dolomitic sections) was accomplished through the application of Wylie's time average equation, after having been adapted to account for shale and dolomite fractions. The results were compared with the measured sonic logs on the root mean square (RMS) basis. We experimented using well data from 46 different wells from Michigan Basin, and were able to predict the sonic logs from the average porosity with a root mean square error of about $3 \mu \mathrm{sec} / \mathrm{ft}$ and with a root mean square error of $4 \mu \mathrm{sec} / \mathrm{ft}$ while using neutron porosity alone. However, there were some wells where data quality was too poor and that affected our results significantly.

As Traverse Limestone has four different mineral fractions (Clacite, dolomite, Quartz and clay), we ran mineral identification by using conventional 4-mineral identification approach (that calculates the shale volume from the gamma ray and then employs it in mineral identification with DGA and UMA) and by using 3-mineral identification approach (that completely neglects the gamma ray log and uses DGA and UMA for 
mineral identification) to determine the each mineral fraction for use in sonic response prediction. In 3-mineral identification we assumed that there is no chert and used the approach to calculate the three minerals (clay, calcite, and dolomite). We had reasonable results from 4-minera identification approach but the results from 3-mineral approach did not look good and revealed the importance of gamma ray log to account for clay content. We corrected the logging data for shale effects depending on gamma ray log and then ran the 3-mineral identification to determine the fraction of Quartz, calcite and dolomite. The results look reasonable in most of the wells. We are not aware of a better approach among them as we do not have any qualitative lithological data to compare the results.

The results from 4-mineral identification and modified 3-mineral (clay exclusive) identification were used in Wylie's Time Average equations having divided the matrix fraction into four parts (calcite, dolomite, chert and clay) to predict the sonic response of Traverse Limestone. The results were not as good as we obtained with the use of average porosity. It could be because of the uncertainties associated with the sonic properties of the mineral constituents, and also the mineral identification approaches have some rooms for errors because of the assumptions made in them. Future work is required to establish the sonic properties of individual mineral constituent that will improve the results of sonic prediction.

We conclude that sonic response in carbonate rocks can be best predicted with the use of average porosity and gamma ray logs. We assumed the fresh water in pores for our calculations. This assumption could have introduced an error of about $1-2 \mu \mathrm{sec} / \mathrm{ft}$ in the results because water in Traverse Limestone is not fresh water it has some amount of salt in it. The results can be improved further with a better data control and data quality. The use of individual mineral constituents can enhance the results even more if all the fractions and their sonic properties are established accurately. Future work is needed to standardize the logging practices and to develop some techniques to compute the mineral fractions more accurately. This will strongly enhance the accuracy of the sonic prediction. 


\section{References}

Adcock, S. (1993), In search of the well tie; what if I don't have a sonic log?, The Leading Edge, 12(12), 1161-1164, doi: 10.1190/1.1436929.

Catacosinos, P. A., J. P. A. Daniels, and W. B. Harrison III (1990), Structure, Stratigraphy, and Petroleum Geology of the Michigan Basin: Chapter 30: Part II. Selected Analog Interior Cratonic Basins: Analog BasinRep., 40 pp.

Dolton, G. L. (1995), Michigan basin province (063)Rep., 31 pp.

Du, Y., D. Lu, and D. Li (2008), An Effective Hash-Based Method for Generating Synthetic Well Log, paper presented at International Conference on Advanced Language Processing and Web Information Technology, doi: 10.1109/ALPIT.2008.19

Faust, L. Y. (1951), Seismic Velocity As A Function Of Depth And Geologic Time, Geophysics, 16(2), 192-206, doi: 10.1190/1.1437658.

Hacikoylu, P., J. Dvorkin, and G. Mavko (2006), Resistivity-velocity transforms revisited, The Leading Edge, 25(8), 1006-1009, doi: 10.1190/1.2335159.

Howell, P. D., and B. A. van der Pluijm (1999), Structural sequences and styles of subsidence in the Michigan basin, Geological Society of America Bulletin, 111(7), 974991, doi: 10.1130/0016-7606.

Lee, M. W. (1999), Methods of generating synthetic acoustic logs from resistivity logs for gas-hydrate-bearing sediments [electronic resource] / by Myung W. Lee, U.S. Dept. of the Interior, U.S. Geological Survey, Denver, Colo.

Lilienthal, R. T. (1974), Subsurface geology of Barry County, MichiganRep., 18 pp, Lansing, Michigan.

Milstein, R. L. (1988), Impact Origin of the Calvin 28 Cryptoexplosive Disturbance, Cass County, Michigan, Abstracts of the Lunar and Planetary Science Conference, 19, 22. 
Newman, E. A. (1936), Geology of Ogemaw County and West Branch Oil Field Rep., 10 pp, Ogemaw, Michigan.

Ojala, I. O. (2009), Using rock physics for constructing synthetic sonic logs, paper presented at 3rd Canus Rock Mechanic Symposium, Toronto, ON, CANADA.

Pringle, G. H. (1937), Geology of Arenac County, MichiganRep., 16 pp, Arena County.

Rolon, L., S. D. Mohaghegh, S. Ameri, R. Gaskari, and B. McDaniel (2009), Using artificial neural networks to generate synthetic well logs, Journal of Natural Gas Science and Engineering, 1(4-5), 118-133, doi:10.1016/j.jngse.2009.08.003.

Wylie, A. S. J., and J. E. Huntoon (2003), Log-curve amplitude slicing: Visualization of log data and depositional trends in the Middle Devonian Traverse Group, Michigan basin, United States, AAPG Bulletin, 87(4), 581-608, doi: 10.1306/12040201057. 


\section{Appendices}

\subsection{Appendix (I)}

Vshl=(GR-GRcl)/(GRshl-GRcl)

RHOBcl=(RHOB-RHOBshl*Vshl)/(1-Vshl)

NPHIcl=(NPHI-NPHIshl*Vshl)

Where

Vshl $=$ Shale Volume

$\mathrm{GRcl}=$ Gamma ray value for shale free lithology (We used $15 \mathrm{API})$

GRshl $=$ Gamma ray for $100 \%$ shale $($ We used 110 API $)$

RHOBcl $=$ Shale Free Bulk Density

RHOB $=$ Bulk Density from logging data

RHOBshl $=$ Shale Density $($ We used $2.65 \mathrm{gm} / \mathrm{cc}$ )

$\mathrm{NPHIcl}=$ Neutron porosity in shale free lithology

$\mathrm{NPHI}=$ Neutron Porosity from logging data

NPHIshl $=$ Neutron Porosity for shale $($ We used $0.25 \mathrm{~V} / \mathrm{V})$

NOTE: Value for GRcl and GRshl were selected on the basis of the general trend of minimum and maximum values of gamma ray log in Traverse Limestone as the overlying Antrim shale shows very high values because of uranium and the lower lying Bell Shale 
has lower and changing value because of carbonates impurity in it. Similarly RHOBcl, RHOBshl, NPHIcl and NPHIshl were selected from the neutron density crossplots colored with respect to corresponding gamma ray response. Limits were applied to RHOBcl and NPHIcl values so that their values should range between $2-3 \mathrm{gm} / \mathrm{cc}$ and ($0.10-0.50 \mathrm{~V} / \mathrm{V})$. All higher and lower values were replaced by the corresponding minimum or maximum values.

\subsection{Appendix (II)}

\section{4-Mineral Identification}

4- Mineral Identification is used to determine the volume fraction of the constituting minerals of a rock sample by using bulk density (RHOB), photoelectric absorption factor (PEF), neutron porosity (NPHI), density porosity (PHID) and gamma ray log.

Gamma ray log is used to calculate the shale volume (Vshl) by using following equation

Vshl $=($ GR-Grcl) $/($ GRshl-Grcl)

Neutron and density porosities are averaged to calculate the average porosity (PHIA).

$\mathrm{PHIA}=(\mathrm{NPHI}+\mathrm{PHID}) / 2$

Photoelectric absorption factor is converted to volumetric cross section (U) by multiplying it with the electron density. In general practice bulk density (RHOB) is used instead of electron density so the numbers are added as conversion factor.

$\mathrm{U}=\mathrm{PEF}^{*}(\mathrm{RHOB}+0.1883) / 1.07$ 
Average porosity is then used to remove the pore fluid effect from the density data and photoelectric volumetric factor to get the Apparent Dry Grain Density (DGA) and Apparent Volumetric Factor (UMA) of matrix by using following relation.

DGA $=($ RHOB-Rhof*PHIA $) /(1-P H I A)$

$\mathrm{UMA}=(\mathrm{U}-\mathrm{U} * \mathrm{PHIA}) /(1-\mathrm{PHIA})$

In mineral identification, these quantities are related to the volumetric fraction of their constituting minerals using linear law of volumetric mixing and following two equations are generated.

$\mathrm{UMA}=\mathrm{U} 1 * \mathrm{~F} 1+\mathrm{U} 2 * \mathrm{~F} 2+\mathrm{U} 3 * \mathrm{~F} 3+\mathrm{U} 4 * \mathrm{~F} 4$

$\mathrm{DGA}=\mathrm{D} 1 * \mathrm{~F} 1+\mathrm{D} 2 * \mathrm{~F} 2+\mathrm{D} 3 * \mathrm{~F} 3+\mathrm{D} 4 * \mathrm{~F} 4$

Third equation is generated by equating clay fraction to shale volume calculated from gamma ray log and fourth equation is generated by applying unity constraints to the sum of all volumetric fractions.

$0 * \mathrm{~F} 1+0 * \mathrm{~F} 2+0 * \mathrm{~F} 3+1 * \mathrm{~F} 4=\mathrm{Vshl}$

$\mathrm{F} 1+\mathrm{F} 2+\mathrm{F} 3+\mathrm{F} 4=1$

This whole process results in four linear equations (A,B,C and D) with four unknowns $(\mathrm{F} 1, \mathrm{~F} 2, \mathrm{~F} 3$ and F4). These equations are then mutually solved to determine the volume fraction of each mineral (F1, F2, F3, F4). 
Below is the explanation of different abbreviations and the input parameters used and their respective values for our work.

GRcl $=$ Gamma ray value for shale free lithology $=15$ API

GRshl $=$ Gamma ray for pure shale $=110$ API

Rhof $=$ Pore Fluid Density $=1.00 \mathrm{gm} / \mathrm{cc}$ (We assumed water in the pores)

Uf=Pore Fluid Volumetric factor $=0.398 \mathrm{~b} / \mathrm{cc}$ (We assumed water in the pores)

$\mathrm{U} 1=$ Limestone's photoelectric volumetric factor $=13.776 \mathrm{~b} / \mathrm{cc}$

$\mathrm{U} 2=$ Chert's photoelectric volumetric factor $=4.88 \mathrm{~b} / \mathrm{cc}$

$\mathrm{U} 3=$ Dolomite's photoelectric volumetric factor $=9.00 \mathrm{~b} / \mathrm{cc}$

$\mathrm{U} 4=$ Clay's photoelectric volumetric factor $=10.00 \mathrm{~b} / \mathrm{cc}$

D1= DGA for limestone $=2.71 \mathrm{gm} / \mathrm{cc}$

$\mathrm{D} 2=\mathrm{DGA}$ for chert $=2.65 \mathrm{gm} / \mathrm{cc}$

$\mathrm{D} 3=$ DGA for dolomite $=2.88 \mathrm{gm} / \mathrm{cc}$

D4= DGA for clay $=2.95 \mathrm{gm} / \mathrm{cc}$ (As ternary diagram showed that the Clay minerals present were illite and its DGA is $2.95 \mathrm{gm} / \mathrm{cc}$ ).

$\mathrm{F} 1=$ Limestone fraction

$\mathrm{F} 2=$ Chert fraction

$\mathrm{F} 3=$ Dolomite fraction

F4= Clay fraction

Acknowledgment: 4-mineral identification is the tool Geographix provides in its software package named as Discovery. We appreciate them for providing us with the details of their code. 


\subsection{Appendix (III)}

\section{3-Mineral Identification}

3-Mineral identification is just similar in solution to the 4-mineral but it does not consider the gamma ray data in any sense and assumes only three minerals. In other words we can say that it is the 4-mineral identification assuming no clay content or no fourth mineral fraction.

It results in following three equations.

$\mathrm{UMA}=\mathrm{F} 1 * \mathrm{U} 1+\mathrm{F} 2 * \mathrm{U} 2+\mathrm{F} 3 * \mathrm{U} 3$

$\mathrm{DGA}=\mathrm{F} 1 * \mathrm{D} 1+\mathrm{F} 2 * \mathrm{D} 2+\mathrm{F} 3 * \mathrm{D} 3$

$\mathrm{F} 1+\mathrm{F} 2+\mathrm{F} 3=1$

These equations are mutually solved to find out the volumetric fraction of all the three minerals. Here U and D represent the respective volumetric factor and dry grain density.

We used this approach to find out the mineral fraction of calcite, dolomite and clay while assuming that there was no chert.

We used same values for input parameters in 3-mineral identification as we used in 4mineral identification.

Acknowledgment: 3-mineral identification is also the part of Geographix's Discovery package. We appreciate them for providing us with the details of their code. 


\subsection{Appendix (IV)}

\section{Modified Mineral Identification}

In modified mineral identification, we tried to fix the shale volume calculated from gamma ray response and then applied 3 mineral identification approach to the data. This 3-mineral approach was designed to divide the shale free volume among other three nonshaly mineral (calcite, dolomite and quartz). Basic idea behind this approach is similar to that of 3mineral identification. Below are the details of the steps used and the scripts written for this.

\section{Calculating shale volume}

Vshl[] $=(\min ,(\max ((\mathrm{GR}[]-\mathrm{Grcl}) /(\mathrm{GRshl}-\mathrm{Grcl}), 1), 0)$

'[]' sign indicates the variable/vector and other values are constant. Min and max commands were applied to limit the shale volume fraction between 0 and 1

where

$\mathrm{GRcl}=$ Gama ray value for clean formations (We used $15 \mathrm{API})$

Grshl $=$ Gamma ray value in pure shale $($ We used $110 \mathrm{API})$

Vshl $=$ Shale Volume

\section{Removing the effect of Shale:}

Density, PEF and Neutron porosity data were cleaned of shale by assuming linear law of volumetric mixing.

\section{Cleaning Density}

At the first step density was cleaned by using the relation given below. For pure shale, no correction was applied because it causes an infinite value for cleaned density but in mineral identification we put $100 \%$ shale for these points and all other fractions were zeroed. 
If $(\operatorname{Vshl}[]<1)$

RHOBcl[] $=($ RHOB[]-RhoShl*Vshl[])/(1-Vshl[])

Else

RHOBcl[]=RHOB[]

End If

Where

$\mathrm{RHOB}=$ Density value from logs $(\mathrm{GM} / \mathrm{CC})$

RHOBcl $=$ Density value in clean formation $(\mathrm{GM} / \mathrm{CC})$

RhoShl $=$ Shale Density Value (We used 2.65 GM/CC)

Some time shale correction causes too high or too low value so we put certain limits to fix that problem. These limits affected our mineral fraction results.

If $(\mathrm{RHOBcl}[]>3.00)$

RHOBcl[ $]=3.00$

Else

If $($ RHOBcl[ $]<2.0)$

$\mathrm{RHOBcl}[]=2.000$

Else

RHOBcl[]=RHOBcl[]

End If

End If

\section{Cleaning PEF}

If $($ Vshl[ $]<1.00)$

PEFcl[] $=(\operatorname{PEF}[]-P E F s h 1 * V s h 1[]) /(1-V s h 1[])$

Else

PEFcl[] $=$ PEF[ $]$

End If

Where 
$\mathrm{PEF}=$ Photoelectric Absorption Factor from logging data $(\mathrm{B} / \mathrm{E})$

$\mathrm{PEF}=\mathrm{PEF}$ value for shale $(\mathrm{We}$ used 3.50 B/E) The value ranges between 2-5.

$\mathrm{PEFcl}=\mathrm{PEF}$ value for shale free units $(\mathrm{B} / \mathrm{E})$

\section{Cleaning neutron porosity}

If $(\operatorname{Vshl}[]<1)$

NPHIcl[] $=(\mathrm{NPHI}[]-\mathrm{NPHIshl} *$ Vshl[])

Else

NPHIcl[]=NPHI[]

End If

WHERE

NPHIcl $=$ Neutron porosity in shale free formation $(\mathrm{V} / \mathrm{V})$

$\mathrm{NPHI}=$ Neutron porosity from logging data $(\mathrm{V} / \mathrm{V})$

NPHIshl $=$ Neutron porosity in shale $(\mathrm{We}$ used $0.25 \mathrm{~V} / \mathrm{V})$

Calculating shale free density porosity

PHIDcl[] $=($ RhoM - RHOBcl[] $) /($ RhoM - RhoF $)$

PHIDcl= Density porosity in clean formation $(\mathrm{V} / \mathrm{V})$

RhoM = Matrix Density (We used 2.71 GM/CC for limestone matrix)

RhoF = Fluid Density (We used 1.00 GM/CC assuming fresh water)

\section{Applying limits to data}

We applied limits to density porosity and neutron porosity so that all values describing porosities higher than 0.50 would be considered as 0.50 .

\section{Limiting density porosity (porosity calculated from the density log data)}

If (PHIDcl[] > 0.50)

PHIDcl[ $]=0.50$ 
Else

PHIDcl[] $=$ PHIDcl[]

End If

\section{Limiting nuetron porosity}

If (NPHIcl[] $>0.50)$

$\mathrm{NPHIcl}[]=0.50$

Else

$\mathrm{NPHIcl}[]=\mathrm{NPHIcl}[]$

End If

\section{Calculating shale free average porosity}

PHIAcl[] $=(\operatorname{PHIDcl}[]+\mathrm{NPHIcl}[]) / 2$

PHIAcl $=$ Calculated average/apparent porosity of shale free unit $(\mathrm{V} / \mathrm{V})$

\section{3-mineral identification with cleaned data}

After removing the shale content, the shale free data were used to compute the volume fraction of other three minerals by using 3-minerall identification.

Data points indicating pure shale on gamma ray log were not processed by 3-mineral approach. For these points, we considered that there was no mineral other than shale so shale fraction was adjusted to 1.00 and all others were considered 0.00 .

If $(\mathrm{Vshl}[]>0.999)$

$\mathrm{P} 4 \mathrm{DSP}[\mathrm{l}=1.00$

$\mathrm{P} 1 \mathrm{DSP}[]=0.00$

$\mathrm{P} 2 \mathrm{DSP}[]=0.00$

$\mathrm{P} 3 \mathrm{DSP}[]=0.00$

Else

\section{Calculating UMA and DGA}

$\mathrm{Ucl}[]=\mathrm{PEFcl}[]^{*}((\mathrm{RHOBcl}[]+0.1883) / 1.07)$

UMAcl[]=(Ucl[]-0.398*PHIAcl[])/(1-PHIAcl[]) 
DGAcl[] $=($ RHOBcl[]-PHIAcl[] $) /(1-\mathrm{PHIAcl}[])$

$\mathrm{Ucl}=$ Shale free photoelctric volumetric factor/Volumetric cross section $(\mathrm{B} / \mathrm{CC})$

$\mathrm{UMAcl}=$ Matrix photoelctric volumetric factor/ Volumetric cross section $(\mathrm{B} / \mathrm{CC})$

DGAcl $=$ Apparent Dry Grain density of clean matrix $(\mathrm{GM} / \mathrm{CC})$

\section{Calculating bulk volume}

$\operatorname{Vcl}[]=1-\operatorname{Vsh} 1[]$

$\mathrm{Vcl}=$ Shale free Bulk Volume

\section{Calculating mineral fractions}

Following equations were generated to find out the mineral fractions from the given data. Also we applied the limits to the data so that each fraction would have values between 0 and 1.

$\mathrm{P} 1 \mathrm{cl}[]=(-\mathrm{D} 2 * \mathrm{UMAcl}[]+\mathrm{D} 3 * \mathrm{UMAcl}[]+\mathrm{DGAcl}[] * \mathrm{U} 2-\mathrm{Vcl}[] * \mathrm{D} 3 * \mathrm{U} 2-$

DGAcl[]*U3+Vcl[]*D2*U3)/(-D2*U1+D3*U1+D1*U2-D3*U2-D1*U3+D2*U3)

If $(\mathrm{P} 1 \mathrm{cl}[]<0)$ Then $\mathrm{P} 1 \mathrm{cl}[]=0$

If $(\mathrm{P} 1 \mathrm{cl}[]>1)$ Then $\mathrm{P} 1 \mathrm{cl}[]=1$

$\mathrm{P} 2 \mathrm{cl}[]=(-\mathrm{D} 1 * \mathrm{UMAcl}[]+\mathrm{D} 3 * \mathrm{UMAcl}[]+\mathrm{DGAcl}[] * \mathrm{U} 1-\mathrm{Vcl}[] * \mathrm{D} 3 * \mathrm{U} 1-$

DGAcl[]*U3+Vcl[]*D1*U3)/(-D2*U1+D3*U1+D1*U2-D3*U2-D1*U3+D2*U3)

If $(\mathrm{P} 2 \mathrm{cl}[]<0)$ Then $\mathrm{P} 2 \mathrm{cl}[]=0$

If $(\mathrm{P} 2 \mathrm{cl}[]>1)$ Then $\mathrm{P} 2 \mathrm{cl}[]=1$

$\mathrm{P} 3 \mathrm{cl}[]=\left(-\mathrm{D} 1 * \mathrm{UMAcl}[]+\mathrm{D} 2 * \mathrm{UMAcl}[]+\mathrm{DGAcl}[] * \mathrm{U} 1-\mathrm{Vcl}\left[{ }^{*} \mathrm{D} 2 * \mathrm{U} 1-\right.\right.$

DGAcl[]*U2+Vcl[]*D1*U2)/(-D2*U1+D3*U1+D1*U2-D3*U2-D1*U3+D2*U3)

If $(\mathrm{P} 3 \mathrm{cl}[]<0)$ Then $\mathrm{P} 3 \mathrm{cl}[]=0$

If $(\mathrm{P} 3 \mathrm{cl}[]>1)$ Then $\mathrm{P} 3 \mathrm{cl}[]=1$

Instead of applying unity constraint like 3 mineral and 4 mineral identification, we used the following equations to constraint the sum of all three minerals to the net shale free volumetric fraction calculated on the basis of gamma ray 


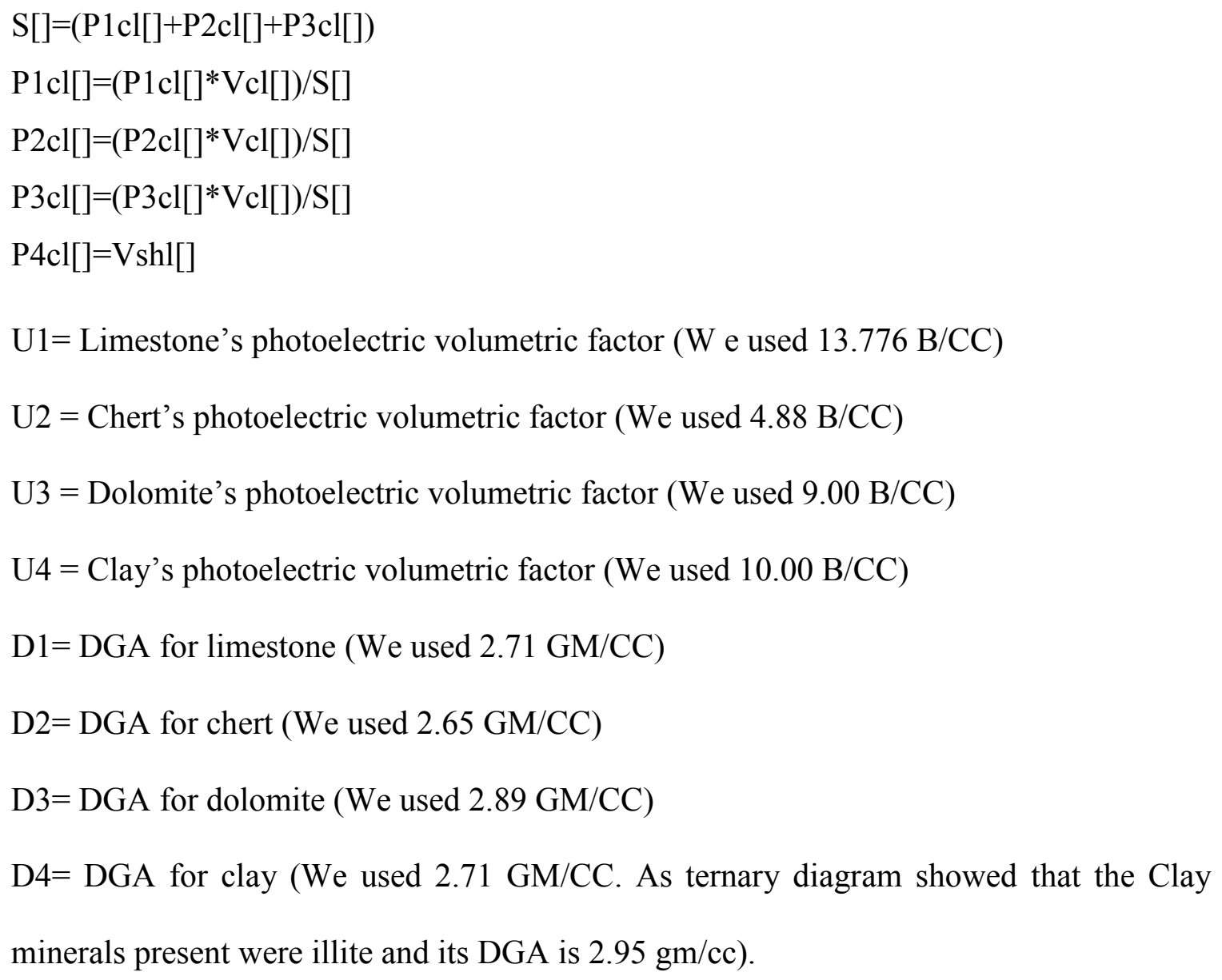

\section{Calculations to display the litholog}

To make the display of these volumetric fractions in the form of log, following calculations were carried out so that we can put all of them in a single track and can see the part of each individual fraction at every point..

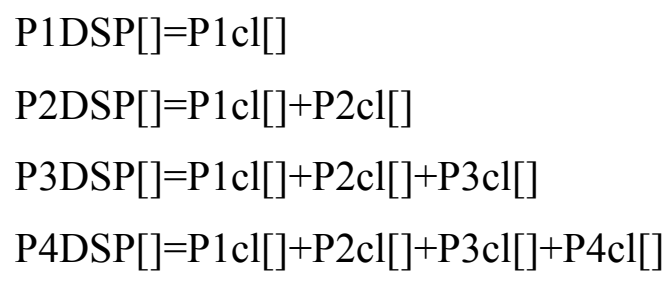




\subsection{Appendix (V)}

\subsubsection{Sonic Prediction from density porosity}

Wylie's Time Average Equation

$\mathrm{DT}=\mathrm{DTma} *(1-\mathrm{PHID})+$ DTfld $*$ PHID

$\mathrm{DT}=$ Sonic transit time $(\mathrm{MS} / \mathrm{FT})$

DTma $=$ Sonic Transit Time in Matrix (We used 50 MS/FT)

PHID $=$ Denisty porosity from density $\log (\mathrm{V} / \mathrm{V})$

DTfld $=$ Fluid Transit Time $($ We used 189 MS/FT $)$

\section{Modified Time Average Equation}

DT $=$ DTma*(I-PHID)*Vcl + DTshl*Vshl*(1-PHID) + DTfld*PHID

DTshl $=$ Shale Transit Time (We used $85.00 \mu \mathrm{sec} / \mathrm{ft}$.

$\mathrm{Vcl}=$ Shale Free Volume of the rock $(\mathrm{V} / \mathrm{V})$

Vshl $=$ Shale Volume Fraction $(\mathrm{V} / \mathrm{V})$

\subsubsection{From Neutron Porosity}

Wylie's Time Average Equation

DT=DTma $*(1-\mathrm{NPHI})+$ DTfld $*$ NPHI

$\mathrm{NPHI}=$ Neutron porosity $(\mathrm{V} / \mathrm{V})$

\section{Modified Equation (I)}

DT $=$ DTma*(1-NPHI) + DTfld $*($ NPHI - NPHIcl*P3)

$\mathrm{NPHI}=$ Shale Free Neutron porosity $(\mathrm{V} / \mathrm{V})$ 


\subsubsection{From Average Porosity}

Wylie's Time Average Equation

DT $=$ DTma $*(1-$ PHIA $)+$ PHIA * DTfld

PHIA = Average Porosity $(\mathrm{V} / \mathrm{V})$

Modified Time Average Equation

DT $=$ DTma $(1-$ Vshl $) *(I-P H I A)+$ DTshl $*$ Vshl $*(1-$ PHIA $)+$ DTfld * PHIA

\section{Modified Equation (II)}

DT $=$ DTma $(1-$ Vsh $) *(I-$ PHIA $)+$ DTshl * Vshl * (1-PHIA $)+$ DTfld * $($ PHIA $-\mathrm{a} *$ PHIE * P3)

Where $\mathrm{a}=$ constant relating effective porosity to the secondary porosity. Its value could be somewhere $\mathrm{b} / \mathrm{w} 0.75$ to 1.25 .

P3= Dolomite Volume Fraction

DTshl= Shale Transit Time (We used between $60-75$ MS/FT)

$\mathrm{DTma}=$ Shale free matrix transit time (We used (50 MS/FT)

\subsubsection{From Mineral Identification}

\section{Modified Equation (III)}

DT=DTls*P1cl+DTchert*P2cl+DTdol*P3cl+DTshl*P4cl+DTfld*PHIAcl + DTfld *

PHIA * P4cl

DTls $=$ Limestone transit time $($ We used $47.50 \mathrm{MS} / \mathrm{FT})$

$\mathrm{P} 1 \mathrm{cl}=$ Limestone fraction $(\mathrm{V} / \mathrm{V})$

DTchert $=$ Chert transit time $($ We used $53 \mathrm{MS} / \mathrm{FT})$

$\mathrm{P} 2 \mathrm{cl}=$ Chert fraction $(\mathrm{V} / \mathrm{V})$

DTdol $=$ Dolomite Transit Time $($ We used 43 MS/FT)

$\mathrm{P} 3 \mathrm{cl}=$ Dolomite fraction $(\mathrm{V} / \mathrm{V})$ 
DTshl $=$ Shale Transit Time $($ We used 50-58 MS/FT)

$\mathrm{P} 4 \mathrm{cl}=$ Clay fraction $(\mathrm{V} / \mathrm{V})$

PHIAcl $=$ Shale free apparent porosity $(\mathrm{V} / \mathrm{V})$

DTfld = Fluid Travsit Time (We used 189 MS/FT)

Vshl $=$ Shale Volume $(\mathrm{V} / \mathrm{V})$

\subsection{Appendix (VI)}

\subsubsection{Gamma ray $\log$}

Gamma ray $\log$ measures the natural radioactivity of the rocks. The radioactivity is mostly caused by the presence of potassium, uranium, and thorium and by some other radioactive elements. Shale has ability to attract the more radioactive elements as compared to other common rocks so it has high radioactivity. Because of this gamma ray $\log$ helps to differentiate the shale content from the other non-shaly components (carbonates and sandstone).

\subsubsection{Neutron Porosity Tool}

Neutron porosity tool emits the fast neutrons. These neutrons while passing through the rock units collide with the hydrogen atoms (sometimes called protons) present in the pores of the rocks and loose some energy. These low energy neutrons are then counted by the detector of the neutron tool and give a measure of the proton density in the formation. These count rates are then converted to porosity according to the standard calibrations.

\subsubsection{Density Tool}

Density tool work similar to the neutron tool but it emits medium energy electrons and record scattered electrons after the Compton scattering caused by the electrons present in the rock matrix. The electron count by the detector of the density tool gives a measure of the electron density that is related with the bulk density of the rock according to the calibration standards. This bulk density id then used to calculate the porosity of the rock according the lithology and pore-fluid. 


\subsubsection{Litho-Density Tool}

Density tool sometimes is used to count not only the scattered electrons but also to record the energy of those electrons. That energy helps to separate the scattered electrons and low energy gamma rays caused by photoelectric absorption. The low energy gamma rays describe the atomic number of the matrix as photoelectric absorption depends upon atomic number. Based on its dependence on atomic number, PEF Log is used to identify the mineral fractions present in the rock unit.

\subsubsection{Sonic Tool}

We used sonic tool only to compare the results of our prediction. A seismic source generates the seismic acoustic waves that travel through the rock fractions and are recorded on the receiver. Sonic tool then records the time taken by the seismic wave to travel a distance of $1 \mathrm{ft}$ in the rock. We often call it as Interval Transit Time. Interval transit time is then used to calculate the porosity of the rock depending upon the lithology and porosity. 